\title{
Do an Insider's Wealth and Income Matter in the Decision to Engage in Insider Trading? ${ }^{\text {a }}$
}

\author{
Jenni Kallunki \\ Oulu Business School, University of Oulu, \\ Pentti Kaiteran katu 1, P.O. Box 8000, FIN-90014 University of Oulu, Finland \\ Juha-Pekka Kallunki ${ }^{b}$ \\ University of Oulu, Finland; Aalto University School of Business, Finland; \\ Stockholm School of Economics, Sweden \\ Henrik Nilsson \\ Stockholm School of Economics, \\ Sveavägen 65, P.O Box 6501, SE-11383 Stockholm, Sweden \\ Mikko Puhakka \\ University of Oulu, Finland \\ Oulu Business School, University of Oulu, \\ Pentti Kaiteran katu 1, P.O. Box 8000, FIN-90014 University of Oulu, Finland
}

\begin{abstract}
We explore why insiders engage in informed trading, given the surprisingly small average insider returns reported in the literature and the potential costs involved. We begin by proposing a model of an insider's decision to engage in insider trading. We then empirically test the model's predictions using archival data of corporate insiders in Sweden. Consistent with the model, we find that less wealthy insiders are more likely to time their insider selling, and to sell in greater magnitudes, prior to abnormal price declines than wealthy insiders. We also find that less wealthy insiders with lower risk aversion as measured by their criminal behavior are particularly prone to timing their selling to avoid price declines.
\end{abstract}

JEL classification: G12, G14, G34, K42

Keywords: Insider trading, Wealth, Income

\footnotetext{
${ }^{\text {a }}$ We are grateful to Christopher Malloy (the referee) for insightful comments that have greatly improved this paper. We also thank Eli Amir, Juha Joenväärä, Petri Sahlström, participants at the $11^{\text {th }}$ Tel Aviv Conference in Accounting, the 2016 American Accounting Association Annual Meeting, the 12 $2^{\text {th }}$ Workshop on Accounting and Economics, the 2016 American Accounting Association Doctoral Consortium, the 39 ${ }^{\text {th }}$ Annual Congress of the European Accounting Association, the $32^{\text {nd }}$ Doctoral Colloquium of the European Accounting Association, the $8^{\text {th }}$ Annual Workshop of the Nordic Corporate Governance Network, the 2016 Nordic Accounting Conference, and seminar participants at Aalto University, Hanken School of Economics, and University of Oulu for numerous comments and suggestions. We acknowledge Euroclear Sweden, Finansinspektionen, Swedish Tax Authorities, and Swedish Research Council for providing the requisite data, as well as NASDAQ OMX Nordic Foundation, Vetenskapsrådet, Handelsbanken Research Foundation, Finnish Savings Banks Group Research Foundation, Marcus Wallenberg Research Foundation, OP Group Research Foundation, Tauno Tönning Foundation, Suomen Arvopaperimarkkinoiden Edistämissäätiö, Finnish Cultural Foundation and Academy of Finland [Project \#243017121] for financial support. This study has been evaluated and approved by the Regional Ethical Review Board in Umeå, Sweden (DNR 08:074 Ö and DNR I3-0449/2009). All remaining errors are our own.

b Corresponding author. Tel: +358405672508 . E-mail address: juha-pekka.kallunki@ oulu.fi. Mailing address: Oulu Business School, University of Oulu, Pentti Kaiteran katu 1, P.O. Box 8000, FIN-90014 University of Oulu, Finland. Facsimile number: +358 8344084 .
} 


\section{Introduction}

A body of literature shows that corporate insiders' trades predict future abnormal returns, suggesting that insiders generally exploit their information advantage about firm prospects to make trading decisions (e.g., Seyhun, 1986; Lakonishok and Lee, 2001; Jeng, Metrick, and Zeckhauser, 2003; Huddart, Ke, and Shi, 2007; Cohen, Malloy, and Pomorski, 2012). ${ }^{1}$ However, the abnormal returns that insiders have been reported to earn are, on average, surprisingly small to justify them engaging in informed trading, given the potential costs involved. In particular, the general public and regulatory authorities monitor insiders' trading and impose costs on insiders when trading is perceived to be opportunistic and self-serving. These costs comprise both the potential reputational losses imposed by outside investors and the media and the potential legal sanctions taken by the regulator (e.g., Seyhun, 1992; Gao, Lisic, and Zhang, 2014; Dai, Parwada, and Zhang, 2015). Thus, an important, yet largely unsolved question is why some insiders decide to engage in informed trading, given the small average abnormal returns and the potential costs of such trading.

In this paper, we address this question by arguing that less wealthy insiders are more likely to trade on private information, because their returns to such trading are large enough to compensate for the potential costs involved, compared to wealthier insiders. We moreover argue that even the less wealthy insiders refrain from informed trading, if the costs associated with being detected are large enough and do not compensate for the returns that could be earned by trading. We begin by proposing a model of an insider's decision to engage in informed insider trading. In the model, the risk-averse insider maximizes her expected utility by trading off between the financial gain and

\footnotetext{
${ }^{1}$ Corporate insiders' trades refer to their trades on the stocks of their own firms which must be disclosed to the regulatory authority and to the general public. In Sweden, this regulatory authority is the Finansinspektionen (the Swedish Financial Supervisory Authority), and in the United States it is the U.S. Securities and Exchange Commission (SEC). Informed insider trading refers to corporate insiders' stock purchases (sales) that they time before abnormal stock price increases (declines).
} 
costs of informed insider trading, both of which include a fixed component and a variable component related to the insider's wealth and income level through the volume of insider trading. ${ }^{2}$ We show that an increase in the insider's wealth and income level decreases her willingness to trade on private information, as long as the trading is subject to a relatively low risk of legal enforcement and therefore not likely to incur large fixed costs such as criminal fines or jail time for the insider. The reason is that a less wealthy insider would be willing to accept a lower probability that her informed trading will not be detected and punished by outsiders than a wealthy insider. This effect is greater in magnitude when the variable costs of trading on private information such as personal reputational damages and other costs related to the volume of insider trading are larger and the insider has lower risk aversion.

We empirically test the predictions of our model using data from Sweden, where archival data on individual wealth, income, and many other demographic variables are available for all insiders of listed firms. Our data set covers 3,388 corporate insiders from all Swedish listed firms and 14,672 reported insider trades by these insiders over the period from January 2000 to December 2008. Corporate insider trading does not typically fall under the definition of legally material information and is consequently associated with low risk of legal enforcement actions taken by the regulator, including criminal fines, disgorgement of profits, or even jail sentences (Seyhun, 1992, 1998). However, insider trades considered to generate excessive personal gains can attract negative investor and media attention, thereby damaging insiders' reputational capital and also increasing the likelihood of scrutiny by the regulator (Gao, Lisic, and Zhang, 2014; Dai, Parwada, and Zhang, 2015).

\footnotetext{
${ }^{2}$ Strictly speaking, an economic agent maximizes her expected utility obtained from consumption, where the level of consumption is determined by her wealth and income levels as in the standard portfolio theory. We include in our empirical analyses both an insider's wealth and income.
} 
We find that the level of wealth and income varies substantially across the insiders in our sample. When we divide insiders into three categories based on the level of their wealth and income, we find that, on average, insiders in the low wealth and income category ('less wealthy insiders') are considerably less wealthy than insiders in the medium and high wealth and income categories ('wealthy insiders'). In particular, the average insider in the low wealth and income category has a personal wealth of only $\$ 266,747$, whereas the wealth owned by the average insider in the medium (high) wealth and income category is as much as $\$ 6,895,621(\$ 12,374,131)$, a 26 (46) times difference. Similarly, insiders with a low level of wealth and income earn, on average, only $\$ 72,294$ per year, which is 2.5 (7) times less compared to insiders with a medium (high) level of wealth and income. These differences suggest that the insider trading behavior could indeed differ between insiders with different levels of wealth and income.

Consistent with our model, the empirical results of analyzing reported insider trades show that insiders' willingness to engage in informed insider selling significantly decreases with the level of their wealth and income. Specifically, we find that less wealthy insiders are more likely to time their selling prior to abnormal stock price declines than wealthy insiders. The size of less wealthy insiders' sales moreover increases with the magnitude of the future stock price decline. The mean (median) buy-and-hold abnormal (market-adjusted) stock return over a one-month period following a single sale transaction by less wealthy insiders is $-1.70 \%(-2.44 \%)$, which translates into an economically significant annualized return of $-18.6 \%(-25.3 \%)$. In contrast, the mean and median abnormal returns following the sales by wealthy insiders are not significantly negative.

We also find that, conditional on being less wealthy, insiders who are more risk-prone as measured by their criminal convictions are more likely to time their selling to avoid stock price declines, compared to non-convicted insiders. We do not observe similar selling behavior for 
wealthy risk-prone insiders. These results continue to hold after controlling for other likely motives for insiders to sell their stocks besides exploitation of private information, including insiders' portfolio diversification objectives, liquidity needs, capital gain taxation considerations, contrarian trading behavior, information asymmetry and other firm characteristics, and year and firm fixed effects. These findings are consistent with less wealthy insiders valuing the financial gain from informed insider selling more than the associated reputational and legal costs. The results also suggest that wealthy insiders' concerns with these potential costs outweigh their benefit from selling on private information, and they therefore decide to time their selling more carefully.

Interestingly, we do not find the same contrasting patterns for insiders' purchases, which they time prior to stock price increases regardless of the level of their wealth and income or attitude towards risk. The asymmetry of this finding is consistent with the argument in prior research that the reputational and legal risk associated with being detected for trading on private information is significantly higher for insider sales compared to purchases (e.g., Cheng and Lo, 2006; Piotroski and Roulstone, 2008; Brochet, 2010; Dai, Parwada, and Zhang, 2015; Alldredge and Cicero, 2015).

We also examine the risk-adjusted post-trade returns earned by insiders with different levels of wealth and income by calculating the intercept from the Capital Asset Pricing Model (CAPM) and the Fama and French three-factor and four-factor calendar-time portfolios. We confirm that, on average, less wealthy insiders earn superior returns from selling their firms' shares after controlling for various risk factors, compared with wealthy insiders. The difference in the returns earned by less and more wealthy insiders is also economically significant. For instance, the portfolio of less wealthy insiders' sales yields a monthly return of $-1.66 \%$ over the portfolio of wealthy insiders' sales, controlling for market risk, size, book-to-market, and stock return 
momentum characteristics of the traded stocks. We also find some evidence that less wealthy insiders earn superior risk-adjusted returns from their purchases.

Our paper contributes to the limited literature on how insiders' personal characteristics or traits affect their insider trading behavior by shedding more light on the question of why some insiders decide to engage in informed trading, given the small average abnormal returns documented in prior studies and the potential costs of trading (e.g., Kallunki, Nilsson, and Hellström, 2009; Gao, Lisic, and Zhang, 2014; Hillier, Korczak, and Korczak, 2015; Kallunki, Mikkonen, Nilsson, and Setterberg, 2016). The paper closest to ours is Kallunki, Nilsson, and Hellström (2009), who find that insiders' portfolio diversification needs, tax considerations, and behavioral biases affect their trading decisions and that insiders who have allocated a great proportion of their wealth to insider stock sell more before bad news. We expand on these papers, especially Kallunki et al. (2009), in the following ways. First, to the best of our knowledge, this is the first paper that presents a theoretical model of how the level of an insider's wealth and income affects her trade-off between the financial benefit and costs of informed insider trading, and consequently, leads to differential trading behavior by less and more wealthy insiders.

Second, while Kallunki, Nilsson, and Hellström (2009) consider an insider's portfolio diversification needs measured as the proportion of her total wealth allocated to insider stock as an incentive for trading on private information, they do not explore whether the level of an insider's wealth and income affects how she considers the potential financial gain and associated cost from engaging in informed insider trading. Analyzing an insider's expected utility from her wealth and income allows us to address the question of why insiders engage in informed trading, given the small abnormal insider returns documented in the literature. Consistent with this view, our empirical results show that the diversification-driven insider selling examined in Kallunki et al. 
(2009) and less wealthy insiders' selling are distinct behaviors by insiders. Third, we examine how the insider's risk aversion, measured by her criminal behavior, affects her willingness to engage in informed trading, given the level of her wealth and income.

Finally, this paper contributes to the recent literature that focuses on the role of individuals and their personal characteristics or traits, as opposed to firm- or industry-level factors, in shaping corporate behavior and outcomes (e.g., Bertrand and Schoar, 2003; Kaplan, Klebanov, and Sorensen, 2012; Malmendier and Tate, 2008; Cronqvist, Makhija, and Yonker, 2012). We show that corporate insiders' personal characteristics play a role not only in shaping corporate decisions, but also in their decisions related to stocks of their own firm. The rest of the paper is organized as follows. In Section 2, we describe our theoretical model for an insider's decision of whether to engage in informed insider trading and report numerical simulations of the model. Section 3 describes our data and empirical methodology. Section 4 presents the empirical results. Finally, we provide concluding remarks in Section 5.

\section{Model}

In this section, we present a model that forms the basis of the empirical analysis. Our model follows the tradition of the economics of crime going back to the seminal work by Becker (1968). Consider an informed insider who contemplates engaging in informed insider trading. The insider's utility ultimately depends on the level of her consumption, which in turn depends on the level of her wealth and income, denoted by $W{ }^{3}$ We assume that the utility function $u(W)$ is strictly increasing and strictly concave:

$$
U=u(W) \text { with } u^{\prime}(W)>0 \text { and } u^{\prime \prime}(W)<0 .
$$

\footnotetext{
${ }^{3}$ Since we have a one-period model, all of the income and wealth end up in consumption.
} 
In addition, we assume the following Inada conditions:

$$
\frac{\lim }{W \rightarrow 0} u^{\prime}(W)=\infty \text { and } \frac{\lim }{W \rightarrow \infty} u^{\prime}(W)=0
$$

All of the standard utility functions fulfil these conditions, which guarantees that the optimal solution is not in the corners. Since the utility function is strictly concave, Jensen's inequality implies that $u(E W)>E u(W)$, where $E$ is the expectations operator.

When deciding whether to engage in informed insider trading, the insider maximizes her expected utility by trading off the financial gain against the costs of such trading. The insider's financial gain from her trade is denoted by $\eta V$, where $\eta$ is the expected percentage change in the stock price given the insider's private information, and $V$ is the (dollar) value of the shares traded, i.e., the number of shares traded times the stock price. An insider has a budget constraint in her trading decisions, that is, there is an upper limit for how many shares she can buy or sell in an insider trade, the limit being determined by her wealth and income level. ${ }^{4}$ There is also a minimum number of shares $V_{\min }(>0)$ that the insider must trade to cover the monetary and non-monetary transaction costs. ${ }^{5}$ The value of an insider trade can therefore be defined as $V=V_{\min }+\theta W$, where $\theta(0 \leq \theta<1)$ is the fraction of the insider's wealth and income level. The insider's financial gain can now be rewritten as $\eta\left(V_{\text {min }}+\theta W\right)=\eta V_{\text {min }}+\eta \theta W$, where the term $\eta V_{\text {min }}$ represents the fixed gain component and the term $\eta \theta W$ represents the variable gain component. Note also that, holding $\theta$ fixed, the insider's financial gain increases with the level of her wealth and income, $W$.

As for the costs of insider trading, classical theoretical settings with incomplete contracts and informational asymmetries (e.g., Klein and Leffler, 1981; Kreps and Wilson, 1982; Shapiro, 1983)

\footnotetext{
${ }^{4}$ We assume that an insider does not sell short insider stocks and does not borrow money for insider purchases.

${ }^{5}$ Monetary and non-monetary transaction costs include, for instance, transaction fees, the costs of reporting the transaction to the regulator, the costs of acquiring possible pre-approval for the transaction from the company, and other transaction costs that the insider incurs when and if she decides to trade.
} 
suggest that reputation serves as an informal enforcement mechanism against opportunistic corporate behavior, such as informed insider trading. ${ }^{6}$ Reputational concerns play an important role in insiders' trading decisions because insiders are required to publicly disclose their trading activities. In particular, opportunistic insider trades are likely to capture negative investor and media attention, thereby damaging insiders' reputational capital and potentially increasing the probability of regulatory scrutiny. ${ }^{7}$ Moreover, since insider trading is regulated by the legislation, the insider's trading on material private information could be subject to legal sanctions imposed by the regulator including criminal fines, disgorgement of trading gains, or even jail time. Therefore, the costs of insider trading comprise both the potential reputational losses imposed by outside investors and the media and the potential legal sanctions taken by the regulator (e.g., Seyhun, 1992; Gao, Lisic, and Zhang, 2014; Dai, Parwada, and Zhang, 2015).

Similarly to Seyhun (1992) and Acharya and Johnson (2010), we assume that there are both fixed and variable costs of informed insider trading. These costs are denoted by $d+\varphi \lambda W$, where $d$ reflects the fixed costs of informed trading such as criminal fines and jail sentences and the term $\varphi \lambda W(\lambda W=V$ and $0<\lambda \leq 1)$ describes the variable costs of informed trading, including disgorgement of trading gains and other costs that are related to the insider trading volume and hence to the magnitude of the profits gained or the losses avoided. For example, the degree of

\footnotetext{
${ }^{6}$ Empirical evidence supports the role of reputation in deterring and disciplining corporate misconduct [see MacLeod (2007) for a review]. For example, Atanasov, Ivanov, and Litvak (2012) show that reputational capital disciplines and deters opportunistic behavior by venture capitalists. According to Gao, Lisic, and Zhang (2014), executives in firms with a socially responsible image are more likely to refrain from informed trading, especially when their personal reputation is more closely tied to the firms' reputation or when they have higher stock ownership. Dai, Parwada, and Zhang (2015) moreover show that dissemination of SEC insider trading filings by the media restricts insider trading profits because insiders are concerned about the adverse impact of informed trading on their reputational capital and personal wealth. Karpoff (2012) notes that opportunism against business counterparties such as investors typically leads to reputational losses that are much larger than any legal penalties.

${ }^{7}$ Opportunistic insider trades do not, however, necessarily trigger formal enforcement actions by the regulator (Cohen, Malloy, and Pomorski, 2012; Dai, Parwada, and Zhang, 2015).
} 
negative publicity resulting from opportunistic trading behavior and thereby the damage to the insider's reputational capital and labor market prospects are likely to increase in the private financial gain that the insider receives from her trading.

Finally, let $p(1-p)$ denote the probability that the costs of informed trading will not be (will be) imposed on the insider by outsiders, i.e., outside investors, media members, or the regulator. Consequently, the insider's expected utility from her informed trade is defined as

$$
E U=p u(W+\eta M+\eta \theta W)+(1-p) u[W-(d+\varphi \lambda W)]
$$

For notational simplicity, we write $\eta V_{\min }, \eta \theta$, and $\varphi \lambda$ as $a, r$, and $c$, respectively. Hence, the insider's expected utility can now be rewritten as

$$
E U=p u[(1+r) W+a]+(1-p) u[(1-c) W-d] .
$$

For the maximization problem to be reasonable, we need the restriction that $W>d /(1-c)$, meaning that the final wealth and income level (i.e., consumption) must be positive. Note that Jensen's inequality entails:

$$
u(p[(1+r) W+a]+(1-p)[(1-c) W-d])>p u[(1+r) W+a]+(1-p) u[(1-c) W-d] .
$$

This implies that the necessary condition for the insider to engage in informed insider trading is that the expected net gain from that activity must be positive, i.e.,

$$
p(r W+a)-(1-p)(c W+d)>0
$$

Note that Jensen's inequality implies $u(W)>E u(W)$, if the expected net gain is zero. The insider decides to engage in informed trade only if her expected utility following the trade is greater than her utility if she does not trade:

$$
p u[(1+r) W+a]+(1-p) u[(1-c) W-d]>u(W) .
$$

Next, we assume that the utility function is of the constant relative risk aversion (CRRA) type, i.e., 


$$
u(W)=\frac{W^{1-\sigma}}{1-\sigma} \text { with } \sigma>0 \text { and } \sigma \neq 1 \text {, }
$$

where $\sigma$ is the Arrow-Pratt measure of the relative risk aversion. If $\sigma=1$, the utility function is logarithmic. Our results below hold for all of the CRRA functions, including the logarithmic function. A CRRA function is general and allows us to perform numerical illustrations.

To understand the conditions under which the insider decides to engage in informed insider trading, we explore the combinations of the probability that the costs will not be imposed by outsiders $(p)$ and the level of the insider's wealth and income $(W)$ such that she is indifferent between engaging and not engaging in informed trading. An indifferent insider decides not to engage in informed trading. A lower (higher) probability for indifference means that the insider, in deciding whether to engage in informed trading, accepts (requires) a lower (higher) probability that such trading remains undetected and unpunished by outsiders. Hence, a lower (higher) probability corresponds to the insider being more (less) willing to trade on the basis of private information. The indifference condition is Eq. (7) written as an equality. Expressing the probability $p$ from the indifference relation as a function of $W$ gives:

$$
\begin{aligned}
& p=\frac{W^{1-\sigma}-[(1-c) W-d]^{1-\sigma}}{[a+(1+r) W]^{1-\sigma}-[(1-c) W-d]^{1-\sigma}}, \text { when } \sigma<1 \text { and } \\
& p=\frac{\left(\frac{1}{(1-c) W-d}\right)^{\sigma-1}-\left(\frac{1}{W}\right)^{\sigma-1}}{\left(\frac{1}{(1-c) W-d}\right)^{\sigma-1}-\left(\frac{1}{(1+r) W+a}\right)^{\sigma-1}}, \text { when } \sigma>1 .
\end{aligned}
$$

We denote the indifference relations (9i) and (9ii) as $p=z(W ; r, a ; c, d)$, and characterize the properties of this function in the following Propositions 1 and 2. We also analyze how changing the magnitude of the fixed and the variable costs of informed insider trading influences the 
insider's decision whether to engage in insider trading, given the level of her wealth and income. The proofs of the propositions are presented in the Internet Appendix.

Proposition 1. The function $z(W ; r, a ; c, d)$ is an increasing function of the level of an insider's wealth and income, i.e., $z_{W}(W ; r, a ; c, d)>0$, if the fixed costs are small relative to the level of her wealth and income, i.e., if $d / W$ is relatively small. Furthermore, the following properties hold: $z_{c}(W ; r, a ; c, d)>0$ and $z_{d}(W ; r, a ; c, d)>0$

Proposition 2. If $d / W$ is relatively small and $\sigma>1$, the slope of the indifference curve with respect to the level of an insider's wealth and income gets steeper (flatter), if the variable costs (c) increase (decrease). If $\sigma<1$, the same result holds for a sufficiently small $a, r$, and $c$.

Proposition 1 says that a decrease in the level of an insider's wealth and income increases her willingness to engage in informed insider trading, as long as the fixed costs of such trading are small relative to the level of her wealth and income. The reason is that a less wealthy insider would be willing to accept a lower probability that her informed trading will not be detected and punished by outsiders than a wealthy insider. Proposition 2 says that an increase (decrease) in the variable costs of informed trading increases (reduces) the relation between the level of the insider's wealth and income and her willingness to engage in informed trading. Finally, the result in Proposition 1 that $z_{c}(W ; r, a ; c, d)>0$ and $z_{d}(W ; r, a ; c, d)>0$ means that an increase in the fixed or variable costs of informed trading will lead to a decline in the insider's willingness to engage in informed trading regardless of the level of her wealth and income. This is because the insider requires a higher probability that her informed trading will not be detected (and punished) by outsiders. 
We illustrate the results in Propositions 1 and 2 numerically in Fig. 1, where we construct three scenarios for an insider's decision whether or not to engage in informed trading, given the magnitude of the fixed and variable costs associated with such trading. ${ }^{8}$ In the first scenario, an insider's informed trading is subject to a low risk of legal enforcement and is thus not likely to incur any fixed costs for the insider $(d=0)$, and also reputational damage and other variable costs related to the magnitude of insider trading are small $(c=0.01)$. In the second scenario, an insider's informed trading still involves a low risk of legal enforcement $(d=0)$, but includes larger reputational and other variable costs $(c=0.06)$ than in the first scenario. In the third scenario, an insider's informed trading is subject to a high risk of legal enforcement and thus likely to incur large fixed costs $(d=1.0)$ and variable costs $(c=0.09)$ for the insider. In all these scenarios, we set $a=0.5$ and $r=0.05$.

Fig. 1 depicts the probability $p$ that makes the insider indifferent between trading and not trading for varying levels of her wealth and income $(W)$ in each of the three scenarios. As shown in Fig. 1, the indifference probability $p$ increases from the first to the third scenario for all levels of wealth and income. In other words, an increase in the fixed or variable costs of informed trading leads to a decline in the insider's willingness to engage in such trading regardless of the level of her wealth and income (Proposition 1). Fig. 1 also shows that the indifference curve increases with the level of the insider's wealth and income in the first and second scenarios, where the insider's informed trading is subject to a low legal risk and therefore likely not to involve any fixed costs such as criminal penalties or jail time (Proposition 1).

\footnotetext{
${ }^{8} \mathrm{We}$ allow the level of the insider's wealth and income, $W$, to range from 0.25 to 8.0. In Fig. 1 , an insider's relative risk aversion coefficient, $\sigma$, is equal to 5.0, and in Fig. 2, $\sigma$ is equal to 5.0 or 0.5. Note that for the expected utility maximization problem to be reasonable, the insider's final wealth and income level must be positive, i.e., $W>d /(1-c)$. In addition, a necessary condition defined in Eq. (6) holds in all numerical analyses.
} 
The indifference curve is moreover steeper in the second than in the first scenario, indicating that the insider's wealth and income level has a greater impact on her willingness to engage in informed trading when the variable costs are larger and has only a minor impact when the variable costs are small (Proposition 2). Contrary to the first and second scenarios, the indifference curve decreases with the increasing level of an insider's wealth and income in the third scenario, where informed trading is subject to a high risk of legal enforcement and thus likely to incur large fixed and variable costs for the insider. The figure moreover shows that, in the third scenario, the probability for indifference does not exist for very low levels of wealth and income. ${ }^{9}$ In other words, when the legal risk of informed insider trading is high, it is not reasonable for an insider with a very low level of wealth and income to even consider engaging in such trading.

(Insert Fig. 1 about here)

Finally, we examine numerically how the insider's risk aversion affects her willingness to engage in informed trading, given the level of her wealth and income, and the fixed and variable costs. In particular, Fig. 2 plots the difference in the indifference probability between the insider with high risk aversion $(\sigma=5.0)$ and the insider with low risk aversion $(\sigma=0.5)$ for varying levels of wealth and income for each of the three scenarios described above. The figure illustrates that the indifference probability is always higher for higher risk aversion, meaning that the insider is less willing to engage in informed trading when she is more risk averse. This effect becomes stronger as the costs of such trading increase. However, risk aversion has less impact on the

\footnotetext{
${ }^{9}$ This is because the condition that $W>d /(1-c)$ must hold for the insider's expected utility maximization problem to be reasonable to begin with.
} 
insider's willingness to trade on private information when the insider is wealthy than when she is less wealthy, irrespective of the amount of the costs.

(Insert Fig. 2 about here)

\section{Data and empirical methodology}

\subsection{Data sources}

We use comprehensive archival data on Swedish insiders obtained from various nationwide official databases maintained by Swedish tax, regulatory, and police authorities. All these data sets are in electronic form, and we use individuals' unique social security codes to merge different databases. Our sample period is from 1 January 2000 through to 31 December $2008 .{ }^{10}$ The final sample includes 3,388 insiders, 393 firms, and 14,672 insider trades, consisting of 5,589 insider sales and 9,083 insider purchases.

Our data on daily insider transactions are obtained from the Finansinspektionen, which is the corresponding regulatory authority to the U.S. SEC. This data set includes an insider's name, a social security code, the name of the firm traded, the number of shares traded, and the day on which the transaction was made. Following the literature on insider trading, we focus on open market purchases and sales by corporate insiders and exclude non-open market transactions, such as option exercises, transactions related to bonuses, pension and other benefit program

\footnotetext{
${ }^{10}$ The Swedish Tax Agency has not collected the data on taxpayers' personal wealth after 2007, which limits our sample period. Although comprehensive archival data on insiders' wealth and income are not publicly available in many countries, such data could be accessed by regulatory authorities screening insider trades. Moreover, previous studies on U.S. insiders have used publicly available, although less precise, proxies for the level of their wealth and income including home values (Ahern, 2017), the value of shares owned in the firm (Gao, Lisic, and Zhang, 2014), and annual compensation (Roulstone, 2003). Hence, we believe that our results based on comprehensive archival data point to insiders' trading behavior that could be traced even with less precise data on insiders' wealth and income.
} 
transactions, and gifts. In the case of multiple insider transactions on the same day for a given insider and her insider firm, we net all these transactions. ${ }^{11}$

The insider trading legislation in Sweden is in accordance with European Union Directives on the Regulation of Insider Trading (EEC Directive 89/592) and on Insider Dealing and Market Manipulation (Directive 2003/6/EC). The Swedish insider legislation is of high quality and quite similar to that of the USA (Beny, 2005). The main differences are as follows. First, while illegal insider trading is both a criminal and a civil offence in the USA, it is only a criminal offence in Sweden. Hence, unlike the SEC in the USA, the Finansinspektionen in Sweden lacks a civil enforcement authority in illegal insider trading. Second, the maximum penalty for trading illegally on insider information in the USA is ten years of imprisonment, compared with the maximum of four years in Sweden.

In addition to formal insider trading laws, country-level corporate culture and governance could influence how acceptable trading on inside information is viewed in corporate practice and by the public and consequently, the likelihood and magnitude of reputational damage resulting from profitable insider trading as perceived by insiders. As for the level of corporate governance, Aggarwal, Erel, Stulz, and Williamson (2009) find that Sweden places among the top ten countries, not far from the USA. Denis and Xu (2013) moreover report that, like US executives, Swedish executives consider insider trading not to be a common practice in the domestic market. In sum, although there are some differences in insider trading legislation, its enforcement, corporate cultures, and the level of corporate governance between Sweden and the USA, previous research suggests that these differences are small. Appendix A briefly discusses the details of the insider trading legislation in Sweden and compares it with that of the USA.

\footnotetext{
${ }^{11}$ We also exclude very small trades (size of trade < SEK 10,000) from our analyses. SEK 1 is equal to USD 0.12 .
} 
We obtain the data on insiders' personal wealth, including the values of real estate, mutual funds, bank holdings, investments in debt securities, and taxable labor income from the Swedish tax authorities (Skatteverket). These data are reported on an annual basis and are public information in Sweden. We obtain the data on insiders' insider and outsider stockholdings from the Nordic Central Securities Depository Group (NCSD). The NCSD maintains an electronic database on the ownership of all Swedish stocks, in which the data are recorded at six-month intervals. From these data, we are also able to identify an insider's year of birth, gender, and a position as an insider.

The data on insiders' criminal convictions are from the Swedish National Council for Crime Prevention (Brå). This data set is a record of all individuals who have been found guilty by a court of law or received summary punishment from prosecutors since 1974. The data set does not include minor offences such as speeding, parking, and violations of local bylaws for which the punishment is an on-the-spot fine. Following previous studies (e.g., Korsell, 2001; Amir, Kallunki, and Nilsson, 2014), we also include data on individuals who have been under investigation for serious crimes to reduce the selection bias from focusing only on individuals who are actually convicted. The data on suspected criminal actions by corporate insiders are obtained from the Swedish National Police Board and are a record of all Swedish citizens who have been under investigation for serious crimes since 1991. Finally, we merge our insider transaction data with firm-level data from Thomson Datastream, including daily stock prices, market capitalizations, and annual accounting data.

\subsection{Sample construction}


We model insiders' decisions to trade their insider stocks using the matched-pair research design commonly used in previous studies exploring insiders' trading behaviour (e.g., Noe, 1999; Kallunki, Nilsson, and Hellström, 2009). We begin by identifying all days when an insider $i$ trades on her insider stock $j$ from our data on daily insider trades. For each insider $i$ and stock $j$, we then construct a timeseries of all trading days over the sample period from 1 January 2000 through 31 December 2008. These timeseries include trading days when there is insider trading and days when there is no insider trading. For each day when there is insider selling (buying) for a given firm, we randomly choose a day without insider selling (buying) from all trading days over the sample period for that firm. The resulting sample has an equal number of 5,589 $(9,083)$ days with insider selling (buying) and 5,589 (9,083) days without insider selling (buying).

\subsection{Measurement of variables}

\subsubsection{Dependent variables}

We construct the following two variables to measure insiders' decisions to engage in informed insider trading. First, we measure insiders' decisions to sell (buy) their insider stocks by a dummy variable $T R A D E_{i j t}$, which equals one if insider $i$ sells (buys) her insider stocks of firm $j$ on day $t$, and zero otherwise. Second, we measure insiders' decisions regarding the magnitude of their sales (buys) by $S I Z E_{i j t}$, which is the natural logarithm of the market value of the shares sold if insider $i$ sells (buys) insider stocks of firm $j$ on day $t$, and zero otherwise. In untabulated tests, we obtain similar results using the percentage of the market value of shares sold (bought) of the value of insider holdings $\left(S I Z E_{-} H O L D_{i j t}\right)$ or the percentage of the market value of shares traded of the value of total personal wealth $\left(S I Z E_{-} W E A L T H_{i j t}\right)$. 


\subsubsection{Independent variables}

\subsubsection{Level of wealth and income}

We construct a measure of the level of an insider's wealth and income using the following procedure. First, we assign all observations in our matched-pair sample of the $11,178(18,166)$ observations used for analyzing insider selling (buying) into two equal-sized portfolios based on the level of an insider's wealth at the end of the previous fiscal year, i.e., low-wealth and highwealth portfolios. Accordingly, we assign all observations in the matched-pair sample into two equal-sized portfolios based on the level of insiders' annual income from the previous year, i.e., low-income and high-income portfolios. We then assign all observations that belong to the portfolios of both low-wealth and low-income into the category 'Low.' In a similar way, we assign all observations that belong to the portfolios of both high-wealth and high-income into the category 'High.' Finally, the remaining observations, i.e., those that belong to the portfolios of high-wealth and low-income or to those of low-wealth and high-income, we assign into the category 'Medium.'

Based on the categories 'Low,' 'Medium,' and 'High,' we construct dummy variables $L O W_{i t}$, $H I G H_{i t}$, and $M E D_{i t}$ to identify insiders with different levels of wealth and income. Specifically, $L O W_{i t}$ is a dummy variable equal to one if an observation in our matched-pair sample belongs to the category 'Low,' and zero otherwise; $H I G H_{i t}$ is a dummy variable equal to one if an observation belongs to the category 'High,' and zero otherwise; and $M E D_{i t}$ is a dummy variable equal to one if an observation belongs to the category 'Medium,' and zero otherwise. In Section 4.4.2, we use an alternative way for grouping insiders based on the level of their wealth and income and find similar results.

\subsubsection{Stock return}


The variable $B H A R_{j t}$ is the buy-and-hold abnormal (market-adjusted) stock return for a onemonth period following day $t$ for firm $j$. A more negative (more positive) abnormal stock return following an insider sale (purchase) indicates exploitation of private information by the insider who made the trade. We choose a one-month return horizon because timing insider trades shortly before large abnormal changes in the stock price is likely to be subject to greater public and regulatory scrutiny and therefore involves higher risk of personal reputation damage or even legal sanctions for the insider. We have also used a three-month and a six-month horizon for future returns and obtained essentially similar results. ${ }^{12}$ These results are not tabulated for the sake of brevity.

\subsubsection{Criminal convictions}

We use an insider's criminal behavior to measure her attitude towards risk. Specifically, broad literature shows that criminal behavior is an indicator of an individual's higher propensity to take risks (e.g., Ehrlich, 1973; Junger, West, and Timman, 2001; Garoupa, 2003). Economic theory of crime suggests that the decision to engage in criminal activity is rational behavior under uncertainty, and that individuals engage in criminal acts if the expected utility from those acts is greater than the utility received from non-criminal behavior (Becker, 1968; Ehrlich, 1973). Ehrlich (1973) shows that a risk-neutral individual spends more time on illegal activities than a risk-averse person, and a risk-loving person spends more time on such activities than both of these other persons. In addition, the behavioral research on crime links criminal behavior to individuals' personal preferences like overconfidence (e.g., Iversen and Rundmo, 2002; Garoupa, 2003). This

\footnotetext{
${ }^{12}$ The only exception is that when we use a six-month horizon for future abnormal returns, the estimated parameter for the three-way interaction variable $L O W_{i t} \times R I S K_{-} T A K E R_{i} \times B H A R_{j t}$ is negative but not statistically significant in the Tobit regression $(p=0.229)$.
} 
literature suggests that many criminals are overconfident risk-takers who have overly optimistic beliefs about the uncertain outcomes of their actions and seem to ignore or not think about the likelihood of punishment, which could then reduce its deterrent effect (Garoupa, 2003).

Overall, the literature discussed above suggests that convicted insiders are likely to have lower risk aversion than their non-convicted peers. In addition, being overly confident could make convicted insiders underestimate the probability that their informed insider trades will be detected (and punished) by outsiders (Bénabou and Tirole, 2002; Van den Steen, 2004; Brunnermeier and Parker, 2005). To measure an insider's attitude towards risk, we construct a dummy variable

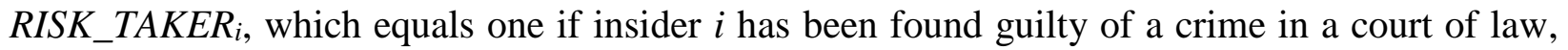
received summary punishments by prosecutors, or been suspected of a serious crime, and otherwise zero. ${ }^{13}$ We have also re-estimated all our regressions by using the natural logarithm of one plus the number of times insider $i$ has been found guilty of a crime in a court of law, received summary punishments by prosecutors, or been suspected of a serious crime. These untabulated results are similar to those based on the dummy variable.

\subsubsection{Control variables}

In our regressions, we include insider- and firm-level control variables that are likely to influence insiders' trading decisions. We control for insiders' gender $\left(G E N D E R_{i}\right)$ because previous studies report that male and female insiders trade differently (e.g., Barber and Odean, 2001;

\footnotetext{
${ }^{13}$ Our data on insiders' criminal convictions begin from 1974, and the data on suspected criminal actions by corporate insiders begin from 1991. We use these data to measure an insider's risk-seeking behavior, which is likely to be a time-invariant personal trait. We hence include data on an insider's proven or suspected criminal behavior observable at any point of time during the sample period 2000-2008. In our sample, there are 161 (289) sales (purchases) made by insiders who were convicted or suspected of a crime after selling (buying) their insider stocks. We have replicated all our analyses by excluding these observations from our sample, or alternatively, recoded the risk-taker dummy variable as zero for these observations, and obtain essentially similar results to those reported in the paper.
} 
Kallunki, Nilsson, and Hellström, 2009). Following Jin and Kothari (2008), we also include control variables for insiders' age $\left(A G E_{i}\right)$ and tenure to account for their entrenchment and career concerns $\left(T E N U R E_{i j t}\right)$. We also control for the number of firms in which she is an insider $\left(N U M I N S_{i j t}\right)$ and her position as an insider in her insider firm with two dummy variables for those insiders who are employed either as the Chief Executive Officer (CEO) $\left(C E O_{i j t}\right)$ or as another executive $\left(E X E C_{i j t}\right)$.

To control for insider trading due to portfolio rebalancing (Ke, Huddart, and Petroni, 2003; Huddart and Ke, 2007; Kallunki, Nilsson, and Hellström, 2009), we include in the regressions the proportion of insiders' total wealth allocated to their insider stock $\left(P R O P_{-} W E A L T H_{i j t}\right) .{ }^{14}$ In addition, we control for insiders' tendency to follow a contrarian trading strategy (Rozeff and Zaman, 1998; Piotroski and Roulstone, 2005) with the variables $M O M E N T U M_{j t}$ and $P B_{j t}$. We also control for the degree of information asymmetry with the firm's idiosyncratic return volatility $\left(I V O L_{j t}\right)$. In the insider-selling models, we control for insider trading for liquidity reasons with the variable measuring their cash and other liquid assets of the wealth $\left(\operatorname{LIQUIDITY}_{i t}\right)$ and for insiders' tendency to sell their losing stocks at the end of the year for capital taxation purposes (DECLOSS $S_{j t}$ ). We also control for the potential effect of firm profitability $\left(R O A_{j t}\right)$ and firm size $\left(M V_{j t}\right)$. We include two dummy variables $P R E_{j t}$ and $P O S T_{j t}$ to control for insiders' differential trading activity before and after earnings announcements (Huddart, Ke, and Shi, 2007; Kallunki, Nilsson, and Hellström, 2009). We further control for the short-term stock returns around the day on which an insider trades $\left(L A G_{-} k_{j t}, R E T_{j t}\right.$, and $\left.L E A D_{-} k_{j}\right)$.

\footnotetext{
${ }^{14}$ We replicated all our analyses by using a mean-adjusted portfolio diversification ratio measuring the extent to which the proportion of an insider's wealth allocated to her insider stock deviates from its longterm level (i.e., the difference of the proportion of an insider's total wealth allocated to her insider stock and the time-series mean of this proportion calculated for each insider over the sample period of nine years) as in Kallunki, Nilsson, and Hellström (2009) and find similar results.
} 
Finally, we use firm-fixed effects to control for the effects of possible omitted time-invariant, firm-specific factors of insider trading $\left(F I R M_{-} s_{j}\right)$ and also include eight yearly dummy variables for the years 2000 - 2007 to control for time-specific effects $\left(Y E A R \_y\right)$.

\subsection{Summary statistics}

Table 1 provides summary statistics on insiders' wealth and income (Panel A), insider trading behavior (Panel B), and criminal behavior (Panel C) of all 3,388 insiders in our sample. The average (median) insider has a personal wealth of SEK 49,636,500 (SEK 4,666,500) and an annual salary income of SEK 1,826,900 (SEK 1,063,600). Moreover, the level of an insider's wealth and income varies considerably across insiders in our sample. Panel B of Table 1 shows that the average insider made 3.18 (3.53) sales (purchases) during the sample period of nine years. Consistent with the previous literature (e.g., Lakonishok and Lee, 2001), insiders' sales are greater than their purchases. The average insider sold (bought) $28.42 \%(22.07 \%)$ of her insider holdings and $14.70 \%(7.52 \%)$ of her total wealth. There is also great variation in these percentage figures across insiders. Panel B of Table 1 also reports the buy-and-hold abnormal (market-adjusted) returns that insiders earn from their sales and purchases, measured over a one-month period following an insider trade. Consistent with prior research (e.g., Seyhun, 1986; Lakonishok and Lee, 2001; Jagolinzer, Larcker, and Taylor, 2011; Alldredge and Cicero, 2015), the mean and median abnormal returns following insider purchases are larger than those following insider sales. Panel C of Table 1 shows that 899 (26.5\%) out of all 3,388 insiders in the sample have been convicted or suspected of one or more crimes. While this percentage figure could seem high to many, it is similar to that of the whole Swedish population (Svensson, 2000). 
(Insert Table 1 about here)

Table 2 reports summary statistics for insiders' selling (Panel A) and buying (Panel B) activity, by the magnitude of the one-month buy-and-hold abnormal (market-adjusted) return following an insider trade. As shown in Panel A of Table 2, the number of insider sales monotonically decreases with the magnitude of the future stock price decline, indicating that insiders tend to refrain from selling prior to declining stock prices. When insiders do, however, sell before stock price declines, they realize economically significant insider gains by avoiding losses. For instance, the average insider who sells before a stock price decline between $20 \%$ and 25\% (more than 40\%) avoids a loss of SEK 165,680 (SEK 204,440) over a one-month period, which represents $2.92 \%$ (6.90\%) of her total wealth. ${ }^{15}$

Interestingly, Panel A of Table 2 also shows that less wealthy insiders (those in the wealth and income category 'Low') clearly sell more frequently before larger stock price declines than wealthy insiders (those in the wealth and income category 'High'). In particular, the proportion of insider sales made by less wealthy insiders increases with the magnitude of the future stock price decline, whereas that of the sales made by wealthy insiders decreases. To illustrate, roughly $29 \%$ (38\%) of all insider sales preceding stock price declines of $5 \%$, or less are conducted by insiders in the low (high) wealth and income category, whereas low (high) wealth/income insiders constitute $64 \%$ (18\%) of all the sales made before stock price declines of more than $40 \%$.

Regarding insiders' purchasing activity, Panel B of Table 2 shows, similarly to insider sales, that the number of insider purchases decreases with the magnitude of the future stock price

\footnotetext{
${ }^{15}$ In each abnormal return category, the mean loss avoided as percent of an insider's total wealth is of similar magnitude across the three wealth and income categories 'Low,' 'Medium,' and 'High' (not tabulated).
} 
increase, with the exception of future returns more than $40 \%$. Insiders also earn economically significant gains from their purchases that are made before stock price increases. For example, the mean gain from a purchase made before a stock price increase between $20 \%$, and $25 \%$ (more than $40 \%$ ) is SEK 152,470 (SEK 190,200), which equals $1.65 \%$ (4.22\%) of an insider's total wealth. Finally, Panel B of Table 2 shows that the proportion of insider purchases made by insiders in the low (high) wealth and income category generally increases (decreases) with the future stock price increase. However, this phenomenon is not as strong as it was for insider selling in Panel A.

(Insert Table 2 about here)

Finally, Table 3 provides descriptive statistics for the selected independent variables based on our matched-pair sample of 11,178 and 18,166 days with and without insider selling (Panel A) and buying (Panel B).

(Insert Table 3 about here)

\section{Empirical results}

\subsection{Univariate analysis}

Table 4 reports the results of the univariate analysis to explore whether the level of an insider's wealth and income affects her decision to engage in informed insider trading, that is, to time her selling (buying) before abnormal stock price declines (increases). Specifically, we test whether the mean and median future one-month abnormal returns $\left(B H A R_{j t}\right)$ are significantly different between the days with and without insider trading in our matched-pair sample. We conduct this analysis for 
all insiders as well as for insiders in our three wealth and income categories ('Low,' 'Medium,' and 'High'). Fig. 3 moreover plots the mean abnormal return over a one-month period following days with insider selling and buying in the three wealth and income categories. The abnormal returns following insider purchases are multiplied by -1 to make the figure comparable to Fig. 1. Thus, higher abnormal returns indicate that insiders are more cautious in making their trading decisions.

Table 4 shows that there is substantial variation in the level of insiders' wealth and income across the three categories, with insiders in the low wealth and income category (the category 'Low') being considerably less wealthy than those in the other two categories ('Medium' and 'High'). In particular, the average insider in the low wealth and income category has a personal wealth of only $\$ 266,747$, which is 26 and 46 times less than the personal wealth of the average insider in the medium and high wealth and income categories, respectively. Similarly, the average insider in the category 'Low' earns only $\$ 72,294$ per year, which is 2.5 and 7 times less than that earned by the average insider in the categories 'Medium' and 'High,' respectively.

The univariate results for insider selling presented in Panel A of Table 4 show that the mean (median) future abnormal return is significantly lower on days when insiders sell than on days when they do not sell, suggesting that the average insider times her selling successfully. However, only the insiders in the low wealth and income category ('Low') time their stock sales before price declines, whereas the insiders in the other two wealth and income categories ('Medium' and 'High') do not. The mean (median) abnormal return following insider sales by insiders in the low wealth and income category is $-1.70 \%(-2.44 \%)$, which is both statistically and economically significant. These returns translate into annualized returns of $-18.6 \%$ at the mean and $-25.3 \%$ at the median. These are economically significant numbers given that they result from one single 
transaction. In contrast, the mean (median) abnormal return following sales by insiders either in the medium or high wealth and income category is not significantly negative. This can also be seen in Fig. 3.

The above analysis provides evidence consistent with less wealthy insiders, on average, considering the expected utility gain of avoiding financial losses due to a decline in stock price to outweigh the disutility due to costs of informed selling. The results also indicate that wealthy insiders, on average, forgo the potential financial gain of informed insider selling to avoid the costs associated with the more profitable insider trading. Our finding that less wealthy insiders are more willing to gain from insider selling than wealthy insiders is consistent with our model's prediction that insiders' willingness to trade on private information decreases with the level of their wealth and income, as long as such trading is likely subject to a low risk of legal enforcement and hence likely not to incur large fixed costs (criminal fines, jail time) for the insider (Proposition 1). It is also consistent with previous research suggesting that the vast majority of corporate insiders' trades do not fall under the definition of legally material information and therefore are not likely to be subject to any legal scrutiny (e.g., Seyhun, 1992).

Panel B of Table 4 reports the univariate results for insider buying. Fig. 3 depicts insider returns following insider purchases in the three wealth and income categories. These results show that although insiders in the category of low wealth and income earn, on average, greater returns from their purchases $(2.43 \%)$ than those in the category of high wealth and income $(1.88 \%)$, insiders in all three wealth and income categories are willing to time their buying before price increases. These findings are consistent with the prediction in Proposition 2 that insiders' wealth and income level has less impact on their decisions to trade on private information when both the fixed and variable costs associated with the trade are small. It is also consistent with the argument 
made in prior research that insiders consider the potential costs of exploiting private information to be significantly lower for purchasing stock versus selling it and hence tend to be more prone to gaining from their purchases than from their sales (e.g., Cheng and Lo, 2006; Piotroski and Roulstone, 2008; Dai, Parwada, and Zhang, 2015; Alldredge and Cicero, 2015).

(Insert Table 4 about here)

(Insert Fig. 3 about here)

Next, we investigate how insiders' attitude towards risk as measured by their criminal behavior affects their willingness to time their buying (selling) before price increases (declines) given the level of their wealth and income. This analysis is motivated by Fig. 2, which shows that while an insider's willingness to engage in informed insider trading increases as she becomes more risk tolerant, this effect is stronger when the insider is less wealthy and the costs associated with the trade are larger. In addition, when the costs are small, risk aversion has little influence on the insider's trading behavior regardless of the level of her wealth and income. Relying on previous literature, we use an individual's proven or suspected criminal behavior as a measure of her lower risk aversion.

Our untabulated results of the univariate analyses, similar to those reported in Table 4 for separate subsamples of convicted and non-convicted insiders, show that convicted insiders in the category of low wealth and income time their selling to avoid significantly more negative mean (median) future abnormal returns than non-convicted insiders in the same wealth and income category. Specifically, the mean (median) future abnormal return following a sale trade in the category of low wealth and income equals $-3.65 \%(-3.94 \%)$ for convicted insiders and $-0.91 \%$ (- 
$1.84 \%$ ) for non-convicted insiders. These results also show that convicted or non-convicted insiders in the categories of medium or high wealth and income do not time their selling before stock price declines. As for insider purchases, we do not find any statistically significant differences in the future abnormal returns earned by convicted and non-convicted insiders. We conclude that our findings are consistent with Fig. 2, implying that risk aversion has a stronger impact on the insider's trading decisions when the insider is less wealthy and the potential costs of gaining from insider trading are larger, which is the case with insider sales more so than with purchases.

\subsection{Multivariate analysis}

Table 5 reports the results of estimating logit (Model 1) and Tobit (Model 2) regressions to explore whether the level of insiders' wealth and income affects their decisions to time their selling (buying), and to sell (buy) in larger magnitudes, before price decreases (increases), controlling for other likely determinants of their trading decisions. Specifically, we estimate the following Models (1) and (2) from our matched-pair sample of an equal number of days with and without insider trading separately for insider selling and buying:

$$
\begin{aligned}
\text { Prob. }\left(T_{\left.R A D E_{i j t}=1\right)=}\right. & \operatorname{logit}\left(\beta_{0}+\beta_{1} L O W_{i t}+\beta_{2} B H A R_{j t}+\beta_{3} L O W_{i t} \times B H A R_{j t}+\beta_{4} M_{i t} D_{i t}\right. \\
& +\beta_{5} M E D_{i t} \times B H A R_{j t}+\beta_{6} R I S K_{-} T A K E R_{i}+\beta_{7} R I S K_{-} T A K E R_{i} \times B H A R_{j t} \\
& \left.+\gamma^{\prime} \boldsymbol{X}_{i j t}+\text { Fixed effects }+\varepsilon_{i j t}\right)
\end{aligned}
$$

Prob. $\left(S I Z E_{i j t}>0\right)=\operatorname{Tobit}\left(\beta_{0}+\beta_{1} L O W_{i t}+\beta_{2} B H A R_{j t}+\beta_{3} L O W_{i t} \times B H A R_{j t}+\beta_{4} M E D_{i t}\right.$

$$
\begin{aligned}
& +\beta_{5} M E D_{i t} \times B H A R_{j t}+\beta_{6} R I S K_{-} T A K E R_{i}+\beta_{7} R I S K_{-} T A K E R_{i} \times B H A R_{j t} \\
& \left.+\gamma^{\prime} \boldsymbol{X}_{i j t}+\text { Fixed effects }+\varepsilon_{i j t}\right),
\end{aligned}
$$


where $i$ denotes insider, $j$ denotes firm, and $t$ denotes day. The dependent variable in Model (1) is a dummy variable that equals one if an insider sells (buys) her insider stock, and zero otherwise $\left(T R A D E_{i j t}\right)$. The dependent variable in Model (2) is the natural logarithm of the market value of shares sold (bought) if an insider sells (buys) her insider stock, and zero otherwise $\left(S I Z E_{i j t}\right) .{ }^{16}$ The independent variables in the models include dummy variables for insiders who belong to the low $\left(L O W_{i t}\right)$ and medium $\left(M E D_{i t}\right)$ wealth and income categories, the high $\left(H I G H_{i t}\right)$ wealth and income category being the control group. ${ }^{17}$ The variable $B H A R_{j t}$ is the buy-and-hold abnormal (marketadjusted) stock return for a one-month period following an insider trade. The vector $\boldsymbol{X}_{i j t}$ includes a comprehensive set of insider- and firm-level control variables that are expected to affect insiders' decisions to trade their insider stocks. We also include firm- and time-fixed effects in the models. All variables are as defined in Section 3.3.2 and Appendix B.

Panel A of Table 5 reports the results of modeling the likelihood of an insider trade in logit regressions (Model 1), whereas Panel B of Table 5 reports the results of modeling the magnitude of an insider trade in Tobit regressions (Model 2). Regarding insider selling, the estimated parameter for the interaction variable $L O W_{i t} \times B H A R_{j t}$ is significantly negative in both the logit and Tobit regressions in Table 5. In other words, insiders in the low wealth and income category are

\footnotetext{
${ }^{16}$ The untabulated results using the percentage of insider holdings sold (bought) or the percentage of total wealth sold (bought) as the dependent variable in Model (2) are similar to those reported for the natural logarithm of the value of shares sold (bought) in Tables 5 and 6.

${ }^{17}$ In untabulated analysis, we replicate the regression analyses of Tables 5 and 6 , including a dummy variable for insiders who belong to the low $\left(L O W_{i t}\right)$ wealth and income category, the medium $\left(M E D_{i t}\right)$ and high $\left(H I G H_{i t}\right)$ wealth and income categories being the control group, or alternatively, including dummy variables for insiders in the low $\left(L O W_{i t}\right)$ and high $\left(H I G H_{i t}\right)$ wealth and income categories, the medium $\left(M E D_{i t}\right)$ wealth and income category being the control group. These results are essentially similar to those presented in Tables 5 and 6, that is, the estimated parameters for the interaction variables $L O W_{i t} \times B H A R_{j t}$ and $L O W_{i t} \times R I S K_{-} T A K E R_{i} \times B H A R_{j t}$, respectively, are significantly negative at the $1 \%$ level in the logit and Tobit regressions.
} 
more prone to timing their selling prior to stock price declines than insiders in the high wealth and income category (the control group). The size of their sales moreover increases with the magnitude of the future stock price decline. The results also show that insiders in the medium wealth and income category $\left(M E D_{i t} \times B H A R_{j t}\right)$ do not time their selling better than insiders in the high wealth and income category. Moreover, convicted insiders, on average, do not time their selling better than non-convicted insiders to avoid insider losses (RISK_TAKER $R_{i} \times B H A R_{j t}$ ), suggesting that they consider the potential costs of exploiting their insider information in insider selling to exceed the potential financial gain. This result is inconsistent with Davidson, Dey, and Smith (2016) who find that executives with legal records earn greater abnormal returns from their insider sales. ${ }^{18}$ The estimated parameters for the control variables have the expected signs.

As for insider buying, we find no evidence that insiders in the low wealth and income category $\left(L O W_{i t} \times B H A R_{j t}\right)$ or those in the medium wealth and income category $\left(M E D_{i t} \times B H A R_{j t}\right)$ are more prone to timing their buying or to buy in larger amounts before stock price increases than insiders in the high wealth and income category (the control group). Moreover, convicted insiders do not time their purchases better than non-convicted insiders $\left(R I S K_{-} T A K E R_{i} \times B H A R_{j t}\right)$. In sum, the multivariate results reported in Table 5 confirm the results from the univariate analyses reported in Table 4 and are consistent with our theoretical model.

(Insert Table 5 about here)

\footnotetext{
${ }^{18}$ Davidson, Dey, and Smith (2016) analyze a manually collected data set in which a great portion of the firms have engaged in fraud, financial reporting errors, and bankruptcy, whereas our results are based on the archival data of all insiders.
} 
Next, we examine how convicted insiders with different levels of wealth and income time their insider trading, compared with non-convicted insiders, when controlling for other determinants of their trading decisions. Specifically, we re-estimate Models (1) and (2) for insider selling and buying by including in the models the three-way interaction variables

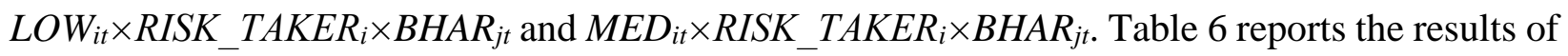
these estimations. ${ }^{19}$

As for insider selling, the results reported in Table 6 show that the interaction variable $L O W_{i t} \times R I S K_{-} T A K E R_{i} \times B H A R_{j t}$ is significantly negative in both logit (Panel A) and Tobit (Panel B) regressions. This result suggests that in the low wealth and income category, convicted insiders are more prone to timing their selling to avoid losses, as opposed to non-convicted insiders. Moreover, we find no evidence that in the medium wealth and income category, convicted insiders are more likely to time their selling before stock price declines than non-convicted insiders $\left(M E D_{i t} \times R I S K_{-} T A K E R_{i} \times B H A R_{j t}\right)$. Regarding insider purchases, the results reported in Table 6 show that the interaction variable $L O W_{i t} \times R I S K_{-} T A K E R_{i} \times B H A R_{j t}$ is statistically insignificant, whereas the interaction variable $M E D_{i t} \times R I S K_{-} T A K E R_{i} \times B H A R_{j t}$ is significantly positive. These results indicate that convicted insiders in the low wealth and income category tend not to time their buying better than non-convicted insiders, but those in the medium wealth and income category do. We conclude that the results reported in Table 6 are consistent with the results from the untabulated univariate analyses and the implications from Fig. 2.

(Insert Table 6 about here)

\footnotetext{
${ }^{19}$ For brevity, we do not report the estimated parameters for the control variables. Their signs and significance levels are similar to those reported in Table 5.
} 


\subsection{Calendar-time portfolio analysis}

We next calculate calendar-time portfolio returns for the three portfolios constructed based on the level of insiders' wealth and income separately for insider sales and purchases. Specifically, we construct the portfolio $L O W_{p t}$, for stocks that were sold (bought) by insiders in the category of low wealth and income in each month during the period from January 2000 to December 2008, $M E D_{p t}$, for stocks that were sold (bought) by insiders in the category of medium wealth and income, and $H I G H_{p t}$, for stocks that were sold (bought) by insiders in the category of high wealth and income.

We calculate the returns for each of the portfolios as follows. For each month in our sample period (January 2000 through December 2008, a total of 108 months), we calculate the raw return over a one-month period following each insider trade in each stock. We then calculate the averages of these monthly raw returns separately for insider sales and purchases in each of the three categories of insiders' wealth and income. This procedure gives us a time-series of equally weighted monthly portfolio returns earned when mimicking the insider trading behavior of insiders with different levels of wealth and income.

To examine the extent to which less wealthy insiders gain more from their insider trades than wealthy insiders, we employ an intercept test using the CAPM, the three-factor model of Fama and French (1993), and the four-factor Carhart (1997) model including stock price momentum. The dependent variable is the calendar-time return of portfolio $L O W_{p t}, M E D_{p t}$, or $H I G H_{p t}$, or the difference between the returns of portfolios $L O W_{p t}$ and $H I G H_{p t}$ (hedge portfolio $L O W_{p t}-H I G H_{p t}$ ). The independent variables are the market return, size, book-to-market, and stock price momentum. 
In particular, we estimate the following CAPM, three-factor and four-factor time-series regressions separately for portfolios of insider sales and purchases as:

$$
\begin{aligned}
& R_{p t}-R_{f t}=\alpha_{p}+\beta_{p}\left(R_{m t}-R_{f t}\right)+\varepsilon_{p t}, \\
& R_{p t}-R_{f t}=\alpha_{p}+\beta_{p}\left(R_{m t}-R_{f t}\right)+\gamma_{p} S M B_{t}+\varsigma_{p} H M L_{t}+\varepsilon_{p t}, \\
& R_{p t}-R_{f t}=\alpha_{p}+\beta_{p}\left(R_{m t}-R_{f t}\right)+\gamma_{p} S M B_{t}+\varsigma_{p} H M L_{t}+\rho_{p} P M O M_{t}+\varepsilon_{p t},
\end{aligned}
$$

where $R_{p t}$ is the month $t$ raw return for portfolio $L O W_{p t}, M E D_{p t}$, or $H I G H_{p t}$ or hedge portfolio $L O W_{p t}-H I G H_{p t}, R_{f t}$ is the month $t$ risk-free rate, $R_{m t}-R_{f t}$ is the month $t$ market excess return, $S M B_{t}$ is the difference between the month $t$ returns on diversified portfolios of small stocks and big stocks, $H M L_{t}$ is the month $t$ difference between the returns on diversified portfolios of high bookto-market (value) stocks and low book-to-market (growth) stocks, and $P M O M_{t}$ is the difference between the month $t$ returns on diversified portfolios of the winners and losers of the past year. ${ }^{20}$

Table 7 reports the calendar-time raw, market-adjusted, and risk-adjusted returns for the three portfolios mimicking the trading behavior of insiders with different levels of wealth and income $\left(L O W_{p t}, M E D_{p t}\right.$, and $\left.H I G H_{p t}\right)$ and for the hedge portfolio of taking a long (short) position in the two extreme portfolios $\left(L O W_{p t}-H I G H_{p t}\right)$. Panel A of Table 7 reports the return results for portfolios of insider sales. ${ }^{21}$ These results show that the mean raw and market-adjusted returns on the portfolio constructed based on the less wealthy insiders' sales $\left(L O W_{p t}\right)$ are significantly more negative than those on the portfolio constructed based on the wealthy insiders' sales $\left(H I G H_{p t}\right)$. Portfolio $L O W_{p t}$ 's mean monthly market-adjusted return of $-1.59 \%$ translates into an economically significant annualized return of $-20.84 \%$, whereas portfolio $H I G H_{p t}$ 's mean monthly market-

${ }^{20}$ The construction of these variables is discussed in detail in Fama and French (1993) and Carhart (1997). We use the data on European three-factor and price momentum factors in Fama and French (2012) for the independent variables in Models (3) - (5). We acknowledge Kenneth French for providing us these data in his webpage.

${ }^{21}$ For insider selling, we lose three out of a total 108 sample months because we require that, for each calendar month, there are insider sales (purchases) in all the three wealth and income categories. 
adjusted return of $-0.03 \%$ is equivalent to an annualized return of only $-0.36 \%$, a $20.48 \%$ point spread. These results hold after controlling for risk by using the CAPM, the Fama-French threefactor model, and the Carhart four-factor model. Specifically, the estimated intercepts from the CAPM, the three-factor, and the four-factor models are significantly negative for the portfolio $L O W_{p t}$ and for the hedge portfolio $\left(L O W_{p t}-H I G H_{p t}\right)$. The risk-adjusted monthly return on the portfolio $L O W_{p t}$ (hedge portfolio $\left.L O W_{p t}-H I G H_{p t}\right)$ is $-2.59 \%(-1.47 \%)$ using the CAPM, $-1.95 \%$ $(-1.49 \%)$ using the three-factor model, and $-2.32 \%(-1.66 \%)$ under the four-factor model.

In Panel B of Table 7, we report the calendar-time returns for insider buying. The returns on all of the three portfolios constructed based on the purchases by insiders with different levels of wealth and income $\left(L O W_{p t}, M E D_{p t}\right.$, and $\left.H I G H_{p t}\right)$ are significantly positive. Moreover, there is a monotonic decrease in both raw and market-adjusted returns as we move from the portfolio of less wealthy insiders' purchases to the portfolio of wealthy insiders' purchases. The mean monthly market-adjusted return on the portfolio $L O W_{p t}\left(H I G H_{p t}\right)$ is $2.99 \%(2.12 \%)$, which translates into an annualized return of $42.41 \%(28.63 \%)$. The mean raw and market-adjusted returns and the riskadjusted return using the CAPM on the hedge portfolio $\left(L O W_{p t}-H I G H_{p t}\right)$ are positive but not significant. By contrast, the estimated intercepts from the three-factor and four-factor models are significantly positive, suggesting that less wealthy insiders earn higher returns on their purchases than wealthy insiders, controlling for various risk factors. In particular, the risk-adjusted monthly return on the hedge portfolio $\left(L O W_{p t}-H I G H_{p t}\right)$ is $1.52 \%$ using the three-factor model, and $1.68 \%$ under the four-factor model.

(Insert Table 7 about here) 


\subsection{Additional analyses}

\subsubsection{Portfolio diversification-driven selling}

In a related paper, Kallunki, Nilsson, and Hellström (2009) show that insiders who have allocated a large proportion of their wealth to a given insider stock time their selling better than other insiders. This raises the question of whether our finding that less wealthy insiders time their selling before stock price declines is actually due to their greater needs to diversify the risk related to their wealth. ${ }^{22}$ We investigate this issue by categorizing our sample of insider sales into quartiles based upon the proportion of wealth that insiders have allocated to their insider stocks, where Quartile 1 (Quartile 4) includes insider sales made by insiders with less (more) of their wealth allocated to insider stock. For each quartile of the proportion of wealth allocated to insider stock, we calculate the mean and median buy-and-hold abnormal stock return measured over a onemonth period after an insider sale $\left(B H A R_{j t}\right)$ separately for insiders in the three wealth and income categories ('Low,' 'Medium,' and 'High').

If less wealthy insiders time their sales prior to stock price declines because they have greater portfolio diversification/rebalancing needs, then we would expect insider sales made by insiders in the low wealth/income category to be followed by negative abnormal returns only in Quartile 4 (with more wealth allocated to insider stock) and not in the Quartiles 1, 2, and 3 (with less wealth allocated to insider stock). Alternatively, if our result that less wealthy insiders time their selling better than wealthy insiders is not related to portfolio diversification-driven selling, we would expect that, in each of these quartiles, the sales by insiders in the low wealth/income category are followed by significantly negative abnormal returns and that these abnormal returns are significantly more negative than those earned by insiders in the high wealth/income category.

\footnotetext{
${ }^{22}$ We thank the referee for raising this issue.
} 
As shown in Table 8, the mean and median abnormal stock returns following the sales made by insiders in the low wealth/income category are significantly negative in all quartiles of the proportion of wealth allocated to insider stocks. For these insiders, we moreover find no significant differences in the abnormal returns between the quartiles of more and less wealth allocated to insider stock (Quartiles 4 and 1). Table 8 also shows that the sales by insiders in the high wealth/income category are not followed by significantly negative abnormal returns, with the exception of the Quartile 4 median. Importantly, Table 8 shows that, for all wealth allocated to insider stock quartiles, insiders in the low wealth/income category sell prior to significantly greater price declines than insiders in the high wealth/income category. Taken together, these results suggest that our finding of less wealthy insiders selling before stock price declines and the portfolio diversification-driven selling reported by Kallunki, Nilsson, and Hellström (2009) are distinct behaviors by insiders.

(Insert Table 8 about here)

In Table 9, we repeat the multivariate analysis presented in Table 5, including an interaction variable between the proportion of wealth that an insider has allocated to her insider stock and the future abnormal stock return $\left(P R O P_{-} W E A L T H \times B H A R_{j t}\right)$ as an independent variable. Table 9 shows that the interaction variable $L O W_{i t} \times B H A R_{j t}$ remains significantly negative in both logit and Tobit regressions indicating that portfolio diversification-driven selling is not driving our findings, consistent with the univariate results presented in Table 8. We also replicate the analysis of Table 6, including the interaction variable $P R O P_{-} W E A L T H \times B H A R_{j t}$ as an independent variable. The untabulated results of these analyses show that the interaction variable 
$L O W_{i t} \times R I S K_{-} T A K E R_{i} \times B H A R_{j t}$ remains significantly negative at the $1 \%$ level in logit and Tobit regressions. In other words, after controlling for the portfolio diversification-driven selling, we continue to find that less wealthy insiders, especially those with lower risk aversion, are significantly more likely to time their insider selling and to sell in greater magnitudes prior to stock price declines relative to wealthy insiders. We also repeat, but do not tabulate, the multivariate analyses presented in Tables 5 and 6 for insider selling, including an interaction variable between a dummy variable for the highest quartile of the proportion of wealth allocated to insider stock (Quartile 4) from Table 8 and the future abnormal stock return, and find similar results.

In additional untabulated tests, we replicate both the univariate and multivariate analyses in this subsection using a mean-adjusted diversification ratio measuring the extent to which the proportion of an insider's wealth allocated to her insider stock deviates from its long-term level (i.e., the difference of the proportion of wealth that an insider has allocated to her insider stock and the time-series mean of this proportion calculated over the sample period of nine years) as in Kallunki, Nilsson, and Hellström (2009) and find similar results. We conclude that our finding of less wealthy insiders selling prior to stock price declines is not due to the portfolio diversificationdriven selling reported by Kallunki et al. (2009).

(Insert Table 9 about here)

\subsubsection{Alternative wealth and income grouping of insiders}

Our analyses thus far are based on categorizing insiders into three groups based on the level of their wealth and income. In this subsection, we use an alternative approach to grouping insiders 
based on the level of their wealth and income. Specifically, we construct a continuous variable of the level of insiders' wealth and income using the following procedure. We first rank all the 11,178 $(18,166)$ observations in our matched-pair sample used for analyzing insider selling (buying) on insiders' wealth at the end of the previous fiscal year. Independent of the wealth rankings, we rank all the observations in the matched-pair sample on an insider's annual income from the previous fiscal year. Finally, we add each insider's wealth ranking to her income ranking, and use the (base 10) logarithm of this variable in the regressions instead of the three groups. A higher value of this wealth and income ranking corresponds to a higher wealth and income level of the insider.

In Table 10, we repeat the univariate analysis of Table 4 by partitioning our sample of insider selling (buying) into five quintiles based upon the continuous wealth and income ranking of insiders. Panel A of Table 10 shows that insiders in the two lowest wealth and income quintiles (Quintiles 1 and 2) time their selling before price declines, whereas the insiders in the higher wealth and income quintiles (Quintiles 3, 4, and 5) do not. The mean and median abnormal returns following insider sales by insiders in Quintile 1 (Quintile 2) are $-1.62 \%$ and $-2.10 \%(-1.32 \%$ and $-2.00 \%$ ), both of which are significantly different from zero at the $1 \%$ level. In contrast, the mean and median abnormal returns following sales by insiders in the higher wealth and income quintiles (Quintiles 3, 4, and 5) are not significant, except for the Quintile 4 median. As for insider buying, Panel B of Table 10 shows that insiders in all the wealth and income quintiles time their purchases prior to stock price increases, with the exception of the Quintile 3 median. Taken together, these univariate results are similar to those using the three wealth and income groups reported in Table 4.

(Insert Table 10 about here) 
We also investigate how insiders with lower risk aversion measured by their criminal behavior time their trading in the five wealth and income quintiles. The untabulated results of these univariate analyses are similar to those based on the three wealth and income groups. Specifically, we find that convicted insiders time their selling to avoid significantly more negative mean (median) future abnormal returns than non-convicted insiders only in the lowest wealth and income quintile (Quintile 1), but not in the other four quintiles (Quintiles 2, 3, 4, and 5). The mean (median) future abnormal return following a sale trade in the lowest wealth and income quintile equals $3.59 \%(-3.44 \%)$ for convicted insiders and $-0.90 \%(-1.64 \%)$ for non-convicted insiders. As for insider purchases, we do not find any statistically significant differences in the future abnormal returns earned by convicted and non-convicted insiders.

We next repeat the multivariate analysis presented in Table 5, but use the logarithm of the continuous wealth and income ranking of insiders, or alternatively, a dummy variable for insiders in the lowest wealth and income quintile (Quintile 1) used in Table 10 instead of the three wealth and income groups. In these regressions, we also control for the portfolio diversification-driven selling reported by Kallunki, Nilsson, and Hellström (2009). The results of these analyses are reported in Table 11. We continue to find that insiders are more likely to time their selling, and to sell in greater magnitudes, prior to a decline in the stock price as the level of their wealth and income decreases. Specifically, the estimated parameter for the interaction variable $\log \left(W I_{-} R A N K_{i t}\right) \times B H A R_{j t}$ is significantly positive in both logit and Tobit regressions in Columns 1 and 5 of Table 11, and the estimated parameter for the interaction variable QUINTILE_ $1_{i t} \times B H A R_{j t}$ is significantly negative in Columns 3 and 7 of Table 11 . We do not find any evidence that insiders' wealth and income level is related to their decisions to time their buying 
before price increases, consistent with the multivariate analysis using the three wealth and income groups presented in Table 5. We conclude that our main result holds using an alternative method for grouping insiders based on the level of their wealth and income.

(Insert Table 11 about here)

In untabulated tests, we repeat our analysis from Table 11, including the three-way interaction variable $\log \left(W I_{-} R A N K_{i t}\right) \times R I S K_{-} T A K E R_{i} \times B H A R_{j}$ or $Q U I N T I L E 1_{i t} \times R I S K_{-} T A K E R_{i} \times B H A R_{j t}$ as an independent variable to examine how convicted insiders time their trading compared with nonconvicted insiders, given the level of their wealth and income. We find that convicted insiders are more likely to time their selling, and to sell in greater magnitudes, before declining stock prices as the level of their wealth and income decreases, compared to non-convicted insiders. In particular, the estimated parameter for the three-way interaction variable $\log \left(W{ }_{-} R A N K_{i t}\right) \times R I S K_{-} T A K E R_{i} \times B H A R_{j}\left(Q_{\text {UINTILE1 }} \times{ }_{i t} \times R I S K_{-} T A K E R_{i} \times B H A R_{j t}\right)$ is significantly positive (negative) at the $1 \%$ level in both logit and Tobit regressions. Regarding insider buying, the untabulated results show that both the interaction variables $\log \left(\right.$ WI_RANK $\left.K_{i t}\right) \times R I S K_{-} T A K E R_{i} \times B H A R_{j} \quad$ and $\quad$ QUINTILE $1_{i t} \times R I S K_{-} T A K E R_{i} \times B H A R_{j t} \quad$ are statistically insignificant in the logit and Tobit models. We conclude that these results are consistent with the univariate results using the five wealth and income quintiles and the regression results using the three wealth and income groups presented in Table 6 .

We conclude the analyses in this subsection by replicating the calendar-time portfolio analysis of Table 7, but this time form the portfolios based on the five wealth and income quintiles from Table 10 instead of the three wealth and income groups. These untabulated results are similar to 
those reported in Table 7. That is, after controlling for various risk factors, we continue to find that less wealthy insiders gain more from their insider sales than wealthy insiders. In particular, the results show that the mean raw and market-adjusted returns on the portfolio mimicking the selling behavior of insiders in the lowest wealth and income quintile $\left(Q 1_{p}\right)$ are significantly more negative than those on the portfolio mimicking the selling behavior of insiders in the highest quintile $\left(Q 5_{p}\right)$. Portfolio $Q 1$ p's mean monthly raw (market-adjusted) return is $-2.37 \%(-1.83 \%)$, whereas portfolio $Q 5_{p}$ 's mean monthly raw (market-adjusted) return is $0.39 \%$ (0.08\%), a $1.91(1.84)$ percentage point spread. The results moreover show that there is a monotonic increase in both raw and marketadjusted monthly returns as we move from the portfolio of less wealthy insiders' sales $\left(Q 1_{p}\right)$ to the portfolio of wealthy insiders' sales $\left(Q 5_{p}\right)$.

These results remain after controlling for risk by using the CAPM and the Fama-French threefactor model and the Carhart four-factor model. In particular, the estimated intercepts from the CAPM and the three- and four-factor models are significantly negative for the portfolio $Q 1_{p}$ and for the hedge portfolio $\left(Q 1_{p}-Q 5_{p}\right)$. The risk-adjusted monthly return on the portfolio $Q 1_{p}$ (hedge portfolio $\left.Q 1_{p}-Q 5_{p}\right)$ is $-2.81 \%(-1.89 \%)$ using the CAPM, $-2.58 \%(-2.16 \%)$ using the threefactor model, and $-2.68 \%(-2.12 \%)$ under the four-factor model.

As for insiders' purchases, the untabulated results show that, consistent with the results presented in Table 7, the raw and market-adjusted returns on all five portfolios constructed based on the purchases by insiders in the wealth and income quintiles are significantly positive. The results moreover show that the risk-adjusted monthly return using the CAPM or the Fama-French three-factor model on the hedge portfolio $\left(Q 1_{p}-Q 5_{p}\right)$ is positive but not statistically significant. However, the estimated intercept from the four-factor model is significantly positive (1.33\%). 


\subsubsection{Cash-strapped insiders}

Our results thus far show that less wealthy insiders time their selling before stock price declines whereas wealthier insiders do not. We next examine whether this result varies based upon whether the insider is cash-strapped. We focus on cash-strapped insiders because the benefits of informed trading could be at their largest relative to the associated costs among this subsample of insiders.

For each insider in our sample, we calculate her debt-to-wealth and interest payments-toincome ratios using yearly data from personal tax filings. An insider's debt-to-wealth ratio shows how much interest-bearing debt she has relative to her wealth, whereas an interest payments-toincome ratio reflects the fraction of income needed for the debt service. We identify cash-strapped insiders using the following procedure. We first divide all the observations in our matched-pair sample used for insider selling (buying) into two equal-sized groups based on an insider's debtto-wealth ratio, i.e., low and high debt-to-wealth groups. Similarly, we divide all observations in the sample into two equal-sized groups based on an insider's interest payments-to-income ratio, i.e., low and high interest payments-to-income groups. We then define cash-strapped insiders as those who belong to the groups of both high debt-to-wealth and high interest payments-to-income. All other insiders are considered as being non-cash-strapped.

We begin by comparing the abnormal returns following insider trades made by cash-strapped insiders to those by non-cash-strapped insiders. If the net benefits of insider trading are greater for cash-strapped insiders than for non-cash-strapped insiders, then we would expect insider trades by cash-strapped insiders to be followed by significantly greater abnormal returns than those by noncash-strapped insiders. The results reported in Table 12 show evidence consistent with this prediction. That is, we find that cash-strapped insiders' sales are followed by significantly more 
negative mean (median) future abnormal returns than the sales by non-cash-strapped insiders. The mean (median) abnormal return over a one-month period following insider sales is $-1.35 \%$ ($1.74 \%)$ for cash-strapped insiders and $0.20 \%(-0.57 \%)$ for non-cash-strapped insiders. We do not, however, find any statistically significant differences in the future abnormal returns earned by cash-strapped and non-cash-strapped insiders on their purchases, consistent with the reputation and litigation risk of being detected for trading on private information being lower when insiders purchase stocks versus when they sell it.

We continue by investigating whether the trading behavior of insiders with different levels of wealth and income differs depending on whether they are cash-strapped. To accomplish this, we sort insider trades in each of the three wealth and income categories into two subgroups based upon whether the insider is cash-strapped. We find that $53 \%, 31 \%$, and $28 \%$ of insider sales in the wealth and income categories 'Low,' 'Medium,' and 'High,' respectively, are made by cashstrapped insiders. This result suggests that being cash-strapped is not only a phenomenon of less wealthy insiders.

The results in Table 12 show that both cash-strapped and non-cash-strapped insiders in the category of low wealth and income sell to avoid significantly negative stock price declines. In particular, in the category of low wealth and income, the mean (median) abnormal return following a sale trade is $-1.82 \%(-2.94 \%)$ for cash-strapped insiders and $-1.55 \%(-1.85 \%)$ for non-cashstrapped insiders, with the difference being statistically insignificant. We further find that the sales by cash-strapped insiders in the medium and high wealth and income categories are followed by significantly negative abnormal returns (with the exception of the high wealth and income category mean), but that those by non-cash-strapped insiders are not. The mean (median) abnormal return following cash-strapped insiders' sales is $-1.23 \%(-0.97 \%)$ in the medium wealth and income 
category and $-0.69 \%(-0.70 \%)$ in the high wealth and income category, whereas the mean (median) abnormal return following non-cash-strapped insiders' sales is $0.47 \%(-0.15 \%)$ in the medium wealth and income category and $0.98 \%(-0.32 \%)$ in the high wealth and income category. The difference in the mean (median) abnormal returns earned by cash-strapped and non-cashstrapped insiders in the high and medium wealth and income categories is statistically significant. Importantly, we continue to find, among both cash-strapped and non-cash-strapped insiders, that insiders in the low wealth and income category sell prior to significantly greater price declines than insiders in the high wealth and income category. As for insider purchases, we do not find any statistically significant variation in the returns earned by cash-strapped and non-cash-strapped insiders across the three wealth and income categories.

(Insert Table 12 about here)

We further examine the selling behavior of cash-strapped and non-cash-strapped insiders with different levels of wealth and income in a multivariate setting. Table 13 reports the results of these analyses. In all these regressions, we also control for other potential factors that can affect how insiders time their selling by including interaction variables between all the insider- and firmspecific control variables in Models (1) and (2) and the future one-month abnormal return. We begin these analyses by repeating the multivariate analysis presented in Table 5, including a dummy variable for cash-strapped insiders $\left(C A S H \_S T R A P P E D_{i t}\right)$ and an interaction variable between this dummy variable and the future abnormal return $\left(C A S H \_S T R A P P E D_{i t} \times B H A R_{j t}\right)$. These results are reported in Columns 1 and 4 of Table 13 and show that the estimated parameter for the interaction variable $C A S H \_S T R A P P E D_{i t} \times B H A R_{j t}$ is significantly negative at the $1 \%$ level 
in both logit and Tobit regressions, indicating that cash-strapped insiders are more likely to time their selling prior to stock price declines than non-cash-strapped insiders (the control group). Moreover, after controlling for cash-strapped insiders' selling, we find that our main result of insiders in the low wealth/income category timing their selling before price declines remains. In Columns 2 and 5 of Table 13, we replicate the multivariate analysis from Table 11 using the logarithm of the continuous wealth and income ranking of insiders, including the interaction variable $C A S H \_S T R A P P E D_{i t} \times B H A R_{j t}$, and find similar results. In additional untabulated tests, we repeat the multivariate analysis presented in Table 11 using the dummy variable for the lowest wealth and income quintile (Quintile 1), including the interaction variable CASH_STRAPPED $D_{i t} \times B H A R_{j t}$, and find similar results.

Next, we repeat the multivariate analysis presented in Table 5, using six new dummy variables instead of the three wealth and income groups to identify cash-strapped and non-cash-strapped insiders with different levels of wealth and income and their interactions with the future one-month abnormal return. We form these six dummy variables by dividing insiders in each of the three wealth and income categories into cash-strapped and non-cash-strapped insiders (the dummy variables LOW_CASH_STRAPPED ${ }_{i t}, \quad L O W_{-} N O N_{-} C A S H \_S T R A P P E D_{i t}$, $M E D \_C A S H \_S T R A P P E D_{i t}, M E D \_N O N \_C A S H \_S T R A P P E D_{i t}, H I G H \_C A S H \_S T R A P P E D_{i t}$, and HIGH_NON_CASH_STRAPPED $\left.{ }_{i t}\right)$. The results of these analyses are reported in Columns 3 and 6 of Table 13. We find that both cash-strapped and non-cash-strapped insiders in the low wealth/income category are more likely to time their selling prior to stock price declines than noncash-strapped insiders in the high wealth/income category (the control group). In particular, the estimated parameters for the interaction variables $L O W_{-} C A S H_{-} S T R A P P E D_{i t} \times B H A R_{j t}$ and $L O W \_N O N \_C A S H \_S T R A P P E D_{i t} \times B H A R_{j t}$ are significantly negative at the $1 \%$ and $5 \%$ levels, 
respectively, in logit and Tobit regressions. Furthermore, we find that cash-strapped insiders in the medium wealth and income category time their sales prior to stock price declines, whereas noncash-strapped insiders in the same wealth and income category do not. We find no evidence that cash-strapped insiders in the high wealth and income category time their selling better than noncash-strapped insiders in the same wealth and income category.

Finally, we repeat the multivariate analysis presented in Table 6, controlling for cash-strapped insiders' selling behavior. The untabulated results from these regressions show that the estimated parameters for the interaction variables CASH_STRAPPED ${ }_{i t} \times B H A R_{j t}$ and $L O W_{i t} \times R I S K_{-} T A K E R_{i} \times B H A R_{j t}$ are significantly negative at the $1 \%$ level in logit and Tobit regressions, indicating that our result of less wealthy and risk-prone insiders being particularly prone to timing their selling prior to stock price declines remains after we control for cash-strapped insiders' selling. In untabulated analysis, we further find that less wealthy and risk-prone insiders time their selling prior to price declines regardless of whether they are cash-strapped or not. We do not observe similar selling behavior for wealthy risk-prone insiders.

(Insert Table 13 about here)

\subsubsection{The 20 least and most wealthy insiders}

In this subsection, we compare the abnormal returns earned by insiders who have very little wealth to those earned by insiders who are extremely wealthy. Specifically, we identify the 20 least wealthy and the 20 most wealthy insiders in the wealth and income groups 'Low' and 'High,' respectively, and report the mean and median future one-month abnormal returns following the insider sales and purchases by these insiders in Table 14. The results reported in Table 14 show 
that the 20 least wealthy insiders sell their insider stocks before abnormal stock price declines, whereas the 20 most wealthy do not. The average (median) abnormal return following an insider sale is $-3.86 \%(-2.97 \%)$ for the 20 least wealthy insiders and $0.63 \%(0.15 \%)$ for the 20 most wealthy insiders, with the difference being both economically and statistically significant. As for insider purchases, we find that the purchases by the 20 least wealthy insiders are (on average) followed by significantly positive abnormal returns, but that those by the 20 most wealthy are not. We conclude that, unlike the 20 most wealthy insiders in our sample, the 20 least wealthy are willing to use private information to make insider trading decisions.

\section{(Insert Table 14 about here)}

\subsubsection{Information asymmetry and firm size}

To further examine how the trade-off between the potential gains and costs of insider trading impacts the trading decisions of insiders with different levels of wealth and income, we investigate the influence of information asymmetry and firm size on the abnormal returns earned by insiders in the three wealth and income categories on their sales and purchases. Following previous studies (e.g., Moeller, Schlingemann, and Stulz, 2007; Boone, Floros, and Johnson, 2016), we measure information asymmetry between insiders and other market participants by a firm's idiosyncratic stock return volatility, calculated as the standard deviation of the residuals from a market model regression estimated from 124 trading days before an insider trade to one trading day before an insider trade. We expect information asymmetry, and thus the amount of private information available for insiders to trade on, to increase in the idiosyncratic return volatility. 
We use firm size (market capitalization) to capture the expected costs that insiders face when they trade their stocks. Large firms face broader media coverage and more investor attention than small firms (Fang and Peress, 2009) meaning that insider trading in large firms is likely to attain more media and investor scrutiny than that in small firms. Consequently, insiders in large firms should face greater expected costs in their trading, compared to insiders in small firms. To examine how the abnormal return following insider selling (buying) varies with information asymmetry and firm size, we construct a $3 \times 2$ table by dividing our sample of insider selling (buying) into three groups based on the idiosyncratic return volatility ('Low ivol.,' 'Medium ivol.,' and 'High ivol.') and into two groups based on firm size ('Small' and 'Large'). For each cell of the $3 \times 2$ table, we calculate the mean and median buy-and-hold abnormal stock return measured over a onemonth period after an insider trade $\left(B H A R_{j t}\right)$ separately for insiders in the three wealth and income categories ('Low,' 'Medium,' and 'High').

We conjecture that, if less wealthy insiders are willing to sell on private information, the abnormal return following the sales by insiders in the low wealth and income category should be decreasing with increasing idiosyncratic return volatility. Moreover, this relation could vary based on firm size because the costs that insiders expect to face from exploiting private information are likely to be smaller in small firms than in large firms. In contrast, if wealthier insiders tend to refrain from selling on private information because the potential costs exceed the potential gains, then we would not expect insiders in the medium or high wealth/income category to sell before significantly negative abnormal stock returns across the idiosyncratic volatility groups.

Consistent with expectations, the untabulated results show that the mean (median) abnormal return following the sales by insiders in the low wealth/income category is significantly more negative in the high idiosyncratic volatility group ('High ivol.') than in the low idiosyncratic 
volatility group ('Low ivol.'). We moreover find that in the high idiosyncratic volatility group, low wealth/income insiders sell before significantly negative abnormal returns in both small and large firms, whereas in the medium idiosyncratic volatility group ('Medium ivol.'), low wealth/income insiders sell before significantly negative abnormal returns only in small firms, but not in large firms. The sales by insiders in the medium and high wealth and income categories are not followed by significantly negative abnormal returns, with the exception of the medium wealth/income category median for the high idiosyncratic volatility group. Regarding insider purchases, we do not find any statistically significant differences in the future abnormal returns earned by insiders in the three wealth and income categories across the idiosyncratic return volatility and firm size groups (not tabulated).

\subsubsection{Costs associated with insider selling versus buying}

Our results show that less wealthy insiders are more likely to time their stock sales prior to abnormal stock price declines than wealthy insiders. In contrast, we do not find the same relation for insiders' purchases, which are profitable regardless of the level of insiders' wealth and income. The asymmetry of this finding is consistent with the argument made in prior research that the reputational and/or legal costs associated with selling insider stocks are greater than those associated with buying (e.g., Cheng and Lo, 2006; Piotroski and Roulstone, 2008; Dai, Parwada, and Zhang, 2015; Alldredge and Cicero, 2015). To gain further support for this argument, we obtained anecdotal evidence on whether the reputational and/or legal costs of exploiting private information are greater when insiders sell stock versus when they purchase it. In particular, we interviewed ten market participants in Sweden including financial analysts, asset managers, and 
market surveillance and compliance officers to ask how they assess the reputational and legal costs of engaging in informed insider selling versus buying.

The respondents concluded that there is significantly more reputational risk associated with selling insider stocks before price declines than with buying before price increases, especially if insiders sell significant amounts of stocks in their own company. Many of them pointed out that while buying insider stocks creates incentives for insiders to maximize shareholder value, insider selling before price declines does not create incentives. Moreover, the returns on insiders' purchases are 'paper gains' in the sense that the end return for a given purchase is not known until insiders eventually sell these stocks. In contrast, selling before stock price declines means that the insider is saving real money by avoiding losses and therefore it is obvious that the insider is profiting at the expense of other shareholders. According to the respondents, the market does not like to see managers who put their own interest before the company and its shareholders. With few exceptions, the respondents concluded that both insider selling and buying should bear the same legal risk.

In sum, based on these interviews, we conclude that there is significantly more reputational risk involved in insider selling before price declines than in buying before price increases, but that there is likely to be no difference between insider selling and buying in terms of legal risk.

\subsubsection{Employee stock option exercises}

We have also examined the buy-and-hold abnormal (market-adjusted) returns following employee stock option (ESO) exercises by insiders with different levels of wealth and income. We calculate the future abnormal returns over one-month, three-month, and six-month horizons. In our sample, there are 214 employee stock option exercises, of which 63, 98, and 53 are made by 
insiders in the low, medium, and high wealth and income categories, respectively. The untabulated results show that insiders in the low wealth and income category exercise their ESOs prior to stock price declines in three-month and six-month horizons, but not in a one-month horizon. The mean and median abnormal returns over a three-month (six-month) period following ESO exercises by insiders in the low wealth and income category are $-4.81 \%$ and $-7.60 \%(-11.34 \%$ and $-14.21 \%)$. In contrast, insiders in the medium or high wealth and income categories do not exercise their ESOs before stock price declines. The difference in the mean and median three-month (six-month) abnormal returns following ESO exercises by insiders in the low and high wealth/income categories is moreover statistically significant at the 5\% (1\%) level. Hence, these results suggest that less wealthy insiders are more willing to exercise their ESOs prior to price declines, compared to wealthy insiders. This result is consistent with our results for insiders' stock trading.

\subsubsection{Mergers and acquisitions}

We conclude our empirical analyses by investigating the trading decisions of insiders with different levels of wealth and income in a setting where informed insider trading is likely subject to a high risk of legal enforcement and thus likely to incur large fixed costs (criminal penalties and cost of jail time) and variable costs (disgorgement of profits, reputational damage, and other costs related to the magnitude of the profits gained or losses avoided) for the insider who trades. Specifically, we examine insider trading prior to merger and acquisition (M\&A) announcements. The risk of legal enforcement as perceived by insiders should be particularly high when insiders trade on information regarding a merger or acquisition because abnormal price and volume changes before significant corporate events such as M\&As are one of the primary ways for the regulator to detect and prosecute illegal insider trading (Ahern, 2017). Consistent with this, as 
much as 51\% and 79\% in Ahern's (2017) and Meulbroek's (1992) sample of illegal insider trading cases discovered and prosecuted by the SEC are takeover-related.

We retrieve the data on M\&A announcements from the Thomson Securities Data Company (SDC) database. From these data, we identify 22 firms among the firms in our sample that were targets for M\&As during the sample period 2000-2008. As shown in Fig. 1 (Scenario 3), if the risk of legal enforcement associated with trading on private information is likely to be high, we would expect that less wealthy insiders are more likely to refrain from trading than wealthy insiders. Consistent with this, we expect that less wealthy insiders make fewer purchases prior to M\&As than wealthy insiders. Our untabulated results show evidence consistent with this prediction. That is, we find that there are 58 insider purchases made during a one-month window prior to an M\&A announcement, out of which $15.5 \%$ (9), 36.2\% (21) and 48.3\% (28) are made by insiders in the low, medium, and high wealth and income categories, respectively. ${ }^{23}$ Chi-square tests show that the lower proportion of purchases by insiders in the low wealth and income category is significantly different from those of insiders in the other two wealth and income categories at the $1 \%$ level.

\section{Conclusions}

We present a model of an insider's decision to engage in informed insider trading. The riskaverse insider in our model maximizes her expected utility by trading off between the potential financial gain and costs of informed insider trading, including the potential damage to an insider's personal reputational capital and the potential legal sanctions. These costs occur because informed insider trading can be regarded as self-serving or even illegal use of insider information by outside

\footnotetext{
${ }^{23}$ In untabulated tests, we have also used three- and six-month horizons to examine insiders' purchases before $M \& A$ announcements and find similar results to those using a one-month horizon.
} 
investors, media members, or the regulatory authority. Our model allows both the financial gain and the costs of informed insider trading to comprise a fixed component as well as a variable component that is related to the volume of insider trading and, as such, to the level of an insider's wealth and income.

We show that an increase in the level of an insider's wealth and income level reduces her willingness to trade on private information, as long as the trading is subject to a relatively low risk of legal enforcement and therefore not likely to incur large fixed costs such as criminal fines or jail time for the insider. Hence, less wealthy insiders should be more prone to engaging in informed insider trading than wealthy insiders when trading is not expected to lead to large fixed costs and only involves variable costs that are related to the insider trading volume such as personal reputational damages. The reason is that a less wealthy insider would be willing to accept a lower probability that her informed trading will not be detected and punished by outsiders than a wealthy insider. This effect is greater (smaller) in magnitude when the variable costs of insider trading are larger (smaller). Our analysis also shows that risk aversion has a stronger impact on the insider's willingness to engage in informed trading as the costs of such trading increase and the insider is less wealthy.

We empirically test the implications of our model by investigating the effects of corporate insiders' wealth, income, and attitude towards risk on their decisions to time their selling (buying) prior to abnormal stock price declines (increases). We analyze Swedish data because archival data on wealth, income, and many other demographic variables are available for all insiders of all listed firms in Sweden. Consistent with our model, the empirical results based on reported insider trades show that less wealthy insiders are more likely to time their selling prior to abnormal stock price declines than wealthy insiders. We also find that those insiders who are both less wealthy and have 
higher risk tolerance as measured by their criminal behavior are particularly prone to timing their selling before price declines. In contrast, we do not observe similar selling behavior for risk-prone insiders who are wealthy. Consistent with the notion that insider buying before price increases involves significantly lower potential costs than insider selling before price declines, we find that insiders time their purchases prior to stock price increases regardless of the level of their wealth and income or risk tolerance. After controlling for market risk, size, book-to-market, and price momentum characteristics of the traded stocks, we find that a portfolio comprised of less wealthy insiders' sales significantly outperforms that of wealthy insiders' sales, with an intercept on the difference $-1.66 \%$ per month. 


\section{Appendix A. Swedish insider trading legislation}

In this appendix, we briefly discuss Swedish insider trading legislation and compare it with that of the United States. In Sweden, insider trading has been regulated since 1985, when the first law prohibiting trading in securities while in possession of non-public, firm-specific information was passed. This law was initially enforced in 1989, when Sweden got its first conviction for illegal insider trading, and regulations were further tightened in 1991 as the European Union Directive on the Regulation of Insider Trading (EEC Directive 89/592) was incorporated into Swedish law. The current insider trading legislation in Sweden is in accordance with European Union Directives on the Regulation of Insider Trading (EEC Directive 89/592) and on Insider Dealing and Market Manipulation (Directive 2003/6/EC). The regulatory authority that holds the responsibility for enforcing insider trading legislation in Sweden is the Finansinspektionen, which is the corresponding authority to the SEC in the USA.

Swedish insider trading legislation is of high quality and similar to that of the USA (Beny, 2005). This is because the U.S. insider trading legislation formed the basis of the Swedish legislation. Despite this, some differences remain. First, illegal insider trading is only a criminal offence in Sweden, whereas it is both a criminal and a civil offence in the USA. Thus, unlike the SEC, the Finansinspektionen lacks a civil enforcement authority in illegal insider trading. Second, as of June 2005, Swedish insiders are prohibited from trading in the firm's shares 30 days prior to the publication of earnings announcements. This trading ban replaced the so-called 'short-term trading rule' (which had been in effect since 1997), under which insiders were not allowed to engage in a round-trip transaction (i.e., a buy followed by a sale) during a three-month trading window. In comparison, insiders in the USA are penalized for trading profits earned less than six months after previous trades ('the short-swing rule' of Section 16(b) of the Securities and Exchange Act of 1934), but there is no legal rule that prohibits insiders from trading prior to an earnings announcement.

Similarly to U.S. insiders who have to file their insider trades with the SEC, Swedish insiders are legally required to report their insider holdings and insider stock trades to the Finansinspektionen (The Act Concerning Reporting Obligations for Certain Holdings of Financial Instruments, 2000:1087). The reporting obligation period for insider trades in Sweden is five business days from the day of the trade, as of January 2001, while in the USA it is two business days, as of August 2002 (Brochet, 2010). The Finansinspektionen disseminates the information about insiders' stock trades to the general public, as it publishes insiders' stock trades on a daily basis on its website. 


\section{Appendix B. Variable definitions}

Variable Description

Panel A: Insider trading variables

$T R A D E_{i j t} \quad$ A dummy variable with a value of one if insider $i$ sells (buys) her insider stocks of firm $j$ on day $t$, and zero otherwise.

The natural logarithm of the market value of the shares sold if insider $i$ sells (buys) insider stocks of firm $j$ on day $t$, and zero otherwise. Empirical analyses also use the ratio of the market value of the shares sold (bought) $\ln \left(S I Z E_{i j t}\right) \quad$ to the value of insider $i$ 's holdings in insider stock $j$ at the end of the fiscal year prior to day $t$ if insider $i$ sells (buys) insider stocks of firm $j$ on day $t$, and zero otherwise $\left(S I Z E_{-} H O L D_{i j t}\right)$ and the ratio of the market value of the shares sold (bought) to the value of insider $i$ 's total wealth at the end of the fiscal year prior to day $t$ if insider $i$ sells (buys) insider stocks of firm $j$ on day $t$, and zero otherwise (SIZE_WEALTH $\left.H_{i j t}\right)$.

The buy-and-hold abnormal (market-adjusted) stock return for the one-month period following day $t$ for firm $j$. Empirical analyses also use the buy-and-hold abnormal (market-adjusted) stock return for the three- and sixmonth periods following day $t$ for firm $j$.

Panel B: Level of an insider's wealth and income

$L O W_{i t}$

A dummy variable equal to one if an observation in our matched-pair sample of the $11,178(18,166)$ observations used to analyze insider selling (buying) belongs to the wealth/income category 'Low,' and zero otherwise. The construction of the wealth and income category 'Low' can be found in Section 3.3.2.1.

A dummy variable equal to one if an observation in our matched-pair sample of the $11,178(18,166)$ observations used to analyze insider selling (buying) belongs to the wealth/income category 'Medium,' and zero otherwise. The construction of the wealth and income category 'Medium' can be found in Section 3.3.2.1.

$H I G H_{i t}$ A dummy variable equal to one if an observation in our matched-pair sample of the $11,178(18,166)$ observations used to analyze insider selling (buying) belongs to the wealth/income category 'High,' and zero otherwise. The construction of the wealth and income category 'High' can be found in Section 3.3.2.1.

Panel C: Attitude towards risk

RISK_TAKER

A dummy variable equal to one if insider $i$ has been found guilty of one or more crimes in a court of law or received summary punishments by prosecutors, or has been suspected of one or more serious crimes, and otherwise zero. Convictions include all convictions since 1974, and suspicions include all suspicions since 1991. 
Empirical analyses also use the natural logarithm of one plus the number of times insider $i$ has been found guilty of a crime in a court of law, received summary punishments by prosecutors, or been suspected of a serious crime.

Panel D: Control variables

GENDER $\quad$ A dummy variable equal to one if insider $i$ is male, and zero otherwise.

$\ln \left(A G E_{i}\right) \quad$ The natural logarithm of the last two numbers of insider $i$ 's birth year.

$\ln \left(1+\right.$ TENURE $\left._{i j t}\right) \quad$ The natural logarithm of one plus the number of days since the beginning of insider $i$ 's insider position in firm $j$ on day $t$.

$C E O_{i j t} \quad$ A dummy variable equal to one if insider $i$ has an insider position as a CEO of firm $j$ on day $t$, and zero otherwise.

$E_{\text {XXE }} \quad$ A dummy variable equal to one if insider $i$ has an insider position as an executive other than CEO of firm $j$ on day $t$, and zero otherwise.

The ratio of the value of insider $i$ 's holdings in insider stock $j$ at the end of the fiscal year prior to day $t$ to the

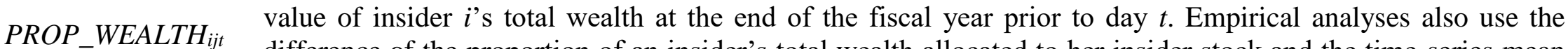
difference of the proportion of an insider's total wealth allocated to her insider stock and the time-series mean of this proportion calculated for each insider over the sample period of nine years.

The natural logarithm of one plus the value of insider $i$ 's cash holdings at the end of a fiscal year prior to day $t$,

$\ln \left(1+\right.$ LIQUIDITY $\left._{i t}\right) \quad \begin{aligned} & \text { minus its time-series mean calculated for insider } i \text { over the sample period. As the variable } \text { LIQUIDITY }_{i t} \text { takes } \\ & \text { both positive and negative values, we take the natural logarithm of one plus the absolute value of } \text { LIOUIDITY }_{i t}\end{aligned}$ and then add back the original sign of LIQUIDITY ${ }_{i t}$ after taking the natural logarithm.

$\ln \left(1+N U M I N S_{i t}\right) \quad$ The natural logarithm of one plus the number of insider stocks owned by an insider $i$ at the end of the fiscal year prior to day $t$.

MOMENTUM $\quad$ The buy-and-hold market-adjusted stock return for firm $j$ for the six-month period prior to day $t$.

$D_{\text {DELOSS }} \quad$ A dummy variable equal to one if the buy-and-hold market-adjusted stock return for the six-month period prior to day $t$ for firm $j$ is negative and day $t$ is in December, and zero otherwise.

$\ln \left(M V_{j t}\right) \quad$ The natural logarithm of the market value of shares for firm $j$ multiplied by the number of shares outstanding from the fiscal year prior to day $t$.

$I V O L_{j t}$

The standard deviation of the residuals from a market model regression estimated for firm $j$ from 124 trading days prior to day $t$ to one trading day prior to day $t$. 


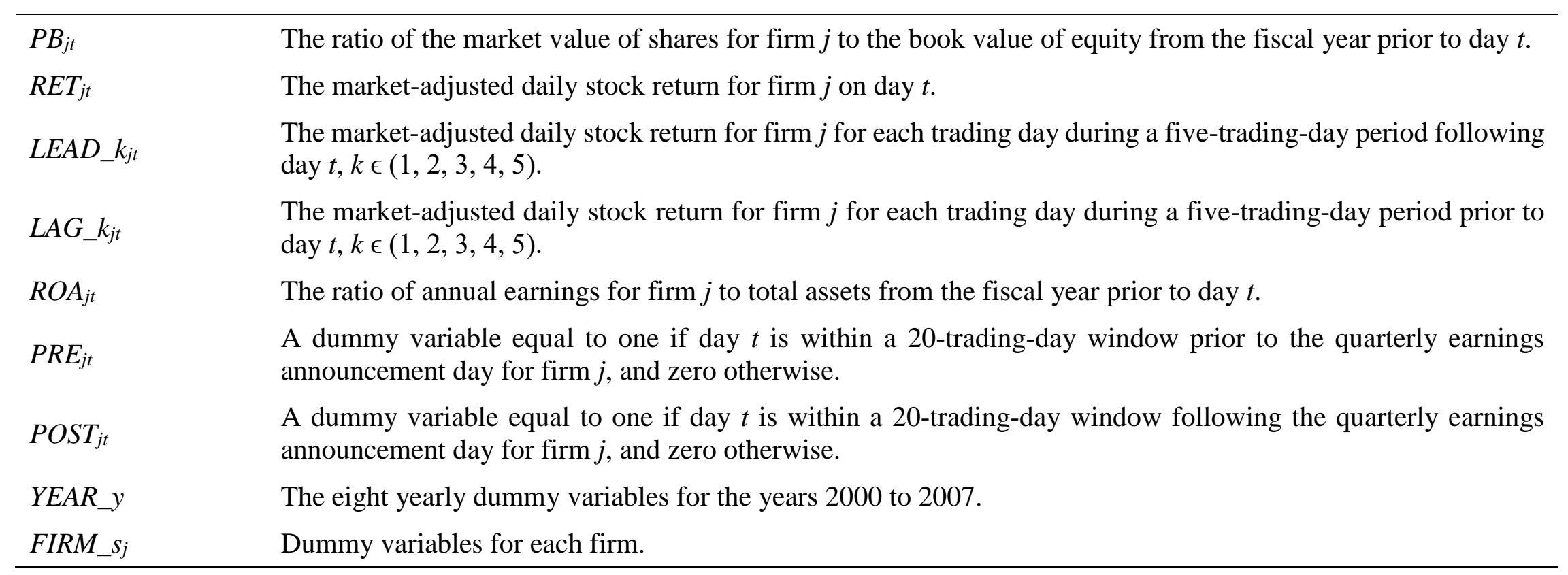

Notes:

All continuous variables are winsorized at the $1^{\text {st }}$ and $99^{\text {th }}$ percentiles of their distributions. 


\section{References}

Acharya, V.V., Johnson, T.C., 2010. More insiders, more insider trading: Evidence from privateequity buyouts. Journal of Financial Economics 98, 500-523.

Aggarwal, R., Erel, I., Stulz, R., Williamson, R., 2009. Differences in governance practices between US and foreign firms: Measurement, causes, and consequences. Review of Financial Studies 22, 3131-3169.

Ahern, K.R., 2017. Information networks: Evidence from illegal insider trading tips. Journal of Financial Economics 125, 26-47

Alldredge, D.M., Cicero, D.C., 2015. Attentive insider trading. Journal of Financial Economics $115,84-101$.

Amir, E., Kallunki, J.P., Nilsson, H., 2014. The association between individual audit partners' risk preferences and the composition of their client portfolios. Review of Accounting Studies 19, $103-133$.

Atanasov, V., Ivanov, V., Litvak, K., 2012. Does reputation limit opportunistic behavior in the VC industry? Evidence from litigation against VCs. Journal of Finance 67, 2215-2246.

Barber, B.M., Odean, T., 2001. Boys will be boys: Gender, overconfidence, and common stock investment. The Quarterly Journal of Economics 116, 261-292.

Becker, G.S., 1968. Crime and punishment: An economic approach. Journal of Political Economy $78,169-217$.

Bénabou, R., Tirole, J., 2002. Self-confidence and personal motivation. The Quarterly Journal of Economics 117, 871-915.

Beny, L.N., 2005. Do insider trading laws matter? Some preliminary comparative evidence. American Law and Economics Review 7, 144-183. 
Bertrand, M., Schoar, A., 2003. Managing with style: The effect of managers on firm policies. The Quarterly Journal of Economics 118, 1169-1208.

Boone, A.L., Floros, I.V., Johnson, S.A., 2016. Redacting proprietary information at the initial public offering. Journal of Financial Economics 120, 102-123.

Brochet, F., 2010. Information content of insider trades before and after the Sarbanes-Oxley Act. The Accounting Review 85, 419-446.

Brunnermeier, M.K., Parker, J.A., 2005. Optimal expectations. American Economic Review 95, 1092-1118.

Carhart, M.M., 1997. On persistence in mutual fund performance. Journal of Finance 52, 57-82.

Cheng, Q., Lo, K., 2006. Insider trading and voluntary disclosures. Journal of Accounting Research 44, 815-848.

Cohen, L., Malloy, C., Pomorski, L., 2012. Decoding inside information. Journal of Finance 67, 1009-1043.

Cronqvist, H., Makhija, A.K., Yonker, S.E., 2012. Behavioral consistency in corporate finance: CEO personal and corporate leverage. Journal of Financial Economics 103, 20-40.

Dai, L., Parwada, J.T., Zhang, B., 2015. The governance effect of the media's news dissemination role: Evidence from insider trading. Journal of Accounting Research 53, 331-366.

Davidson, R., Dey, A., Smith, A.J., 2016. Executives' legal records and insider trading activities. Unpublished working paper. University of Chicago.

Denis, D.J., Xu, J., 2013. Insider trading restrictions and top executive compensation. Journal of Accounting and Economics 56, 91-112.

Ehrlich, I., 1973. Participation in illegitimate activities: A theoretical and empirical investigation. Journal of Political Economy 81, 521-565. 
Fama, E.F., French, K.R., 1993. Common risk factors in the returns on stocks and bonds. Journal of Financial Economics 33, 3-56.

Fama, E.F., French, K.R., 2012. Size, value, and momentum in international stock returns. Journal of Financial Economics 105, 457-472.

Fang, L., Peress, J., 2009. Media coverage and the cross-section of stock returns. Journal of Finance 64, 2023-2052.

Gao, F., Lisic, L.L., Zhang, I.X., 2014. Commitment to social good and insider trading. Journal of Accounting and Economics 57, 149-175.

Garoupa, N., 2003. Behavioral economic analysis of crime: A critical review. European Journal of Law and Economics 15, 5-15.

Hillier, D., Korczak, A., Korczak, P., 2015. The impact of personal attributes on corporate insider trading. Journal of Corporate Finance 30, 150-167.

Huddart, S., Ke, B., 2007. Information asymmetry and cross-sectional variation in insider trading. Contemporary Accounting Research 24, 195-232.

Huddart, S., Ke, B., Shi, C., 2007. Jeopardy, non-public information, and insider trading around SEC 10-K and 10-Q filings. Journal of Accounting and Economics 43, 3-36.

Iversen, H., Rundmo, T., 2002. Personality, risky driving and accident involvement among Norwegian drivers. Personality and Individual Differences 33, 1251-1263.

Jagolinzer, A.D., Larcker, D.F., Taylor, D.J., 2011. Corporate governance and the information content of insider trades. Journal of Accounting Research 49, 1249-1274.

Jeng, L.A., Metrick, A., Zeckhauser, R., 2003. Estimating the returns to insider trading: A performance-evaluation perspective. Review of Economics and Statistics 85, 453-471.

Jin, L., Kothari, S.P., 2008. Effect of personal taxes on managers' decisions to sell their stock. Journal of Accounting and Economics 46, 23-46. 
Junger, M., West, R., Timman, R., 2001. Crime and risky behavior in traffic: An example of crosssituational consistency. Journal of Research in Crime and Delinquency 38, 439-459.

Kallunki, J-P., Nilsson, H., Hellström, J., 2009. Why do insiders trade? Evidence based on unique data on Swedish insiders. Journal of Accounting and Economics 48, 37-53.

Kallunki, J.P., Mikkonen, J., Nilsson, H., Setterberg, H., 2016. Tax noncompliance and insider trading. Journal of Corporate Finance 36, 157-173.

Kaplan, S.N., Klebanov, M.M., Sorensen, M., 2012. Which CEO characteristics and abilities matter? Journal of Finance 67, 973-1007.

Karpoff, J., 2012. Does reputation work to discipline corporate misconduct? In: Pollock, T., Barnett, M. (Eds.), Handbook of Corporate Reputation. Oxford University Press, Oxford, UK, pp. 361-382.

Ke, B., Huddart, S., Petroni, K., 2003. What insiders know about future earnings and how they use it: Evidence from insider trades. Journal of Accounting and Economics 35, 315-346.

Klein, B., Leffler, K.B., 1981. The role of market forces in assuring contractual performance. Journal of Political Economy 89, 615-641.

Korsell, L., 2001. Three decades of researching and combating economic crime: The Swedish case. In: Lindgren, S.A. (Ed.), White-Collar Crime Research. Old Views and Future Potentials. The Swedish National Council for Crime Prevention, Stockholm, pp. 91-106.

Kreps, D.M., Wilson, R., 1982. Reputation and imperfect information. Journal of Economic Theory 27, 253-279.

Lakonishok, J., Lee, I., 2001. Are insider trades informative? Review of Financial Studies 14, 79111.

MacLeod, W.B., 2007. Reputations, relationships, and contract enforcement. Journal of Economic Literature 45, 595-628. 
Malmendier, U., Tate, G., 2008. Who makes acquisitions? CEO overconfidence and the market's reaction. Journal of Financial Economics 89, 20-43.

Meulbroek, L.K., 1992. An empirical analysis of illegal insider trading. Journal of Finance 47, 1661-1699.

Moeller, S.B., Schlingemann, F.P., Stulz, R.M., 2007. How do diversity of opinion and information asymmetry affect acquirer returns? Review of Financial Studies 20, 2047-2078.

Noe, C.F., 1999. Voluntary disclosures and insider transactions. Journal of Accounting and Economics 27, 305-326.

Piotroski, J.D., Roulstone, D.T., 2005. Do insider trades reflect both contrarian beliefs and superior knowledge about future cash flow realizations? Journal of Accounting and Economics $39,55-81$.

Piotroski, J.D., Roulstone, D.T., 2008. Evidence on the non-linear relation between insider trading decisions and future earnings information. Journal of Law, Economics \& Policy 4, 409-448.

Roulstone, D.T., 2003. The relation between insider-trading restrictions and executive compensation. Journal of Accounting Research 41, 525-551.

Rozeff, M.S., Zaman, M.A., 1998. Overreaction and insider trading: Evidence from growth and value portfolios. Journal of Finance 53, 701-716.

Seyhun, H.N., 1986. Insiders' profits, costs of trading, and market efficiency. Journal of Financial Economics 16, 189-212.

Seyhun, H.N., 1992. The effectiveness of the insider-trading sanctions. The Journal of Law \& Economics 35, 149-182.

Seyhun, H.N., 1998. Investment Intelligence from Insider Trading. MIT Press, Cambridge, MA.

Shapiro, C., 1983. Premiums for high quality products as returns to reputations. The Quarterly Journal of Economics 98, 659-679. 
Svensson, R., 2000. Strategic crimes - What type of crimes predict a future criminal career. In: Brå-report, The Swedish National Council for Crime Prevention, Stockholm, pp. 1-53.

Van den Steen, E., 2004. Rational overoptimism (and other biases). American Economic Review 94, 1141-1151. 


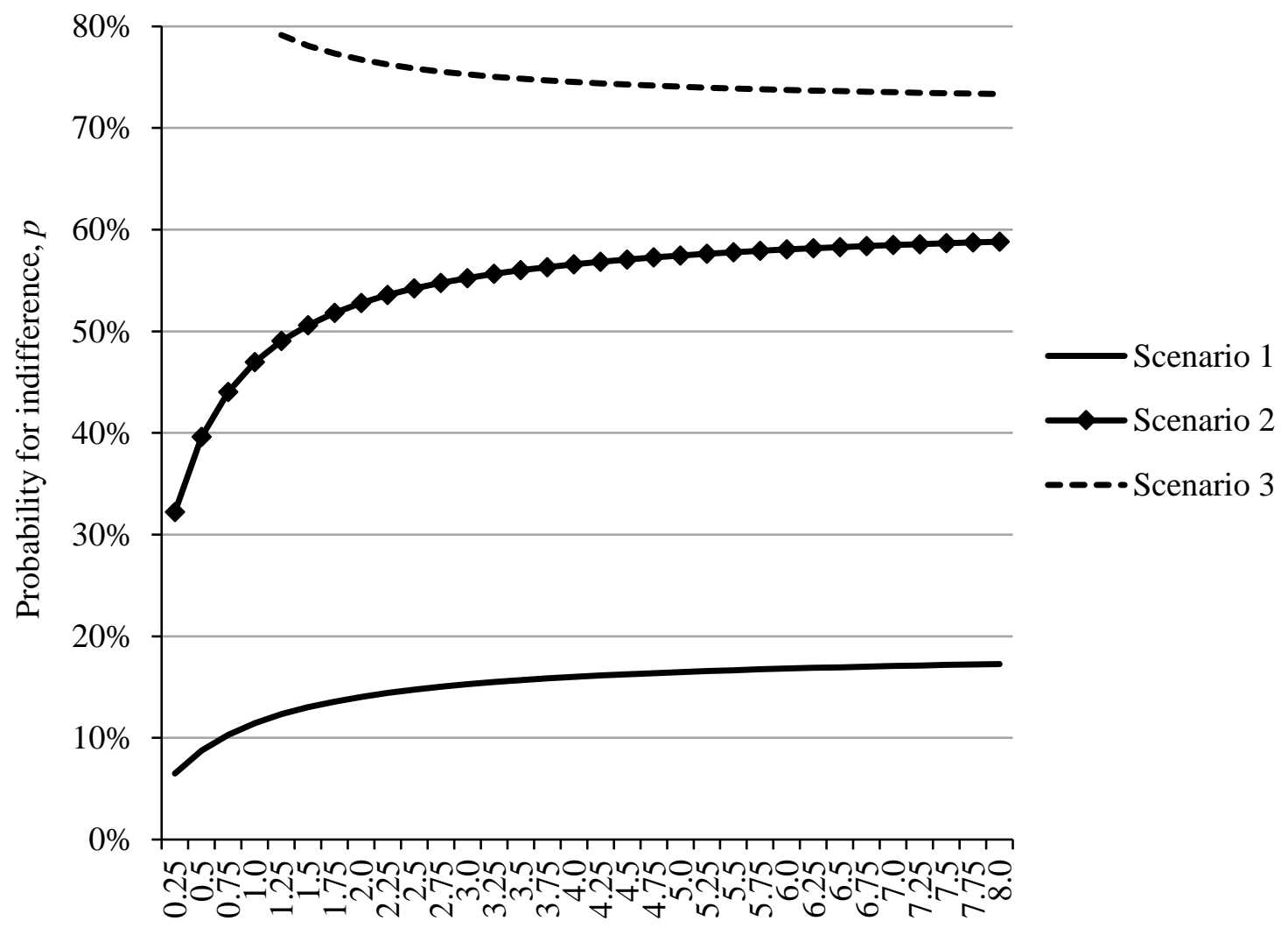

Insider's wealth and income level, $W$

Fig. 1. This figure plots the probability for indifference between engaging (above the curve) and not engaging (below the curve) in informed trading for varying levels of wealth and income $(W)$ in three different scenarios. In Scenario 1, an insider's informed trading is subject to a low risk of legal enforcement and is thus not likely to incur any fixed costs for the insider $(d=0)$, and also reputational damage and other variable costs related to the magnitude of insider trading are small $(c=0.01)$. In Scenario 2, an insider's informed trading still involves a low risk of legal enforcement $(d=0)$, but includes larger reputational and other variable costs $(c=0.06)$ than in Scenario 1. In Scenario 3, an insider's informed trading is subject to a high risk of legal enforcement and thus likely to incur large fixed costs $(d=1.0)$ and variable costs $(c=$ 0.09 ) for the insider. In each of the three scenarios, we further set $a=0.5, r=0.05$, and $\sigma=5.0$. 


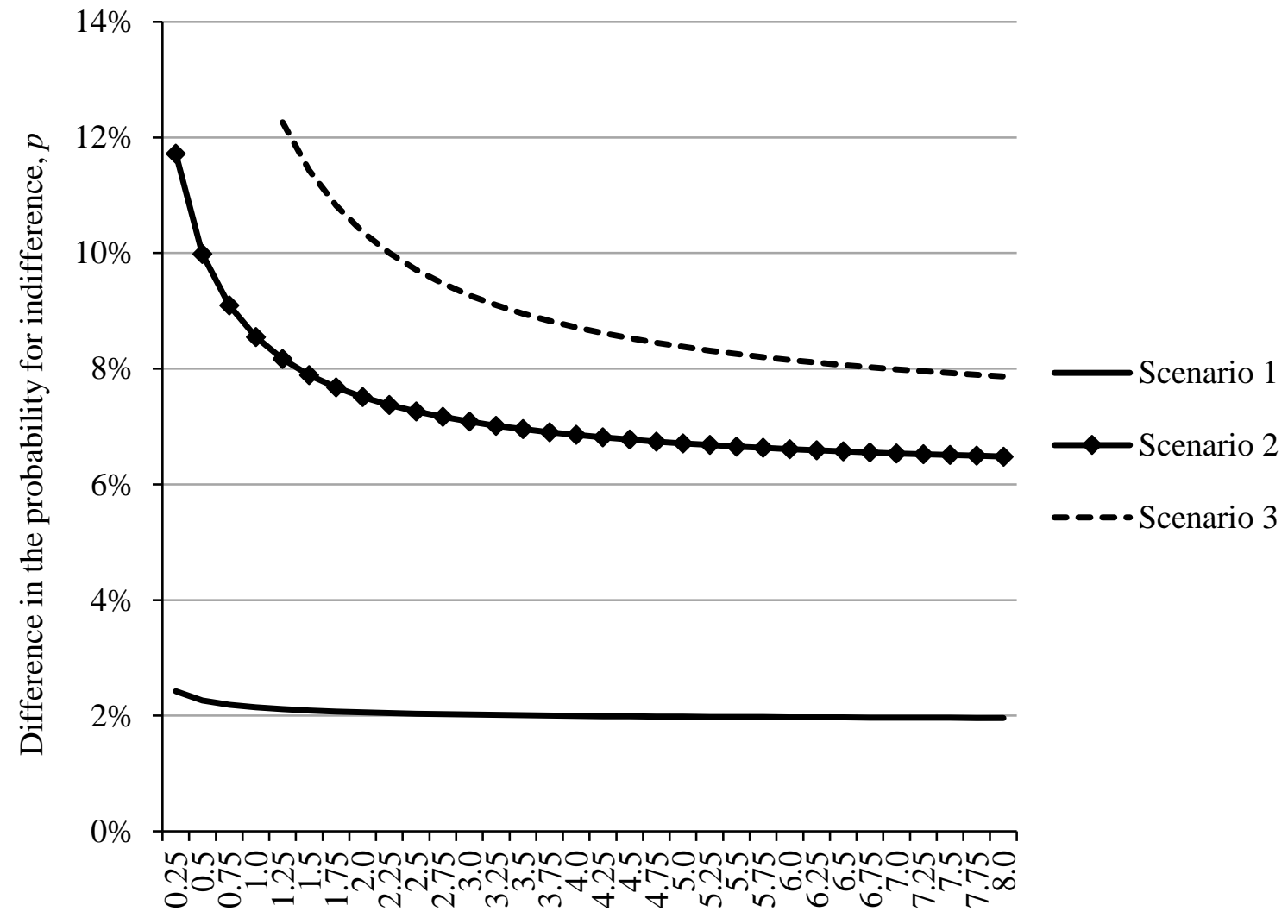

Insider's wealth and income level, $W$

Fig. 2. This figure plots the difference in the probability for indifference between engaging and not engaging in informed trading between an insider with higher risk aversion $(\sigma=5.0)$ and an insider with lower risk aversion $(\sigma=0.5)$ for varying levels of wealth and income $(W)$ in three different scenarios. In Scenario 1, we set $d=0$ and $c=0.01$. In Scenario 2, we set $d=0$ and $c=0.06$. In Scenario 3, we set $d=1.0$ and $c=$ 0.09 . In all three scenarios, we further set $a=0.5$ and $r=0.05$. 


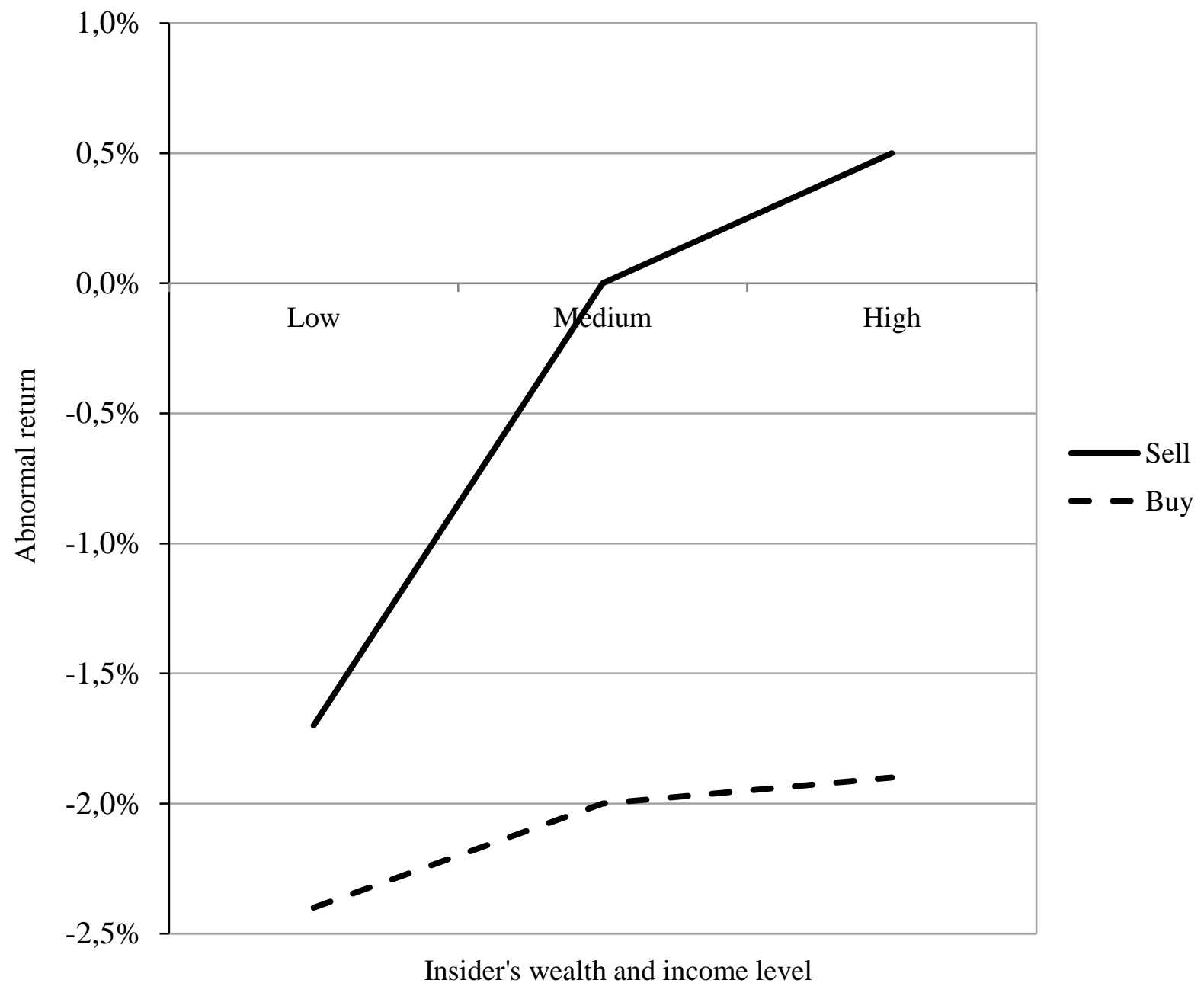

Fig. 3. This figure plots the mean buy-and-hold abnormal (market-adjusted) return over the one-month period following the 5,589 and 9,083 insiders' sales and purchases in the sample, respectively, in three categories of the level of an insider's wealth and income ('Low,' 'Medium,' and 'High'). The abnormal returns following purchases are multiplied by -1 to make the figure comparable to Fig. 1, i.e., higher insider returns indicate that insiders are more cautious in their trading decisions. Refer to Section 3.3.2.1 and Appendix B for the construction of the wealth and income categories. The sample includes all 3,388 insiders in all 393 listed firms in Sweden with at least one insider trade during the period from January 2000 to December 2008. 


\section{Table 1}

Summary statistics of insiders' wealth and income, insider trading, and criminal behavior.

\begin{tabular}{|c|c|c|c|c|c|c|c|}
\hline & \multirow[b]{2}{*}{ Mean } & \multirow[b]{2}{*}{ S.D. } & \multicolumn{5}{|c|}{ Percentiles } \\
\hline & & & Min & 25 th & 50 th & 75th & Max \\
\hline \multicolumn{8}{|l|}{ Panel A: Wealth and income } \\
\hline Total wealth (thousands of SEK) & $49,636.5$ & $1,140,524.1$ & 0.0 & $2,081.0$ & $4,666.5$ & $12,995.5$ & $73,799,093.9$ \\
\hline Annual income (thousands of SEK) & $1,826.9$ & $2,414.1$ & 0.0 & 606.9 & $1,063.6$ & $2,149.1$ & $32,484.8$ \\
\hline \multicolumn{8}{|l|}{ Panel B: Insider trading behaviour } \\
\hline \multicolumn{8}{|l|}{ Insider sales $(\mathrm{N}=5,589)$} \\
\hline Number of sales per insider & 3.2 & 7.3 & 1.0 & 1.0 & 2.0 & 3.0 & 211.0 \\
\hline Trade size (thousands of SEK) & $2,798.1$ & $8,107.6$ & 10.0 & 94.0 & 314.8 & $1,298.6$ & $1,605,000.0$ \\
\hline Trade size/insider holdings (\%) & 28.4 & 37.2 & 0.0 & 0.3 & 7.6 & 48.0 & 100.0 \\
\hline Trade size/total wealth $(\%)$ & 14.7 & 25.0 & 0.0 & 1.3 & 4.2 & 14.1 & 100.0 \\
\hline Abnormal return $(\%)$ & -0.4 & 12.9 & -59.0 & -7.4 & -1.0 & 5.4 & 223.2 \\
\hline \multicolumn{8}{|l|}{ Insider purchases $(\mathrm{N}=9,083)$} \\
\hline Number of purchases per insider & 3.5 & 10.7 & 1.0 & 1.0 & 2.0 & 3.0 & 310.0 \\
\hline Trade size (thousands of SEK) & $1,932.7$ & $7,619.9$ & 10.0 & 48.0 & 151.5 & 595.4 & $945,029.0$ \\
\hline Trade size/insider holdings (\%) & 22.1 & 34.9 & 0.0 & 0.0 & 1.2 & 30.0 & 100.0 \\
\hline Trade size/total wealth $(\%)$ & 7.5 & 18.2 & 0.0 & 0.5 & 1.6 & 5.1 & 100.0 \\
\hline Abnormal return $(\%)$ & 2.1 & 12.3 & -60.7 & -4.5 & 1.0 & 7.3 & 227.9 \\
\hline \multicolumn{8}{|l|}{ Panel C: Criminal behaviour } \\
\hline & & & & & & Number & Percent \\
\hline Convicted insiders & & & & & & 899 & 26.5 \\
\hline Non-convicted insiders & & & & & & 2,489 & 73.5 \\
\hline Total & & & & & & 3,388 & 100.0 \\
\hline
\end{tabular}

\section{Notes:}

1. This table presents summary statistics of insiders' wealth and income (Panel A), insider trading behavior (Panel B), and criminal behavior (Panel C). The sample includes all 3,388 insiders in all 393 listed firms in Sweden with at least one insider trade over the sample period from January 
2000 to December 2008. Panel A reports summary statistics on insiders' total wealth and annual income based on the 6,582 insider-year observations in the sample. Panel B reports summary statistics on insiders' trading behavior in their insider stocks based on the 5,589 insider sales and the 9,083 insider purchases in the sample. Panel C reports the number and percentage of insiders who have been convicted or suspected of a crime (convicted insiders) and those who have not been convicted or suspected of a crime (non-convicted insiders).

2. Trade size is the market value of the shares traded. Abnormal return is the buy-and-hold abnormal (market-adjusted) stock return over a onemonth period following the trade. The means of the variables trade size and abnormal return are winsorized to the $1^{\text {st }}$ and $99^{\text {th }}$ percentiles of their distributions. 1 SEK is equal to 0.12 USD. 
Table 2

Summary statistics of insider trading by the magnitude of the future abnormal return.

\begin{tabular}{|c|c|c|c|c|c|c|}
\hline \multirow[b]{2}{*}{ Abnormal return } & \multicolumn{2}{|c|}{ Mean profit/loss avoided } & \multirow[t]{2}{*}{$\begin{array}{l}\text { Number of } \\
\text { insider trades }\end{array}$} & \multicolumn{3}{|c|}{$\begin{array}{l}\text { Proportion of trades made by insiders with differen } \\
\text { levels of wealth and income (as percent of trades) }\end{array}$} \\
\hline & $\begin{array}{l}\text { in thousands of } \\
\text { SEK }\end{array}$ & $\begin{array}{l}\text { as percentage of total } \\
\text { wealth }\end{array}$ & & Low & Medium & High \\
\hline \multicolumn{7}{|c|}{ Panel A: Insider sales $(N=5,589)$} \\
\hline$\geq 0 \%$ & 160.40 & 1.24 & 2,567 & 27.4 & 36.5 & 36.1 \\
\hline$-0-5 \%$ & -74.93 & -0.33 & 1,215 & 28.7 & 33.3 & 38.0 \\
\hline$-5-10 \%$ & -128.46 & -1.00 & 804 & 34.0 & 34.2 & 31.8 \\
\hline$-10-15 \%$ & -194.09 & -1.78 & 482 & 35.9 & 32.6 & 31.5 \\
\hline$-15-20 \%$ & -171.78 & -1.95 & 238 & 37.4 & 34.9 & 27.7 \\
\hline$-20-25 \%$ & -165.68 & -2.92 & 121 & 48.8 & 32.2 & 19.0 \\
\hline$-25-30 \%$ & -262.99 & -2.78 & 73 & 37.0 & 39.7 & 23.3 \\
\hline$-30-35 \%$ & -151.69 & -4.03 & 42 & 45.2 & 38.1 & 16.7 \\
\hline$-35-40 \%$ & -243.78 & -4.99 & 25 & 60.0 & 24.0 & 16.0 \\
\hline$<-40 \%$ & -204.44 & -6.90 & 22 & 63.6 & 18.2 & 18.2 \\
\hline \multicolumn{7}{|c|}{ Panel B: Insider purchases $(N=9,083)$} \\
\hline$\leq 0 \%$ & -71.73 & -0.55 & 4,185 & 27.1 & 36.5 & 36.4 \\
\hline $0-5 \%$ & 54.58 & 0.15 & 1,939 & 22.4 & 37.2 & 40.4 \\
\hline $5-10 \%$ & 136.61 & 0.59 & 1,272 & 25.7 & 34.9 & 39.4 \\
\hline $10-15 \%$ & 138.37 & 0.82 & 694 & 28.8 & 34.7 & 36.5 \\
\hline $15-20 \%$ & 158.21 & 1.52 & 361 & 30.7 & 32.7 & 36.6 \\
\hline $20-25 \%$ & 152.47 & 1.65 & 231 & 31.2 & 42.4 & 26.4 \\
\hline $25-30 \%$ & 185.78 & 1.43 & 119 & 34.5 & 39.5 & 26.0 \\
\hline $30-35 \%$ & 179.59 & 1.58 & 72 & 36.1 & 31.9 & 31.9 \\
\hline $35-40 \%$ & 190.46 & 2.84 & 45 & 26.7 & 48.9 & 24.4 \\
\hline$>40 \%$ & 190.20 & 4.22 & 165 & 39.4 & 39.4 & 21.2 \\
\hline
\end{tabular}

Notes: 
1. Panel A (Panel B) presents summary statistics for the 5,589 insider sales (the 9,083 insider purchases) in the sample, summarized by the buyand-hold abnormal (market-adjusted) stock return over a one-month period following an insider trade. Profit/loss avoided is the market value of the shares traded multiplied by the buy-and-hold abnormal stock return over a one-month period following the trade, expressed either in thousands of SEK or as percentage of an insider's total wealth. Insider trades are grouped into three categories based on the level of an insider's wealth and income ('Low,' 'Medium,' and 'High').

2. Refer to Section 3.3.2.1 and Appendix B for the construction of the wealth and income categories. The sample includes all 3,388 insiders in all 393 listed firms in Sweden with at least one insider trade over the period from January 2000 to December 2008. Profit/loss avoided (in thousands of SEK) is winsorized to the $1^{\text {st }}$ and $99^{\text {th }}$ percentiles of its distribution. 1 SEK is equal to 0.12 USD. 
Table 3

Descriptive statistics of the selected independent variables.

\begin{tabular}{|c|c|c|c|c|c|}
\hline Variable & Mean & Median & S.D. & Min & Max \\
\hline \multicolumn{6}{|c|}{ Panel A: Insider selling $(N=11,178)$} \\
\hline$L O W_{i t}$ & 0.324 & 0.000 & 0.468 & 0.000 & 1.000 \\
\hline$M E D_{i t}$ & 0.351 & 0.000 & 0.477 & 0.000 & 1.000 \\
\hline$H I G H_{i t}$ & 0.324 & 0.000 & 0.468 & 0.000 & 1.000 \\
\hline$R I S K_{-} T A K E R_{i}$ & 0.311 & 0.000 & 0.463 & 0.000 & 1.000 \\
\hline$G E N \bar{D} E R_{i}$ & 0.883 & 1.000 & 0.321 & 0.000 & 1.000 \\
\hline $\ln \left(A G E_{i}\right)$ & 3.977 & 3.989 & 0.179 & 2.996 & 4.454 \\
\hline $\ln \left(1+T E N U R E_{i j t}\right)$ & 7.092 & 7.220 & 0.974 & 0.000 & 9.007 \\
\hline MOMENTUM & 0.125 & 0.060 & 0.433 & -0.665 & 2.112 \\
\hline PROP_WEALTH $H_{i j t}$ & 0.256 & 0.062 & 0.338 & 0.000 & 1.000 \\
\hline$D E C L O S S_{j t}$ & 0.039 & 0.000 & 0.193 & 0.000 & 1.000 \\
\hline $\ln \left(1+\right.$ LIQUIDITY $\left._{i t}\right)$ & -4.554 & -11.031 & 11.636 & -17.193 & 17.222 \\
\hline $\ln \left(1+N U M I N S_{i t}\right)$ & 0.719 & 0.693 & 0.463 & 0.000 & 2.197 \\
\hline$C E O_{i j t}$ & 0.094 & 0.000 & 0.291 & 0.000 & 1.000 \\
\hline$E X E C_{i j t}$ & 0.459 & 0.000 & 0.498 & 0.000 & 1.000 \\
\hline$P R E_{j t}$ & 0.182 & 0.000 & 0.386 & 0.000 & 1.000 \\
\hline$P O S T_{j t}$ & 0.305 & 0.000 & 0.460 & 0.000 & 1.000 \\
\hline $\ln \left(M V_{j t}\right)$ & 0.132 & 0.000 & 2.131 & -6.215 & 6.976 \\
\hline$P B_{j t}$ & 3.529 & 2.311 & 3.609 & 0.364 & 20.527 \\
\hline$R O A_{j t}$ & -0.019 & 0.042 & 0.279 & -1.567 & 0.526 \\
\hline$I V O L_{j t}$ & 0.032 & 0.026 & 0.019 & 0.001 & 0.106 \\
\hline \multicolumn{6}{|c|}{ Panel B: Insider buying $(N=18,166)$} \\
\hline$L O W_{i t}$ & 0.319 & 0.000 & 0.466 & 0.000 & 1.000 \\
\hline$M E D_{i t}$ & 0.361 & 0.000 & 0.480 & 0.000 & 1.000 \\
\hline$H I G H_{i t}$ & 0.319 & 0.000 & 0.466 & 0.000 & 1.000 \\
\hline$R I S K_{-} T A K E R_{i}$ & 0.319 & 0.000 & 0.466 & 0.000 & 1.000 \\
\hline$G E N \bar{D} E R_{i}$ & 0.880 & 1.000 & 0.325 & 0.000 & 1.000 \\
\hline $\ln \left(A G E_{i}\right)$ & 3.967 & 3.970 & 0.188 & 2.996 & 4.407 \\
\hline $\ln \left(1+T E N U R E_{i j t}\right)$ & 6.828 & 7.055 & 1.245 & 0.000 & 9.066 \\
\hline$M O M E N T U M_{j t}$ & 0.040 & 0.016 & 0.310 & -0.674 & 1.208 \\
\hline PROP_WEALTH $H_{i j t}$ & 0.148 & 0.020 & 0.257 & 0.000 & 1.000 \\
\hline $\ln \left(1+N U M I N S_{i t}\right)$ & 0.634 & 0.693 & 0.507 & 0.000 & 2.197 \\
\hline$C E O_{i j t}$ & 0.109 & 0.000 & 0.312 & 0.000 & 1.000 \\
\hline$E X E C_{i j t}$ & 0.393 & 0.000 & 0.489 & 0.000 & 1.000 \\
\hline$P R E_{j t}$ & 0.172 & 0.000 & 0.377 & 0.000 & 1.000 \\
\hline$P O S T_{j t}$ & 0.339 & 0.000 & 0.473 & 0.000 & 1.000 \\
\hline $\ln \left(M V_{j t}\right)$ & 0.540 & 0.223 & 2.274 & -6.215 & 6.976 \\
\hline$P B_{j t}$ & 2.935 & 1.999 & 2.970 & 0.393 & 18.269 \\
\hline$R O A_{j t}$ & -0.004 & 0.042 & 0.221 & -1.159 & 0.508 \\
\hline$I V O L_{j t}$ & 0.029 & 0.024 & 0.017 & 0.000 & 0.098 \\
\hline
\end{tabular}

Notes: 
1. The table reports descriptive statistics of the selected independent variables used in the analyses based on our matched-pair sample of 5,589 (9,083) days with insider selling (buying) and 5,589 $(9,083)$ days without insider selling (buying). Panel A (Panel B) reports descriptive statistics for insider selling (buying). The sample includes all 3,388 insiders in all 393 listed firms in Sweden with at least one insider trade over the period from January 2000 to December 2008. Refer to Appendix B for variable definitions. All continuous variables are winsorized to the $1^{\text {st }}$ and $99^{\text {th }}$ percentiles of their distributions. 
Table 4

Univariate analysis of how insiders with different levels of wealth and income time their insider trading.

\begin{tabular}{|c|c|c|c|c|c|}
\hline & \multirow[t]{2}{*}{ All insiders } & \multicolumn{3}{|c|}{ Insiders with different levels of wealth and income } & \\
\hline & & Low & \multirow{2}{*}{$\begin{array}{c}\text { Medium } \\
\text { Mean } \\
\text { (Median) }\end{array}$} & \multicolumn{2}{|l|}{ High } \\
\hline & $\begin{array}{c}\text { Mean } \\
\text { (Median) }\end{array}$ & $\begin{array}{c}\text { Mean } \\
\text { (Median) }\end{array}$ & & $\begin{array}{c}\text { Mean } \\
\text { (Median) }\end{array}$ & $\begin{array}{l}\text { Difference: } \\
\text { Low - High }\end{array}$ \\
\hline Total wealth (thousands of SEK) & $\begin{array}{c}49,636.5 \\
(4,666.5)\end{array}$ & $\begin{array}{c}2,222.9 \\
(1,930.1)\end{array}$ & $\begin{array}{l}57,436.5 \\
(4,993.7)\end{array}$ & $\begin{array}{l}103,117.8 \\
(16,214.2)\end{array}$ & $\begin{array}{l}-100,894.9 \\
(-14,284.1)\end{array}$ \\
\hline Annual income (thousands of SEK) & $\begin{array}{c}1,826.9 \\
(1,063.6) \\
\end{array}$ & $\begin{array}{c}602.5 \\
(607.6) \\
\end{array}$ & $\begin{array}{c}1,535.8 \\
(1,245.5) \\
\end{array}$ & $\begin{array}{c}3,944.0 \\
(2,744.1) \\
\end{array}$ & $\begin{array}{r}-3,341.6 \\
(-2,136.5) \\
\end{array}$ \\
\hline \multicolumn{6}{|l|}{ Panel A: Insider selling } \\
\hline Days without insider selling & $\begin{array}{c}0.40 \% * * \\
(-0.04 \%)\end{array}$ & $\begin{array}{c}0.58 \% * \\
(-0.14 \%)\end{array}$ & $\begin{array}{l}-0.03 \% \\
(-0.35 \%)\end{array}$ & $\begin{array}{c}0.71 \% * * \\
(0.26 \% * *)\end{array}$ & $\begin{array}{l}-0.13 \% \\
(-0.40 \%)\end{array}$ \\
\hline Days with insider selling & $\begin{array}{l}\mathrm{N}=5,589 \\
\quad-0.37 \% * * * \\
(-0.96 \% * * *) \\
\mathrm{N}=5,589\end{array}$ & $\begin{array}{l}\mathrm{N}=1,904 \\
\quad-1.70 \% * * * \\
(-2.44 \% * * *) \\
\mathrm{N}=1,721\end{array}$ & $\begin{array}{c}\mathrm{N}=1,976 \\
\quad-0.06 \% \\
(-0.39 \%) \\
\mathrm{N}=1,952\end{array}$ & $\begin{array}{l}\mathrm{N}=1,709 \\
\quad 0.50 \% * * * \\
(-0.50 \%) \\
\mathrm{N}=1,916\end{array}$ & $\begin{array}{l}-2.20 \% * * * \\
(-1.94 \% * * *)\end{array}$ \\
\hline $\begin{array}{l}\text { Difference: Days without insider sell } \\
\text { Mean } \\
\text { (Median) }\end{array}$ & $\begin{array}{l}\text { s with insider se } \\
0.77 \% * * * \\
(0.92 \% * * *)\end{array}$ & $\begin{array}{l}\operatorname{ling} \\
\begin{array}{l}2.28 \% * * * \\
(2.30 \% * * *)\end{array}\end{array}$ & $\begin{array}{c}0.03 \% \\
(0.04 \%)\end{array}$ & $\begin{array}{l}0.21 \% \\
(0.76 \% *)\end{array}$ & \\
\hline \multicolumn{6}{|l|}{ Panel B: Insider buying } \\
\hline Days without insider buying & $\begin{array}{c}0.94 \% * * * \\
(0.36 \% * * *)\end{array}$ & $\begin{array}{r}1.10 \% * * * \\
(0.23 \% * *)\end{array}$ & $\begin{array}{c}0.85 \% * * * \\
(0.45 \% * * *)\end{array}$ & $\begin{array}{c}0.84 \% * * * \\
(0.44 \% * * *)\end{array}$ & $\begin{array}{c}0.26 \% \\
(-0.21 \%)\end{array}$ \\
\hline Days with insider buying & $\begin{array}{l}\mathrm{N}=9,083 \\
2.08 \% * * * \\
(0.97 \% * * *) \\
\mathrm{N}=9,083\end{array}$ & $\begin{aligned} \mathrm{N}= & 3,373 \\
& 2.43 \% * * * \\
& (0.98 \% * * *) \\
\mathrm{N}= & 2,425\end{aligned}$ & $\begin{aligned} \mathrm{N}= & 3,259 \\
& 2.04 \% * * * \\
& (0.90 \% * * *) \\
\mathrm{N}= & 3,307\end{aligned}$ & $\begin{array}{l}\mathrm{N}=2,451 \\
\quad 1.88 \% * * * \\
(1.02 \% * * *) \\
\mathrm{N}=3,351\end{array}$ & $\begin{array}{r}0.55 \% * \\
(-0.04 \%)\end{array}$ \\
\hline \multicolumn{6}{|c|}{ Difference: Days without insider buying - Days with insider buying } \\
\hline $\begin{array}{l}\text { Mean } \\
\text { (Median) }\end{array}$ & $\begin{array}{l}-1.14 \% * * * \\
(-0.61 \% * * *)\end{array}$ & $\begin{array}{c}-1.33 \% * * * \\
(-0.75 \% * * *)\end{array}$ & $\begin{array}{c}-1.19 \% * * * \\
(-0.45 \% * * *)\end{array}$ & $\begin{array}{l}-1.04 \% * * * \\
(-0.58 \% * * *)\end{array}$ & \\
\hline
\end{tabular}


Notes:

1. This table presents the results of univariate analysis to explore how insiders with different levels of wealth and income time their insider selling (Panel A) and buying (Panel B). We first report the mean (median) SEK values of insiders' total wealth and annual income for insiders in the three categories of the level of insiders' wealth and income ('Low,' 'Medium,' and 'High'). We then test whether the mean (median) future one-month buy-and-hold abnormal (market-adjusted) returns are significantly different between the days with and without insider selling and buying, respectively, in our matched-pair sample by using a two-tailed $t$-test (Wilcoxon rank-sum test). We conduct this analysis for insiders in the three wealth and income categories. In addition, we test for difference in the mean (median) values of the future one-month abnormal returns between the wealth and income categories 'Low' and 'High' by using a two-tailed $t$-test (Wilcoxon rank-sum test).

2. Refer to Section 3.3.2.1 and Appendix B for the construction of the wealth and income categories. The mean and median values of insiders' total wealth and annual income are based on the 2,338, 2,542, and 1,702 insider-year observations in the wealth and income categories 'Low,' 'Medium,' and 'High,' respectively. The sample includes all 3,388 insiders in all 393 listed firms in Sweden with at least one insider trade over the period from January 2000 to December 2008.

3. 1 SEK is equal to 0.12 USD. Significance at the $1 \%, 5 \%$, and $10 \%$ (two-tailed) levels is indicated by ***, **, and *. 
Table 5

Multivariate analysis of how insiders with different levels of wealth and income time their insider trading.

\begin{tabular}{|c|c|c|c|c|}
\hline \multirow[b]{3}{*}{ Independent variables } & \multicolumn{2}{|c|}{$\begin{array}{l}\text { Panel A: Likelihood of } \\
\quad \text { insider trading }\end{array}$} & \multicolumn{2}{|c|}{$\begin{array}{l}\text { Panel B: Magnitude of } \\
\text { insider trading }\end{array}$} \\
\hline & Selling & Buying & Selling & Buying \\
\hline & (1) & (2) & (3) & (4) \\
\hline$L O W_{i t} \times B H A R_{j t}$ & $\begin{array}{l}-1.046^{* *} \\
(0.014)\end{array}$ & $\begin{array}{c}-0.430 \\
(0.230)\end{array}$ & $\begin{array}{l}-5.017 * * \\
(0.027)\end{array}$ & $\begin{array}{c}-1.574 \\
(0.392)\end{array}$ \\
\hline$M E D_{i t} \times B H A R_{j t}$ & $\begin{array}{c}0.237 \\
(0.589)\end{array}$ & $\begin{array}{l}-0.433 \\
(0.224)\end{array}$ & $\begin{array}{c}1.660 \\
(0.478)\end{array}$ & $\begin{array}{l}-2.104 \\
(0.232)\end{array}$ \\
\hline$L O W_{i t}$ & $\begin{array}{l}-0.058 \\
(0.421)\end{array}$ & $\begin{array}{l}-0.531 * * * \\
(0.000)\end{array}$ & $\begin{array}{l}-0.946 * * \\
(0.017)\end{array}$ & $\begin{array}{l}-3.296 * * * \\
(0.000)\end{array}$ \\
\hline$M E D_{i t}$ & $\begin{array}{l}-0.146 * * \\
(0.016)\end{array}$ & $\begin{array}{l}-0.279 * * * \\
(0.000)\end{array}$ & $\begin{array}{l}-0.977 * * * \\
(0.004)\end{array}$ & $\begin{array}{l}-1.669 * * * \\
(0.000)\end{array}$ \\
\hline$R I S K_{-} T A K E R_{i} \times B H A R_{j t}$ & $\begin{array}{c}0.569 \\
(0.120)\end{array}$ & $\begin{array}{c}0.298 \\
(0.310)\end{array}$ & $\begin{array}{c}3.135 \\
(0.102)\end{array}$ & $\begin{array}{c}1.494 \\
(0.318)\end{array}$ \\
\hline$B H A R_{j t}$ & $\begin{array}{c}0.064 \\
(0.860)\end{array}$ & $\begin{array}{l}0.849 * * * \\
(0.006)\end{array}$ & $\begin{array}{c}0.256 \\
(0.896)\end{array}$ & $\begin{array}{l}4.000 * * * \\
(0.009)\end{array}$ \\
\hline$R I S K \_T A K E R_{i}$ & $\begin{array}{l}0.205 * * * \\
(0.000)\end{array}$ & $\begin{array}{l}0.087 * * \\
(0.028)\end{array}$ & $\begin{array}{l}1.286 * * * \\
(0.000)\end{array}$ & $\begin{array}{l}0.634 * * * \\
(0.003)\end{array}$ \\
\hline$G E N D E R_{i}$ & $\begin{array}{l}0.554 * * * \\
(0.000)\end{array}$ & $\begin{array}{l}0.433 * * * \\
(0.000)\end{array}$ & $\begin{array}{l}3.506 * * * \\
(0.000)\end{array}$ & $\begin{array}{l}2.651 * * * \\
(0.000)\end{array}$ \\
\hline $\ln \left(A G E_{i}\right)$ & $\begin{array}{l}0.086 \\
(0.574)^{*}\end{array}$ & $\begin{array}{r}-0.166 \\
(0.151)\end{array}$ & $\begin{array}{c}0.400 \\
(0.637)\end{array}$ & $\begin{array}{l}-0.437 \\
(0.479)\end{array}$ \\
\hline $\ln \left(1+T E N U R E_{i j t}\right)$ & $\begin{array}{c}0.050 * \\
(0.065)\end{array}$ & $\begin{array}{c}-0.342 * * * \\
(0.000)\end{array}$ & $\begin{array}{l}0.348^{* *} \\
(0.029)\end{array}$ & $\begin{array}{l}-1.602 * * * \\
(0.000)\end{array}$ \\
\hline$M O M E N T U M_{j t}$ & $\begin{array}{l}0.859 * * * \\
(0.000)\end{array}$ & $\begin{array}{l}-0.205 * * * \\
(0.001)\end{array}$ & $\begin{array}{l}4.432 * * * \\
(0.000)\end{array}$ & $\begin{array}{l}-0.776^{* *} \\
(0.018)\end{array}$ \\
\hline$P R O P \_W E A L T H_{i j t}$ & $\begin{array}{l}1.532 * * * \\
(0.000)\end{array}$ & $\begin{array}{l}-0.267 * * * \\
(0.001)\end{array}$ & $\begin{array}{l}8.234 * * * \\
(0.000)\end{array}$ & $\begin{array}{l}-1.287 * * * \\
(0.003)\end{array}$ \\
\hline$D E C L O S S_{j t}$ & $\begin{array}{l}0.553 * * * \\
(0.000)\end{array}$ & & $\begin{array}{l}2.838 * * * \\
(0.000)\end{array}$ & \\
\hline $\ln \left(1+L I Q U I D I T Y_{i t}\right)$ & $\begin{array}{c}0.001 \\
(0.590)\end{array}$ & & $\begin{array}{c}0.009 \\
(0.435)\end{array}$ & \\
\hline $\ln \left(1+N U M I N S_{i t}\right)$ & $\begin{array}{c}0.345 \\
(0.000)\end{array}$ & $\begin{array}{l}-0.005 \\
(0.912)\end{array}$ & $\begin{array}{l}2.015 * * * \\
(0.000)\end{array}$ & $\begin{array}{c}0.144 \\
(0.500)\end{array}$ \\
\hline$C E O_{i j t}$ & $\begin{array}{l}-0.419 \\
(0.000)\end{array}$ & $\begin{array}{c}0.090 \\
(0.144)\end{array}$ & $\begin{array}{l}-2.164 * * * \\
(0.000)\end{array}$ & $\begin{array}{c}0.368 \\
(0.243)\end{array}$ \\
\hline$E X E C_{i j t}$ & $\begin{array}{c}0.162 \\
(0.007)\end{array}$ & $\begin{array}{l}-0.452 * * * \\
(0.000)\end{array}$ & $\begin{array}{c}0.463 \\
(0.167)\end{array}$ & $\begin{array}{l}-2.946 * * * \\
(0.000)\end{array}$ \\
\hline$P R E_{j t}$ & $\begin{array}{c}-1.003 \\
(0.000)\end{array}$ & $\begin{array}{c}-1.286^{* * * *} \\
(0.000)\end{array}$ & $\begin{array}{l}-6.189 * * * \\
(0.000)\end{array}$ & $\begin{array}{l}-7.777 * * * \\
(0.000)\end{array}$ \\
\hline$P O S T_{j t}$ & $\begin{array}{c}0.433 \\
(0.000)\end{array}$ & $\begin{array}{l}0.519 * * * \\
(0.000)\end{array}$ & $\begin{array}{l}2.219 * * * \\
(0.000)\end{array}$ & $\begin{array}{l}2.637 * * * \\
(0.000)\end{array}$ \\
\hline $\ln \left(M V_{j t}\right)$ & 0.248 & -0.015 & $1.522 * * *$ & 0.046 \\
\hline
\end{tabular}




\begin{tabular}{lcccc}
\hline & $(0.000)$ & $(0.704)$ & $(0.000)$ & $(0.828)$ \\
$P B_{j t}$ & 0.035 & -0.010 & $0.153 * *$ & -0.028 \\
& $(0.003)$ & $(0.351)$ & $(0.012)$ & $(0.610)$ \\
$R O A_{j t}$ & -0.167 & -0.082 & -0.500 & -0.510 \\
$I V O L_{j t}$ & $(0.243)$ & $(0.548)$ & $(0.528)$ & $(0.480)$ \\
& 1.916 & 2.366 & 6.842 & 12.485 \\
Constant & $(0.378)$ & $(0.178)$ & $(0.573)$ & $(0.179)$ \\
Variables $R E T_{j t,}$ & $-3.216^{* * *}$ & $3.127^{* * *}$ & $-16.422^{* * *}$ & $16.064^{* * *}$ \\
$L E A D \_k_{j t,} L A G_{k j t}$ & $(0.000)$ & $(0.000)$ & $(0.000)$ & $(0.000)$ \\
Year-fixed effects & Yes & Yes & Yes & Yes \\
Firm-fixed effects & Yes & Yes & Yes & Yes \\
Pseudo $R^{2}$ & Yes & Yes & Yes & Yes \\
N Obs & 0.1233 & 0.1087 & 0.0397 & 0.0364 \\
\hline
\end{tabular}

Notes:

1. This table presents the results of estimating logit and Tobit regressions from our matched-pair sample of 5,589 $(9,083)$ days with insider selling (buying) and 5,589 $(9,083)$ days without insider selling (buying) to explore whether the level of insiders' wealth and income affects their willingness to time their selling (buying) before abnormal price decreases (increases). The sample includes all 3,388 insiders in all 393 listed firms in Sweden with at least one insider trade over the period from January 2000 to December 2008. Panel A reports the results of modeling the likelihood of insider selling or buying in logit regressions (Model 1). Panel B reports the results of modeling the magnitude of insider selling or buying in Tobit regressions (Model 2).

2. Models (1) and (2) are as follows:

$$
\text { Prob. } \begin{aligned}
\left(T R A D E_{i j t}=1\right)= & \operatorname{logit}\left(\beta_{0}+\beta_{1} L O W_{i t}+\beta_{2} \text { BHAR }_{j t}+\beta_{3} L O W_{i t} \times B H A R_{j t}+\beta_{4} M E D_{i t}\right. \\
& +\beta_{5} M E D_{i t} \times B H A R_{j t}+\beta_{6} R I S K_{-} T A K E R_{i}+\beta_{7} R I S K_{-} T A K E R_{i} \times B H A R_{j t} \\
& \left.+\gamma^{\prime} \boldsymbol{X}_{i j t}+\text { Fixed effects }+\varepsilon_{i j t}\right)
\end{aligned}
$$

Prob. $\left(\right.$ SIZE $\left._{i j t}>0\right)=\operatorname{Tobit}\left(\beta_{0}+\beta_{1} L O W_{i t}+\beta_{2} B H A R_{j t}+\beta_{3} L O W_{i t} \times B H A R_{j t}+\beta_{4} M E D_{i t}\right.$

$$
\begin{aligned}
& +\beta_{5} M E D_{i t} \times B H A R_{j t}+\beta_{6} R I S K_{-} \text {TAKER }_{i}+\beta_{7} R I S K_{-} T A K E R_{i} \times B H A R_{j t} \\
& \left.+\gamma^{\prime} \boldsymbol{X}_{i j t}+\text { Fixed effects }+\varepsilon_{i j t}\right)
\end{aligned}
$$

3. The dependent variable in Model (1) is a dummy variable equal to one if insider $i$ trades insider stocks of firm $j$ on day $t$, and zero otherwise $\left(T R A D E_{i j t}\right)$. The dependent variable in Model (2) is the natural logarithm of the market value of the shares traded if insider $i$ trades insider stocks of firm $j$ on day $t$, and zero otherwise $\left(S I Z E_{i j t}\right)$. The independent variables in the models include two dummy variables for insiders in the low and medium wealth/income categories ( $L O W_{i t}$ and $M E D_{i t}$, respectively), the high wealth/income category $\left(H I G H_{i t}\right)$ being the control group. The variable $B H A R_{j t}$ is the buy-andhold abnormal (market-adjusted) return over a one-month period following day $t$ for firm $j$. The vector $\boldsymbol{X}$ includes a set of insider- and firm-level control variables that are expected to affect insiders' decisions to trade their insider stocks. Control variables $R E T_{j t}, L E A D_{-} k_{j t}, L A G_{-k j t}$, and year- and firmfixed effects are included but not reported for brevity.

4. Refer to Section 3.3.2 and Appendix B for the construction of the wealth and income categories and variable definitions. All continuous variables are winsorized to the $1^{\text {st }}$ and $99^{\text {th }}$ percentiles of their 
distributions. $p$-values from robust standard errors are presented in parentheses. Significance at the $1 \%, 5 \%$, and $10 \%$ (two-tailed) levels is indicated by ***, **, and *. 


\section{Table 6}

Multivariate analysis of how insiders with different levels of wealth and income and attitude towards risk time their insider trading.

\begin{tabular}{|c|c|c|c|c|}
\hline \multirow[b]{3}{*}{ Independent variables } & \multicolumn{2}{|c|}{$\begin{array}{c}\text { Panel A: Likelihood of } \\
\text { insider trading }\end{array}$} & \multicolumn{2}{|c|}{$\begin{array}{l}\text { Panel B: Magnitude of } \\
\text { insider trading }\end{array}$} \\
\hline & Selling & Buying & Selling & Buying \\
\hline & (1) & (2) & (3) & (4) \\
\hline$L O W_{i t} \times R I S K_{-} T A K E R_{i} \times B H A R_{j t}$ & $\begin{array}{l}-3.993 * * * \\
(0.000)\end{array}$ & $\begin{array}{l}-0.809 \\
(0.292)\end{array}$ & $\begin{array}{c}-19.857 * * * \\
(0.000)\end{array}$ & $\begin{array}{l}-4.548 \\
(0.251)\end{array}$ \\
\hline$M E D_{i t} \times R I S K_{-} T A K E R_{i} \times B H A R_{j t}$ & $\begin{array}{l}-0.910 \\
(0.319)\end{array}$ & $\begin{array}{l}1.222 * \\
(0.093)\end{array}$ & $\begin{array}{l}-4.454 \\
(0.357)\end{array}$ & $\begin{array}{l}6.729 * \\
(0.062)\end{array}$ \\
\hline$L O W_{i t}$ & $\begin{array}{l}-0.188 * * \\
(0.022)\end{array}$ & $\begin{array}{l}-0.595^{* * *} \\
(0.000)\end{array}$ & $\begin{array}{l}-1.567 * * * \\
(0.001)\end{array}$ & $\begin{array}{l}-3.641 * * * \\
(0.000)\end{array}$ \\
\hline$M E D_{i t}$ & $\begin{array}{l}-0.185^{* *} \\
(0.010)\end{array}$ & $\begin{array}{l}-0.274 * * * \\
(0.000)\end{array}$ & $\begin{array}{l}-1.141 * * * \\
(0.005)\end{array}$ & $\begin{array}{l}-1.608 * * * \\
(0.000)\end{array}$ \\
\hline$L O W_{i t} \times R I S K_{-} T A K E R_{i}$ & $\begin{array}{l}0.421 * * * \\
(0.001)\end{array}$ & $\begin{array}{l}0.239 * * \\
(0.015)\end{array}$ & $\begin{array}{l}1.964 * * * \\
(0.004)\end{array}$ & $\begin{array}{l}1.283 * * \\
(0.015)\end{array}$ \\
\hline$M E D_{i t} \times R I S K_{-} T A K E R_{i}$ & $\begin{array}{c}0.092 \\
(0.420)\end{array}$ & $\begin{array}{l}-0.017 \\
(0.850)\end{array}$ & $\begin{array}{c}0.366 \\
(0.563)\end{array}$ & $\begin{array}{l}-0.202 \\
(0.666)\end{array}$ \\
\hline$L O W_{i t} \times B H A R_{j t}$ & $\begin{array}{c}0.307 \\
(0.558)\end{array}$ & $\begin{array}{c}-0.251 \\
(0.566)\end{array}$ & $\begin{array}{c}1.953 \\
(0.489)\end{array}$ & $\begin{array}{c}-0.572 \\
(0.797)\end{array}$ \\
\hline$M E D_{i t} \times B H A R_{j t}$ & $\begin{array}{c}0.533 \\
(0.340)\end{array}$ & $\begin{array}{r}-0.889 * \\
(0.051)\end{array}$ & $\begin{array}{c}3.034 \\
(0.315)\end{array}$ & $\begin{array}{l}-4.674 * * \\
(0.040)\end{array}$ \\
\hline$R I S K \_T A K E R_{i}$ & $\begin{array}{c}0.047 \\
(0.575)\end{array}$ & $\begin{array}{c}0.031 \\
(0.637)\end{array}$ & $\begin{array}{c}0.567 \\
(0.224)\end{array}$ & $\begin{array}{c}0.386 \\
(0.255)\end{array}$ \\
\hline$B H A R_{j t}$ & $\begin{array}{l}-0.586 \\
(0.165)\end{array}$ & $\begin{array}{l}0.934 * * \\
(0.010)\end{array}$ & $\begin{array}{l}-2.962 \\
(0.191)\end{array}$ & $\begin{array}{l}4.513 * * \\
(0.012)\end{array}$ \\
\hline$R I S K_{-} T A K E R_{i} \times B H A R_{j t}$ & $\begin{array}{l}2.377 * * * \\
(0.000)\end{array}$ & $\begin{array}{c}0.066 \\
(0.907)\end{array}$ & $\begin{array}{c}12.147^{* * *} \\
(0.001)\end{array}$ & $\begin{array}{c}0.134 \\
(0.961)\end{array}$ \\
\hline Constant & $\begin{array}{c}-3.211 * * * \\
(0.000)\end{array}$ & $\begin{array}{l}3.110 * * * \\
(0.000)\end{array}$ & $\begin{array}{c}-16.192 * * * \\
(0.000)\end{array}$ & $\begin{array}{l}15.934 * * * \\
(0.000)\end{array}$ \\
\hline Other control variables from Table 5 & Yes & Yes & Yes & Yes \\
\hline Year-fixed effects & Yes & Yes & Yes & Yes \\
\hline Firm-fixed effects & Yes & Yes & Yes & Yes \\
\hline Pseudo $R^{2}$ & 0.1255 & 0.1094 & 0.0403 & 0.0366 \\
\hline N Obs & 11,178 & 18,166 & 11,178 & 18,166 \\
\hline
\end{tabular}

Notes:

1. This table presents the results of estimating logit and Tobit Models (1) and (2) by including in the models the three-way interaction variables $L O W_{i t} \times R I S K_{-} T A K E R_{i} \times B H A R_{j t}$ and $M E D_{i t} \times R I S K_{-} T A K E R_{i} \times B H A R_{j t}$ to explore how insiders with different levels of wealth and income and lower risk aversion as measured by their criminal behavior time their insider trading, compared to insiders who are more risk averse. The sample includes all 3,388 insiders in all 393 listed firms in Sweden with at least one insider trade over the period from January 2000 to December 2008. 
2. In Panel A, the dependent variable is a dummy variable that equals one if insider $i$ trades her insider stocks on day $t$, and zero otherwise $\left(T R A D E_{i j t}\right)$. In Panel $\mathrm{B}$, the dependent variable is the natural logarithm of the value of the trade if insider $i$ trades insider stocks of firm $j$ on day $t$, and zero otherwise $\left(S I Z E_{i j t}\right)$. The dummy variables $L O W_{i t}$ and $M E D_{i t}$ equal one for insiders in the low and medium wealth/income categories, respectively, the high wealth and income category $\left(H I G H_{i t}\right)$ being the control group. The dummy variable $R I S K_{-} T A K E R_{i}$ measures an insider's lower risk aversion and equals one for insiders who have been convicted or suspected of crimes, and zero otherwise. The variable $B H A R_{j t}$ is the buy-and hold abnormal (market-adjusted) return over a one-month period following day $t$ for firm $j$. Insider- and firm-level control variables from Table 5 and year- and firmfixed effects are included in all regressions but are not tabulated for the sake of brevity.

3. Refer to Section 3.3.2 and Appendix B for the construction of the wealth and income categories and variable definitions. All continuous variables are winsorized to the $1^{\text {st }}$ and $99^{\text {th }}$ percentiles of their distributions. $p$-values from robust standard errors are presented in parentheses. Significance at the $1 \%, 5 \%$, and $10 \%$ (two-tailed) levels is indicated by $* * *, * *$, and $*$. 
Table 7

Percentage monthly returns earned on portfolios formed on the basis of insider trading by insiders with different levels of wealth and income.

\begin{tabular}{|c|c|c|c|c|c|c|c|c|c|c|c|}
\hline \multirow{2}{*}{ Portfolio } & \multirow{2}{*}{$\begin{array}{c}\text { Mean } \\
\text { monthly } \\
\text { number of } \\
\text { insider trades }\end{array}$} & \multirow{2}{*}{$\begin{array}{l}\text { Mean } \\
\text { raw } \\
\text { return }\end{array}$} & \multirow{2}{*}{$\begin{array}{l}\text { Mean } \\
\text { market- } \\
\text { adjusted } \\
\text { return }\end{array}$} & \multicolumn{3}{|c|}{ Intercept from } & \multicolumn{4}{|c|}{$\begin{array}{l}\text { Coefficient estimates for the four-factor } \\
\text { model }\end{array}$} & \multirow[b]{2}{*}{$R^{2}$} \\
\hline & & & & CAPM & $\begin{array}{l}\text { Three- } \\
\text { factor }\end{array}$ & $\begin{array}{l}\text { Four- } \\
\text { factor }\end{array}$ & $R_{m t}-R_{f t}$ & $S M B_{t}$ & $H M L_{t}$ & $\mathrm{PMOM}_{t}$ & \\
\hline (1) & (2) & (3) & (4) & $(5)$ & (6) & (7) & (8) & (9) & (10) & (11) & (12) \\
\hline \multicolumn{12}{|c|}{ Panel A: Insider selling ( $N=105$ months) } \\
\hline$L O W_{p t}$ & 16 & -2.15 & $\begin{array}{l}-1.59 * * \\
(-2.25)\end{array}$ & $\begin{array}{l}-2.59 * * * \\
(-3.14)\end{array}$ & $\begin{array}{l}-1.95 * * \\
(-2.30)\end{array}$ & $\begin{array}{l}-2.32 * * \\
(-2.51)\end{array}$ & $\begin{array}{l}0.77 * * * \\
(3.40)\end{array}$ & $\begin{array}{c}0.19 \\
(0.35)\end{array}$ & $\begin{array}{l}-0.55^{*} \\
(-1.77)\end{array}$ & $\begin{array}{c}0.32 \\
(1.52)\end{array}$ & 0.213 \\
\hline$M E D_{p t}$ & 18 & -0.98 & $\begin{array}{l}-0.18 \\
(-0.27)\end{array}$ & $\begin{array}{l}-1.47^{*} \\
(-1.73)\end{array}$ & $\begin{array}{l}-0.70 \\
(-0.72)\end{array}$ & $\begin{array}{l}-0.67 \\
(-0.70)\end{array}$ & $\begin{array}{l}0.85 * * * \\
(5.19)\end{array}$ & $\begin{array}{c}0.33 \\
(0.76)\end{array}$ & $\begin{array}{l}-0.70^{* * *} \\
(-2.72)\end{array}$ & $\begin{array}{l}-0.03 \\
(-0.15)\end{array}$ & 0.259 \\
\hline$H I G H_{p t}$ & 18 & -0.67 & $\begin{array}{l}-0.03 \\
(-0.06)\end{array}$ & $\begin{array}{l}-1.12 \\
(-1.52)\end{array}$ & $\begin{array}{l}-0.45 \\
(-0.51)\end{array}$ & $\begin{array}{l}-0.66 \\
(-0.72)\end{array}$ & $\begin{array}{l}0.76^{* * *} \\
(3.94)\end{array}$ & $\begin{array}{c}0.33 \\
(0.96)\end{array}$ & $\begin{array}{l}-0.59^{*} \\
(-1.68)\end{array}$ & $\begin{array}{c}0.18 \\
(1.35)\end{array}$ & 0.306 \\
\hline $\begin{array}{l}L O W_{p t}- \\
H I G H_{p t}\end{array}$ & 34 & $\begin{array}{l}-1.49 * * \\
(-2.36)\end{array}$ & $\begin{array}{l}-1.56^{* *} \\
(-2.55)\end{array}$ & $\begin{array}{l}-1.47 * * \\
(-2.08)\end{array}$ & $\begin{array}{l}-1.49 * * \\
(-2.07)\end{array}$ & $\begin{array}{l}-1.66^{* *} \\
(-2.39)\end{array}$ & $\begin{array}{c}0.01 \\
(0.04)\end{array}$ & $\begin{array}{l}-0.14 \\
(-0.41)\end{array}$ & $\begin{array}{c}0.04 \\
(0.16)\end{array}$ & $\begin{array}{c}0.14 \\
(0.74)\end{array}$ & 0.010 \\
\hline \multicolumn{12}{|c|}{ Panel B: Insider buying ( $N=108$ months) } \\
\hline$L O W_{p t}$ & 22 & 2.75 & $\begin{array}{l}2.99 * * * \\
(4.99)\end{array}$ & $\begin{array}{l}2.55^{* * * *} \\
(3.69)\end{array}$ & $\begin{array}{l}3.33 * * * \\
(4.49)\end{array}$ & $\begin{array}{l}3.67 * * * \\
(5.09)\end{array}$ & $\begin{array}{l}0.48 * * * \\
(3.55)\end{array}$ & $\begin{array}{c}0.27 \\
(0.91)\end{array}$ & $\begin{array}{l}-0.76 * * * \\
(-3.09)\end{array}$ & $\begin{array}{c}-0.30 * \\
(-1.88)\end{array}$ & 0.263 \\
\hline$M E D_{p t}$ & 31 & 2.33 & $\begin{array}{l}2.47 * * * \\
(4.96)\end{array}$ & $\begin{array}{l}2.13^{* * * *} \\
(3.35)\end{array}$ & $\begin{array}{l}2.53 * * * \\
(3.53)\end{array}$ & $\begin{array}{l}2.78^{* * * *} \\
(3.96)\end{array}$ & $\begin{array}{l}0.53 * * * \\
(3.32)\end{array}$ & $\begin{array}{c}0.08 \\
(0.26)\end{array}$ & $\begin{array}{l}-0.39 * * \\
(-1.99)\end{array}$ & $\begin{array}{l}-0.22 \\
(-1.45)\end{array}$ & 0.243 \\
\hline$H I G H_{p t}$ & 31 & 1.89 & $\begin{array}{l}2.12^{* * * *} \\
(4.43)\end{array}$ & $\begin{array}{l}1.68 * * * \\
(2.84)\end{array}$ & $\begin{array}{l}1.81 * * * \\
(2.70)\end{array}$ & $\begin{array}{l}2.00 * * * \\
(3.02)\end{array}$ & $\begin{array}{l}0.39 * * * \\
(2.86)\end{array}$ & $\begin{array}{c}0.21 \\
(0.90)\end{array}$ & $\begin{array}{c}-0.16 \\
(-0.89)\end{array}$ & $\begin{array}{l}-0.16 \\
(-1.28)\end{array}$ & 0.168 \\
\hline $\begin{array}{l}L O W_{p t}- \\
H I G H_{p t}\end{array}$ & 53 & $\begin{array}{c}0.85 \\
(1.40)\end{array}$ & $\begin{array}{c}0.87 \\
(1.45)\end{array}$ & $\begin{array}{c}0.87 \\
(1.29)\end{array}$ & $\begin{array}{l}1.52 * * \\
(2.45)\end{array}$ & $\begin{array}{l}1.68^{* * * *} \\
(2.66)\end{array}$ & $\begin{array}{c}0.09 \\
(0.69)\end{array}$ & $\begin{array}{c}0.06 \\
(0.24)\end{array}$ & $\begin{array}{l}-0.60^{* * * *} \\
(-3.08)\end{array}$ & $\begin{array}{l}-0.14 \\
(-0.89)\end{array}$ & 0.088 \\
\hline
\end{tabular}

Notes:

1. This table presents percentage monthly returns earned on portfolios formed according to insider selling (Panel A) and insider buying (Panel B) by insiders with different levels of wealth and income. We calculate the returns for each of the three portfolios as follows. For each calendar month between January 2000 through December 2008, we calculate, for each wealth and income category ('Low,' 'Medium,' and 'High'), the mean raw return over the one-month period following each insider trade date over all insider trades during the month. Raw returns are the mean percentage monthly returns earned by each portfolio. Market-adjusted returns are the mean raw return less the return on an equally weighted market index. The CAPM intercept is the estimated intercept from a time-series regression of the portfolio return $\left(R_{t}-R_{f t}\right)$ on the market excess 
return $\left(R_{m t}-R_{f t}\right)$. The intercept for the Fama-French three-factor model is the estimated intercept from a time-series regression of the portfolio return on the market excess return $\left(R_{m t}-R_{f t}\right)$, a zero investment size portfolio $\left(S M B_{t}\right)$, and a zero-investment book-to-market portfolio $\left(H M L_{t}\right)$. The four-factor model intercept is estimated by adding a zero-investment price momentum portfolio $\left(P M O M_{t}\right)$ as an independent variable. The final line shows the difference in returns between portfolios $L O W_{p t}$ and $H I G H_{p t}$. The mean monthly number of insider trades in each portfolio is also reported. Newey-West (1987) adjusted $t$-statistics appear in parentheses below the returns and the coefficient estimates. Each $t$-statistic pertains to the null hypothesis that the associated return or coefficient is zero, expect for the $t$-statistic on the coefficient estimate of $\left(R_{m t}-R_{f t}\right)$ for portfolios $L O W_{p t}, M E D_{p t}$, and $H I G H_{p t}$, for which the null hypothesis is that the coefficient is one.

2. Refer to Section 3.3.2.1 and Appendix B for the construction of the wealth and income categories 'Low,' 'Medium,' and 'High.' The sample includes insider trades by 3,388 insiders in 393 listed firms in Sweden over the period from January 2000 to December 2008. For insider selling, we lose three out of a total 108 sample months because we require that, for each calendar month, there are insider sales (purchases) in all the three wealth and income categories. Significance at the $1 \%, 5 \%$, and $10 \%$ (two-tailed) levels is indicated by ***,**, and *. 
Table 8

Abnormal returns following insider selling by the proportion of an insider's wealth allocated to insider stock.

\begin{tabular}{|c|c|c|c|c|c|}
\hline \multirow{3}{*}{$\begin{array}{l}\text { Quartile of the proportion } \\
\text { of an insider's wealth } \\
\text { allocated to insider stock }\end{array}$} & \multirow[t]{2}{*}{ All insiders } & \multicolumn{3}{|c|}{$\begin{array}{l}\text { Insiders with different levels of wealth and } \\
\text { income }\end{array}$} & \\
\hline & & Low & Medium & High & \\
\hline & $\begin{array}{l}\text { Mean } \\
\text { (Median) }\end{array}$ & $\begin{array}{l}\text { Mean } \\
\text { (Median) }\end{array}$ & $\begin{array}{l}\text { Mean } \\
\text { (Median) }\end{array}$ & $\begin{array}{c}\text { Mean } \\
\text { (Median) }\end{array}$ & $\begin{array}{l}\text { Difference: } \\
\text { Low - High }\end{array}$ \\
\hline $\begin{array}{l}\text { Quartile } 1 \\
\text { (less wealth allocated) }\end{array}$ & $\begin{array}{l}0.07 \% \\
(-0.83 \% * *) \\
\mathrm{N}=1,276\end{array}$ & $\begin{array}{l}-1.09 \% * * * \\
(-2.17 \% * * *) \\
\mathrm{N}=457\end{array}$ & $\begin{array}{c}0.44 \% \\
(-0.49 \%) \\
\mathrm{N}=462\end{array}$ & $\begin{array}{c}1.09 \% \\
(-0.51 \%) \\
\mathrm{N}=357\end{array}$ & $\begin{array}{l}-2.18 \% * * \\
(-1.66 \% * * *)\end{array}$ \\
\hline Quartile 2 & $\begin{array}{l}0.12 \% \\
(0.12 \%) \\
\mathrm{N}=990\end{array}$ & $\begin{array}{c}-1.79 \% * * * \\
(-0.10 \% * *) \\
\mathrm{N}=305\end{array}$ & $\begin{array}{l}0.78 \% \\
(0.80 \%) \\
\mathrm{N}=301\end{array}$ & $\begin{array}{l}1.12 \% * * \\
(0.40 \%) \\
\mathrm{N}=384\end{array}$ & $\begin{array}{l}-2.91 \% * * * \\
(-0.50 \% * * *)\end{array}$ \\
\hline Quartile 3 & $\begin{array}{l}-0.47 \% \\
(-1.08 \% * * *) \\
\mathrm{N}=1,491\end{array}$ & $\begin{array}{l}-1.78 \% * * * \\
(-2.93 \% * * *) \\
\mathrm{N}=441\end{array}$ & $\begin{array}{l}-0.15 \% \\
(-0.97 \% * *) \\
\mathrm{N}=497\end{array}$ & $\begin{array}{c}0.29 \% \\
(-0.23 \%) \\
\mathrm{N}=553\end{array}$ & $\begin{array}{l}-2.07 \% * * * \\
(-2.70 \% * * *)\end{array}$ \\
\hline $\begin{array}{l}\text { Quartile } 4 \\
\text { (more wealth allocated) }\end{array}$ & $\begin{array}{l}-0.86 \% * * * \\
(-1.69 \% * * *) \\
\mathrm{N}=1,832\end{array}$ & $\begin{array}{l}-2.10 \% * * * \\
(-3.16 \% * * *) \\
\mathrm{N}=518\end{array}$ & $\begin{array}{l}-0.70 \% \\
(-0.73 \% * *) \\
\mathrm{N}=692\end{array}$ & $\begin{array}{l}-0.02 \% \\
(-1.05 \% * *) \\
\mathrm{N}=622\end{array}$ & $\begin{array}{l}-2.08 \% * * \\
-2.11 \% * * *)\end{array}$ \\
\hline Difference: Q1 - Q4 & & & & & \\
\hline $\begin{array}{l}\text { Mean } \\
\text { (Median) }\end{array}$ & $\begin{array}{c}0.93 \% * \\
(0.86 \% *)\end{array}$ & $\begin{array}{l}1.01 \% \\
(0.99 \%)\end{array}$ & $\begin{array}{l}1.14 \% \\
(0.24 \%)\end{array}$ & $\begin{array}{l}1.11 \% \\
(0.54 \% *)\end{array}$ & \\
\hline
\end{tabular}

Notes:

1. This table reports the mean (median) one-month buy-and-hold abnormal (market-adjusted) returns following the 5,589 insider sales in the sample made by insiders with different levels of wealth and income ('Low,' 'Medium,' and 'High'), broken into quartiles based upon the proportion of an insider's total wealth allocated to her insider stock (Q1 - Q4). Quartile 1 (4) includes insider sales by insiders who have allocated less (more) of their wealth to their insider stock prior to selling them. In each quartile group (Q1 - Q4), we test for difference in the mean (median) future one-month abnormal returns between the wealth and income categories 'Low' and 'High' by using a two-tailed $t$-test (Wilcoxon rank-sum test). In addition, in each wealth and income category, we test for difference in the mean (median) future onemonth abnormal returns between the quartile groups 1 and 4 by using a two-tailed $t$-test (Wilcoxon ranksum test).

2. Refer to Section 3.3.2.1 and Appendix B for the construction of the wealth and income categories 'Low,' 'Medium,' and 'High.' The sample includes all 3,388 insiders in all 393 listed firms in Sweden with at least one insider trade over the period from January 2000 to December 2008. Significance at the 1\%, 5\%, and $10 \%$ (two-tailed) levels is indicated by $* * *, * *$, and *. 
Table 9

Multivariate analysis, including interaction between insiders' portfolio diversification objectives and future abnormal return.

\begin{tabular}{lcc}
\hline Independent variables & $\begin{array}{c}\text { Panel A: Likelihood of } \\
\text { insider selling }\end{array}$ & $\begin{array}{c}\text { Panel B: Magnitude of } \\
\text { insider selling }\end{array}$ \\
\hline$L O W_{i t} \times B H A R_{j t}$ & $-1.040^{* *}$ & $-5.015^{* *}$ \\
$M E D_{i t} \times B H A R_{j t}$ & $(0.015)$ & $(0.028)$ \\
& 0.225 & 1.546 \\
$L O W_{i t}$ & $(0.607)$ & $(0.510)$ \\
& -0.058 & $-0.941^{* *}$ \\
$M E D_{i t}$ & $(0.424)$ & $(0.018)$ \\
& $-0.146^{* *}$ & $-0.975^{* * *}$ \\
PROP_WEALTH ${ }_{i j t} \times B H A R_{j t}$ & $(0.017)$ & $(0.004)$ \\
& 0.343 & 2.357 \\
$B H A R_{j t}$ & $(0.486)$ & $(0.309)$ \\
& -0.023 & -0.395 \\
PROP_WEALTH $H_{i j t}$ & $(0.952)$ & $(0.849)$ \\
& $1.533^{* * *}$ & $8.249^{* * *}$ \\
Constant & $(0.000)$ & $(0.000)$ \\
Other control variables from Table 5 & $-3.219^{* * *}$ & $-16.423^{* * *}$ \\
Year-fixed effects & $(0.000)$ & $(0.000)$ \\
Firm-fixed effects & Yes & Yes \\
Pseudo $R^{2}$ & Yes & Yes \\
N Obs & Yes & Yes \\
\hline
\end{tabular}

Notes:

1. This table repeats the analysis presented in Table 5 but includes the two-way interaction variable PROP_WEALTH $H_{i j t} \times B H A R_{j t}$ to control for the portfolio diversification-driven selling reported by Kallunki et al. (2009). In Panel A, the dependent variable is a dummy variable equal to one if insider $i$ trades insider stocks of firm $j$ on day $t$, and zero otherwise $\left(T R A D E_{i j t}\right)$. In Panel $\mathrm{B}$, the dependent variable is the natural logarithm of the market value of the shares traded if insider $i$ trades insider stocks of firm $j$ on day $t$, and zero otherwise $\left(S I Z E_{i j t}\right)$. The independent variables include two dummy variables for insiders in the low and medium wealth/income categories ( $L O W_{i t}$ and $M E D_{i t}$, respectively), the high wealth/income category $\left(H I G H_{i t}\right)$ being the control group. The variable $B H A R_{j t}$ is the buy-and-hold abnormal (market-adjusted) return over a one-month period following day $t$ for firm $j$. The variable PROP_WEALTH $H_{i j t}$ is the ratio of the market value of insider $i$ 's holdings in insider stock $j$ at the end of the fiscal year prior to day $t$ to the value of insider $i$ 's total wealth at the end of the fiscal year prior to day $t$. Insider- and firm-level control variables from Table 5 and year- and firm-fixed effects are included in all regressions but are not tabulated for the sake of brevity.

2. Refer to Section 3.3.2 and Appendix B for the construction of the wealth and income categories and variable definitions. The sample includes all 3,388 insiders in all 393 listed firms in Sweden with at least one insider trade over the period from January 2000 to December 2008. All continuous variables are winsorized to the $1^{\text {st }}$ and $99^{\text {th }}$ percentiles of their distributions. $p$-values from robust standard errors are presented in parentheses. Significance at the $1 \%, 5 \%$, and $10 \%$ (two-tailed) levels is indicated by $* * *, * *$, and *. 
Table 10

Univariate analysis using alternative wealth and income grouping of insiders.

\begin{tabular}{|c|c|c|c|c|c|c|}
\hline & \multicolumn{5}{|c|}{ Insiders' wealth and income level quintile } & \multirow[b]{3}{*}{$\begin{array}{c}\text { Difference: } \\
\text { Q1-Q5 }\end{array}$} \\
\hline & Quintile 1 (lowest) & Quintile 2 & Quintile 3 & Quintile 4 & Quintile 5 (highest) & \\
\hline & $\begin{array}{c}\text { Mean } \\
\text { (Median) }\end{array}$ & $\begin{array}{c}\text { Mean } \\
\text { (Median) }\end{array}$ & $\begin{array}{c}\text { Mean } \\
\text { (Median) }\end{array}$ & $\begin{array}{c}\text { Mean } \\
\text { (Median) }\end{array}$ & $\begin{array}{c}\text { Mean } \\
\text { (Median) }\end{array}$ & \\
\hline Total wealth (thousands of SEK) & $\begin{array}{c}1,493.5 \\
(1,274.7)\end{array}$ & $\begin{array}{c}4,698.6 \\
(2,912.5)\end{array}$ & $\begin{array}{l}76,150.0 \\
(5,434.7)\end{array}$ & $\begin{array}{l}35,685.0 \\
(8,745.6)\end{array}$ & $\begin{array}{l}173,775.0 \\
(24,557.8)\end{array}$ & $\begin{array}{l}-172,281.5 \\
(-23,283.1)\end{array}$ \\
\hline Annual income (thousands of SEK) & $\begin{array}{c}476.4 \\
(484.3) \\
\end{array}$ & $\begin{array}{c}878.2 \\
(869.0) \\
\end{array}$ & $\begin{array}{c}1,289.4 \\
(1,165.3) \\
\end{array}$ & $\begin{array}{c}2,350.0 \\
(2,084.9)\end{array}$ & $\begin{array}{c}5,539.1 \\
(4,280.9)\end{array}$ & $\begin{array}{r}-5,062.7 \\
(3,796.6) \\
\end{array}$ \\
\hline Days without insider selling & $\begin{array}{c}0.89 \% * \\
(-0.26 \%)\end{array}$ & $\begin{array}{c}0.02 \% \\
(-0.55 \%)\end{array}$ & $\begin{array}{l}-0.08 \% \\
(0.03 \%)\end{array}$ & $\begin{array}{l}0.66 \% * \\
(0.19 \%)\end{array}$ & $\begin{array}{l}0.53 \% \\
(0.09 \%)\end{array}$ & $\begin{array}{c}0.36 \% \\
(-0.35 \%)\end{array}$ \\
\hline Days with insider selling & $\begin{array}{l}\mathrm{N}=1,180 \\
-1.62 \% * * * \\
(-2.10 \% * * *) \\
\mathrm{N}=1,056\end{array}$ & $\begin{array}{c}\mathrm{N}=1,165 \\
-1.32 \% * * * \\
(-2.00 \% * * *) \\
\mathrm{N}=1,070\end{array}$ & $\begin{array}{c}\mathrm{N}=1,118 \\
0.62 \% \\
(-0.39 \%) \\
\mathrm{N}=1,118\end{array}$ & $\begin{array}{c}\mathrm{N}=1,084 \\
0.11 \% \\
(-0.63 \% *) \\
\mathrm{N}=1,152\end{array}$ & $\begin{array}{c}\mathrm{N}=1,042 \\
0.19 \% \\
(-0.56 \%) \\
\mathrm{N}=1,193\end{array}$ & $\begin{array}{r}-1.81 \% * * * \\
(-1.54 \% * * *)\end{array}$ \\
\hline \multicolumn{7}{|l|}{ Panel B: Insider buying } \\
\hline Days without insider buying & $\begin{array}{l}0.96 \% * * * \\
(0.13 \%) \\
\mathrm{N}=2,148\end{array}$ & $\begin{array}{l}1.16 \% * * * \\
(0.32 \% * *) \\
\mathrm{N}=1,975\end{array}$ & $\begin{array}{l}1.02 \% * * * \\
(0.32 \% * *) \\
\mathrm{N}=1,892\end{array}$ & $\begin{array}{l}0.79 \% * * * \\
(0.62 \% * * *) \\
N=1,646\end{array}$ & $\begin{array}{l}0.67 \% * * \\
(0.50 \% * *) \\
N=1,422\end{array}$ & $\begin{array}{c}0.29 \% \\
(-0.37 \%)\end{array}$ \\
\hline Days with insider buying & $\begin{array}{c}2.21 \% * * * \\
(0.84 \% * * *) \\
\mathrm{N}=1,485\end{array}$ & $\begin{array}{l}2.45 \% * * * \\
(1.25 \% * * *) \\
\mathrm{N}=1,656\end{array}$ & $\begin{array}{c}1.89 \% * * * \\
(0.50 \% * * *) \\
\mathrm{N}=1,740\end{array}$ & $\begin{array}{c}1.89 \% * * * \\
(1.09 \% * * *) \\
\mathrm{N}=1,991\end{array}$ & $\begin{array}{l}2.06 \% * * * \\
(1.05 \% * * *) \\
\mathrm{N}=2,211\end{array}$ & $\begin{array}{c}0.15 \% \\
(-0.21 \%)\end{array}$ \\
\hline \multicolumn{7}{|c|}{ Difference: Days without insider buying - Days with insider buying } \\
\hline $\begin{array}{l}\text { Mean } \\
\text { (Median) }\end{array}$ & $\begin{array}{c}-1.25 \% * * * \\
(-0.71 \% * * *)\end{array}$ & $\begin{array}{c}-1.29 \% * * * \\
(-0.93 \% * *)\end{array}$ & $\begin{array}{l}-0.87 \% * * \\
(-0.18 \%)\end{array}$ & $\begin{array}{l}-1.10 \% * * * \\
(-0.47 \% *)\end{array}$ & $\begin{array}{c}-1.39 \% * * * \\
(-0.55 \% * * *)\end{array}$ & \\
\hline
\end{tabular}


Notes:

1. This table repeats the univariate analysis presented in Table 4 but using an alternative way for grouping insiders based on the level of their wealth and income instead of the three wealth/income groups. Specifically, we divide our matched-pair sample of days with and without insider selling (buying) into five quintiles based upon the continuous wealth and income ranking of insiders (Quintiles 1-5). We first report the mean (median) SEK values of insiders' total wealth and annual income for insiders in these five wealth and income quintiles. In each wealth and income quintile, we then test whether the mean and median future one-month buy-and-hold abnormal (market-adjusted) returns are significantly different between the days with and without insider selling and buying by using a two-tailed $t$-test for means and Wilcoxon rank-sum test for medians. In addition, we test for difference in the mean (median) values of the future one-month abnormal returns between the wealth and income Quintiles 1 and 5 by using a two-tailed $t$-test (Wilcoxon rank-sum test). Panel A (Panel B) reports the results for insider selling (buying).

2. Refer to Section 4.4.2 for the construction of the wealth and income quintiles. The sample includes all 3,388 insiders in all 393 listed firms in Sweden with at least one insider trade over the period from January 2000 to December 2008. 1 SEK is equal to 0.12 USD. Significance at the $1 \%$, 5\%, and 10\% (twotailed) levels is indicated by $* * *, * *$, and *. 
Table 11

Multivariate analysis using alternative wealth and income grouping of insiders.

\begin{tabular}{|c|c|c|c|c|c|c|c|c|}
\hline \multirow[b]{4}{*}{ Independent variables } & \multicolumn{4}{|c|}{ Panel A: Likelihood of insider trading } & \multicolumn{4}{|c|}{ Panel B: Magnitude of insider trading } \\
\hline & \multicolumn{2}{|c|}{$\begin{array}{l}\log (\text { Continuous wealth } \\
\text { and income ranking) }\end{array}$} & \multicolumn{2}{|c|}{$\begin{array}{l}\text { Lowest wealth and } \\
\text { income quintile }\end{array}$} & \multicolumn{2}{|c|}{$\begin{array}{l}\log (\text { Continuous wealth } \\
\text { and income ranking) }\end{array}$} & \multicolumn{2}{|c|}{$\begin{array}{l}\text { Lowest wealth and } \\
\text { income quintile }\end{array}$} \\
\hline & Selling & Buying & Selling & Buying & Selling & Buying & Selling & Buying \\
\hline & $(1)$ & $(2)$ & (3) & (4) & $(5)$ & (6) & $(7)$ & $(8)$ \\
\hline $\log \left(W I \_R A N K_{i t}\right) \times B H A R_{j t}$ & $\begin{array}{l}1.703 * * * \\
(0.003)\end{array}$ & $\begin{array}{c}0.671 \\
(0.150)\end{array}$ & & & $\begin{array}{l}8.662 * * * \\
(0.005)\end{array}$ & $\begin{array}{c}2.764 \\
(0.279)\end{array}$ & & \\
\hline $\log \left(W I \_R A N K_{i t}\right)$ & $\begin{array}{c}0.061 \\
(0.549)\end{array}$ & $\begin{array}{l}0.809^{* * *} \\
(0.000)\end{array}$ & & & $\begin{array}{c}1.304 \\
(0.023)\end{array}$ & $\begin{array}{l}4.990 * * * \\
(0.000)\end{array}$ & & \\
\hline QUINTILE_ $1_{i t} \times B H A R_{j t}$ & & & $\begin{array}{l}-1.299 * * * \\
(0.001)\end{array}$ & $\begin{array}{l}-0.111 \\
(0.735)\end{array}$ & & & $\begin{array}{l}-6.686 * * * \\
(0.001)\end{array}$ & $\begin{array}{l}-0.073 \\
(0.967)\end{array}$ \\
\hline QUINTILE_ $1_{i t}$ & & & $\begin{array}{c}0.061 \\
(0.340)\end{array}$ & $\begin{array}{l}-0.292 * * * \\
(0.000)\end{array}$ & & & $\begin{array}{c}-0.082 \\
(0.814)\end{array}$ & $\begin{array}{l}-1.793 \\
(0.000)\end{array}$ \\
\hline$R I S K_{-} T A K E R_{i} \times B H A R_{j t}$ & $\begin{array}{l}0.591 * * \\
(0.105)\end{array}$ & $\begin{array}{c}0.304 \\
(0.297)\end{array}$ & $\begin{array}{l}0.611^{*} \\
(0.093)\end{array}$ & $\begin{array}{c}0.280 \\
(0.335)\end{array}$ & $\begin{array}{r}3.242 * \\
(0.091)\end{array}$ & $\begin{array}{l}1.574 \\
(0.287)\end{array}$ & $\begin{array}{r}3.275^{*} \\
(0.088)\end{array}$ & $\begin{array}{l}1.413 \\
(0.342)\end{array}$ \\
\hline$P R O P \_W E A L T H_{i j t} \times B H A R_{j t}$ & $\begin{array}{c}0.405 \\
(0.410)\end{array}$ & $\begin{array}{c}0.261 \\
(0.615)\end{array}$ & $\begin{array}{c}0.344 \\
(0.485)\end{array}$ & $\begin{array}{c}0.311 \\
(0.552)\end{array}$ & $\begin{array}{c}2.839 \\
(0.220)\end{array}$ & $\begin{array}{l}2.233 \\
(0.431)\end{array}$ & $\begin{array}{l}2.444 \\
(0.292)\end{array}$ & $\begin{array}{c}2.514 \\
(0.378)\end{array}$ \\
\hline$R I S K_{-} T A K E R_{i}$ & $\begin{array}{l}0.201 * * * \\
(0.000)\end{array}$ & $\begin{array}{l}0.083 * * \\
(0.035)\end{array}$ & $\begin{array}{l}0.206^{* * *} \\
(0.000)\end{array}$ & $\begin{array}{l}0.102 * * \\
(0.010)\end{array}$ & $\begin{array}{l}1.272 * * * \\
(0.000)\end{array}$ & $\begin{array}{l}0.612 * * * \\
(0.004)\end{array}$ & $\begin{array}{l}1.303^{* * *} \\
(0.000)\end{array}$ & $\begin{array}{l}0.715^{* * *} \\
(0.001)\end{array}$ \\
\hline PROP_WEALTH $H_{i j t}$ & $\begin{array}{l}1.527^{* * *} \\
(0.000)\end{array}$ & $\begin{array}{l}-0.249 * * * \\
(0.002)\end{array}$ & $\begin{array}{l}1.533^{* * *} \\
(0.000)\end{array}$ & $\begin{array}{l}-0.262 * * * \\
(0.001)\end{array}$ & $\begin{array}{l}8.249 * * * \\
(0.000)\end{array}$ & $\begin{array}{l}-1.183^{* * *} \\
(0.008)\end{array}$ & $\begin{array}{l}8.280^{* * *} \\
(0.000)\end{array}$ & $\begin{array}{l}-1.287^{* * * *} \\
(0.004)\end{array}$ \\
\hline$B H A R_{j t}$ & $\begin{array}{l}-7.060 * * * \\
(0.002)\end{array}$ & $\begin{array}{c}-2.313 \\
(0.230)\end{array}$ & $\begin{array}{l}-0.024 \\
(0.932)\end{array}$ & $\begin{array}{r}0.432 * \\
(0.050)\end{array}$ & $\begin{array}{c}-35.971 * * * \\
(0.003)\end{array}$ & $\begin{array}{c}-9.341 \\
(0.379)\end{array}$ & $\begin{array}{l}-0.098 \\
(0.952)\end{array}$ & $\begin{array}{l}1.902 * \\
(0.094)\end{array}$ \\
\hline Constant & $\begin{array}{l}-3.550 * * * \\
(0.000)\end{array}$ & $\begin{array}{l}-0.800 \\
(0.241)\end{array}$ & $\begin{array}{l}-3.205^{* * *} \\
(0.000)\end{array}$ & $\begin{array}{l}2.967 * * * \\
(0.000)\end{array}$ & $\begin{array}{c}-22.464 * * * \\
(0.000)\end{array}$ & $\begin{array}{l}-8.079 * * \\
(0.027)\end{array}$ & $\begin{array}{l}-16.372^{* * * *} \\
(0.000)\end{array}$ & $\begin{array}{l}15.071^{* * * *} \\
(0.000)\end{array}$ \\
\hline $\begin{array}{l}\text { Other control variables from } \\
\text { Table } 5\end{array}$ & Yes & Yes & Yes & Yes & Yes & Yes & Yes & Yes \\
\hline Year-fixed effects & Yes & Yes & Yes & Yes & Yes & Yes & Yes & Yes \\
\hline Firm-fixed effects & Yes & Yes & Yes & Yes & Yes & Yes & Yes & Yes \\
\hline Pseudo $R^{2}$ & 0.1227 & 0.1095 & 0.1229 & 0.1075 & 0.0396 & 0.0367 & 0.0396 & 0.0358 \\
\hline
\end{tabular}


Notes:

1. This table repeats the multivariate analysis presented in Table 5 but using an alternative method of grouping insiders based on the level of their wealth and income instead of the three wealth and income groups. All regressions also include the two-way interaction variable $P R O P_{-} W E A L T H_{i j t} \times B H A R_{j t}$ to control for the portfolio diversification-driven selling reported by Kallunki et al. (2009). In Panel A, the dependent variable is a dummy variable equal to one if insider $i$ trades insider stocks of firm $j$ on day $t$, and zero otherwise $\left(T R A D E_{i j t}\right)$. In Panel $\mathrm{B}$, the dependent variable is the natural logarithm of the market value of the shares traded if insider $i$ trades insider stocks of firm $j$ on day $t$, and zero otherwise $\left(S I Z E_{i j t}\right)$. The variable $\log \left(W I \_R A N K_{i t}\right)$ is the (base 10) logarithm of the continuous wealth and income ranking of insiders, where larger values correspond to a higher wealth and income level of the insider (Columns 1, 2, 5, and 6). The dummy variable QUINTILE_ $1_{i t}$ equals one for insiders in the lowest wealth and income (Quintile 1) from Table 10, insiders in the wealth and income Quintiles $2-5$ being the control group (Columns 3, 4, 7, and 8). The variable BHAR $R_{j t}$ is the buy-and-hold abnormal (marketadjusted) return over a one-month period following day $t$ for firm $j$. The variable PROP_WEALTH $H_{i j t}$ is the ratio of the market value of insider $i$ 's holdings in insider stock $j$ at the end of the fiscal year prior to day $t$ to the value of insider $i$ 's total wealth at the end of the fiscal year prior to day $t$. Insider- and firmlevel control variables from Table 5 and year- and firm-fixed effects are included in all regressions but are not tabulated for the sake of brevity.

2. Refer to Section 4.4.2 for the construction of the variables $W I \_R A N K_{i t}$ and $Q U I N T I L E \_I_{i t}$. All other variables are defined as in Appendix B. All continuous variables are winsorized to the $1^{\text {st }}$ and $99^{\text {th }}$ percentiles of their distributions, with the exception of the variable WI_RANK $K_{i t}$. The sample includes all 3,388 insiders in all 393 listed firms in Sweden with at least one insider trade over the period 2000-2008. $p$-values from robust standard errors are presented in parentheses. Significance at the $1 \%, 5 \%$, and $10 \%$ (two-tailed) levels is indicated by ***,**, and *. 
Table 12

Abnormal returns following insider trading by cash-strapped and non-cash-strapped insiders with different levels of wealth and income.

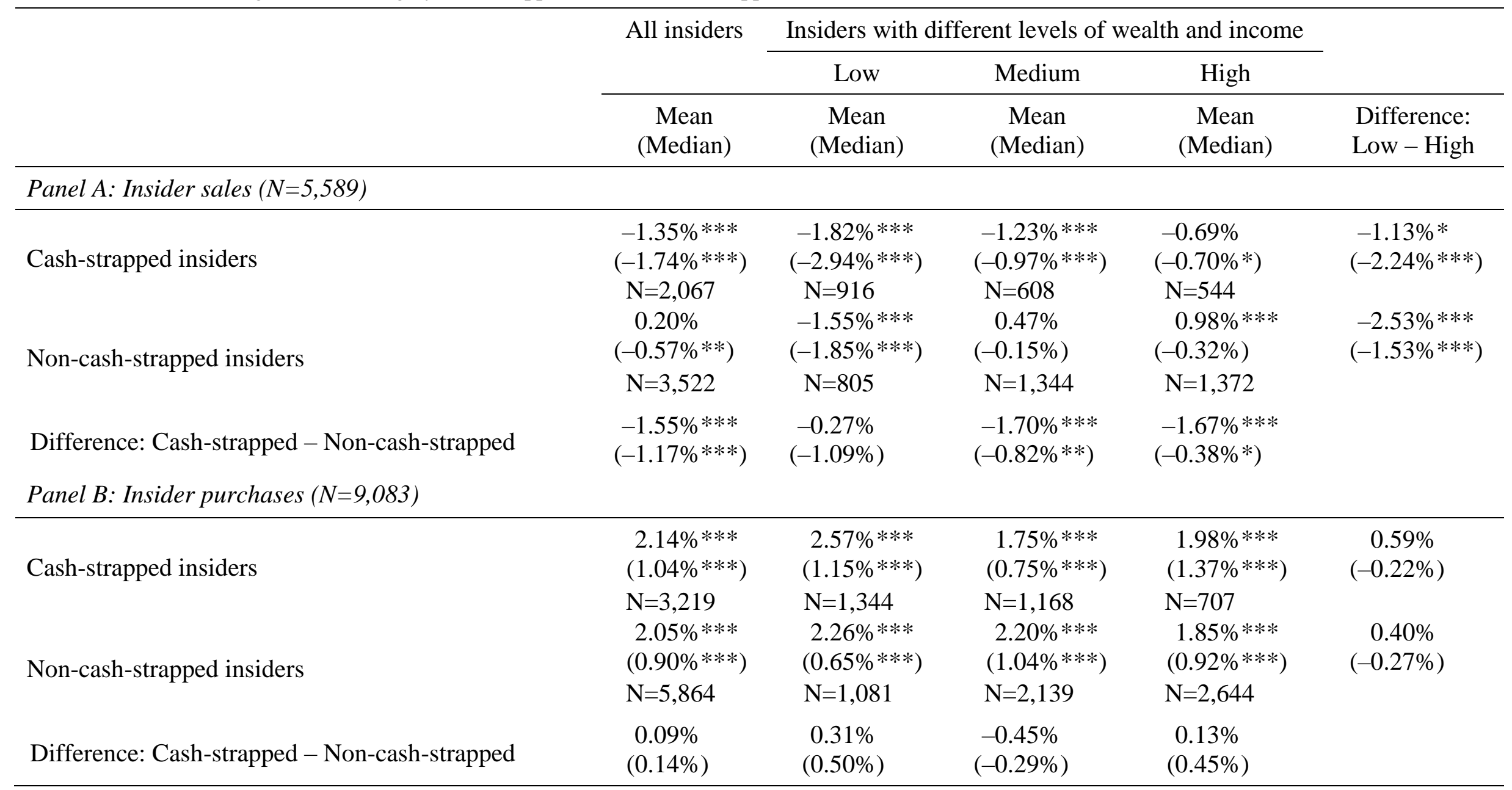

Notes:

1. This table reports the mean (median) one-month buy-and-hold abnormal (market-adjusted) returns following the 5,589 insider sales (Panel A) and 9,083 insider purchases (Panel B) in the sample made by cash-strapped and non-cash-strapped insiders with different levels of wealth and income ('Low,' 'Medium,' and 'High'). Cash-strapped insiders are defined as those who have both high debt-to-wealth and high interest payments-to-income ratios. All other insiders are considered to be non-cash-strapped. We test whether the mean (median) future one-month buy-and-hold abnormal (market-adjusted) 
returns are significantly different between insider sales and purchases by cash-strapped and those by non-cash-strapped insiders by using a two-tailed $t$-test (Wilcoxon rank-sum test). We conduct this analysis for insiders in the three wealth and income categories ('Low,' 'Medium,' and 'High'). In addition, we test for difference in the mean (median) values of the future abnormal returns between the wealth and income categories 'Low' and 'High' separately for the subgroups of cash-strapped and non-cash-strapped insiders by using a two-tailed $t$-test (Wilcoxon rank-sum test).

2. We use the following procedure to identify cash-strapped insiders. We first divide all the observations in our sample used for insider selling (buying) into two equal-sized groups based on an insider's debt-to-wealth ratio, i.e., low and high debt-to-wealth groups. Similarly, we divide all observations in the sample into two equal-sized groups based on an insider's interest payments-to-income ratio, i.e., low and high interest payments-to-income groups. An insider's debt-to-wealth ratio shows how much interest-bearing debt she has relative to her wealth, whereas an interest payments-to-income ratio reflects the fraction of income needed for the debt service. We then define cash-strapped insiders as those who belong to the groups of both high debt-to-wealth and high interest payments-to-income.

3. Refer to Section 3.3.2.1 and Appendix B for the construction of the wealth and income categories. The sample includes all 3,388 insiders in all 393 listed firms in Sweden with at least one insider trade over the period from January 2000 to December 2008. Significance at the 1\%, 5\%, and 10\% (two-tailed) levels is indicated by ***,**, and *. 
Table 13

Multivariate analysis of how cash-strapped and non-cash-strapped insiders with different levels of wealth and income time their insider selling.

\begin{tabular}{|c|c|c|c|c|c|c|}
\hline \multirow[b]{2}{*}{ Independent variables } & \multicolumn{3}{|c|}{ Panel A: Likelihood of insider selling } & \multicolumn{3}{|c|}{ Panel B: Magnitude of insider selling } \\
\hline & (1) & (2) & (3) & (4) & $(5)$ & (6) \\
\hline$L O W_{i t} \times B H A R_{j t}$ & $\begin{array}{l}-1.415^{* *} \\
(0.010)\end{array}$ & & & $\begin{array}{l}-6.727 * * \\
(0.017)\end{array}$ & & \\
\hline$M E D_{i t} \times B H A R_{j t}$ & $\begin{array}{c}-0.274 \\
(0.563)\end{array}$ & & & $\begin{array}{c}-1.124 \\
(0.652)\end{array}$ & & \\
\hline$L O W_{i t}$ & $\begin{array}{l}-0.057 \\
(0.437)\end{array}$ & & & $\begin{array}{l}-0.902 * * \\
(0.024)\end{array}$ & & \\
\hline$M E D_{i t}$ & $\begin{array}{l}-0.147 * * \\
(0.017)\end{array}$ & & & $\begin{array}{l}-0.982 * * * \\
(0.003)\end{array}$ & & \\
\hline $\log \left(W I \_R A N K_{i t}\right) \times B H A R_{j t}$ & & $\begin{array}{l}2.141 * * * \\
(0.003)\end{array}$ & & & $\begin{array}{l}10.685^{* * *} \\
(0.005)\end{array}$ & \\
\hline $\log \left(W I \_R A N K_{i t}\right)$ & & $\begin{array}{c}0.055 \\
(0.584)\end{array}$ & & & $\begin{array}{l}1.253^{* *} \\
(0.030)\end{array}$ & \\
\hline$C A S H \_S T R A P P E D_{i t} \times B H A R_{j t}$ & $\begin{array}{l}-1.061^{* * *} \\
(0.006)\end{array}$ & $\begin{array}{c}-1.132 * * * \\
(0.003)\end{array}$ & & $\begin{array}{l}-5.511 * * * \\
(0.007)\end{array}$ & $\begin{array}{l}-5.770 * * * \\
(0.004)\end{array}$ & \\
\hline CASH_STRAPPED $D_{i t}$ & $\begin{array}{c}0.002 \\
(0.971)\end{array}$ & $\begin{array}{c}0.009 \\
(0.850)\end{array}$ & & $\begin{array}{l}-0.238 \\
(0.376)\end{array}$ & $\begin{array}{l}-0.213 \\
(0.425)\end{array}$ & \\
\hline$L O W \_C A S H \_S T R A P P E D_{i t} \times B H A R_{j t}$ & & & $\begin{array}{l}-2.407 * * * \\
(0.000)\end{array}$ & & & $\begin{array}{l}-12.005^{* * *} \\
(0.000)\end{array}$ \\
\hline$L O W \_N O N \_C A S H \_S T R A P P E D_{i t} \times B H A R_{j t}$ & & & $\begin{array}{l}-1.602 * * \\
(0.012)\end{array}$ & & & $\begin{array}{l}-7.604 * * \\
(0.021)\end{array}$ \\
\hline$M E D \_C A S H \_S T R A P P E D_{i t} \times B H A R_{j t}$ & & & $\begin{array}{l}-1.637 * * \\
(0.019)\end{array}$ & & & $\begin{array}{l}-7.875 * * \\
(0.039)\end{array}$ \\
\hline$M E D \_N O N \_C A S H \_S T R A P P E D_{i t} \times B H A R_{j t}$ & & & $\begin{array}{l}-0.217 \\
(0.688)\end{array}$ & & & $\begin{array}{l}-1.066 \\
(0.707)\end{array}$ \\
\hline$H I G H \_C A S H \_S T R A P P E D_{i t} \times B H A R_{j t}$ & & & $\begin{array}{l}-1.136 \\
(0.151)\end{array}$ & & & $\begin{array}{l}-6.136 \\
(0.142)\end{array}$ \\
\hline
\end{tabular}




\begin{tabular}{|c|c|c|c|c|c|c|}
\hline$L O W_{-} C A S H \_S T R A P P E D_{i t}$ & & & \multicolumn{2}{|l|}{$\begin{array}{c}-0.044 \\
(0.618)\end{array}$} & & $\begin{array}{l}-1.079 * * \\
(0.023)\end{array}$ \\
\hline$L O W \_N O N \_C A S H \_S T R A P P E D_{i t}$ & & & $\begin{array}{c}0.010 \\
(0.912)\end{array}$ & & & $\begin{array}{l}-0.623 \\
(0.187)\end{array}$ \\
\hline$M E D \_C A S H \_S T R A P P E D_{i t}$ & & & $\begin{array}{c}-0.150^{*} \\
(0.083)\end{array}$ & & & $\begin{array}{l}-1.269 * * * \\
(0.008)\end{array}$ \\
\hline MED_NON_CASH_STRAPPED ${ }_{i t}$ & & & $\begin{array}{c}-0.088 \\
(0.209)\end{array}$ & & & $\begin{array}{c}-0.711 * \\
(0.064)\end{array}$ \\
\hline$H I G H \_C A S H \_S T R A P P E D_{i t}$ & & & $\begin{array}{c}0.150^{*} \\
(0.093)\end{array}$ & & & $\begin{array}{c}0.393 \\
(0.411)\end{array}$ \\
\hline$R I S K_{-} T A K E R_{i} \times B H A R_{j t}$ & $\begin{array}{c}0.331 \\
(0.383)\end{array}$ & $\begin{array}{c}0.319 \\
(0.391)\end{array}$ & $\begin{array}{c}0.330 \\
(0.384)\end{array}$ & $\begin{array}{l}1.808 \\
(0.359)\end{array}$ & $\begin{array}{c}1.711 \\
(0.385)\end{array}$ & $\begin{array}{c}1.782 \\
(0.367)\end{array}$ \\
\hline$B H A R_{j t}$ & $\begin{array}{l}-9.798 * * \\
(0.035)\end{array}$ & $\begin{array}{l}-18.966 * * * \\
(0.001)\end{array}$ & $\begin{array}{l}-9.752 * * \\
(0.037)\end{array}$ & $\begin{array}{c}-51.836^{* *} \\
(0.033)\end{array}$ & $\begin{array}{l}-96.668 * * * \\
(0.001)\end{array}$ & $\begin{array}{l}-51.223 * * \\
(0.035)\end{array}$ \\
\hline$R I S K_{-} T A K E R_{i}$ & $\begin{array}{l}0.212 * * * \\
(0.000)\end{array}$ & $\begin{array}{l}0.207 * * * \\
(0.000)\end{array}$ & $\begin{array}{l}0.215^{* * * *} \\
(0.000)\end{array}$ & $\begin{array}{l}1.315^{* * *} \\
(0.000)\end{array}$ & $\begin{array}{l}1.292 * * * \\
(0.000)\end{array}$ & $\begin{array}{l}1.324 * * * \\
(0.000)\end{array}$ \\
\hline Constant & $\begin{array}{l}-3.320 * * * \\
(0.000)\end{array}$ & $\begin{array}{l}-3.604 * * * \\
(0.000)\end{array}$ & $\begin{array}{l}-3.334 * * * \\
(0.000)\end{array}$ & $\begin{array}{l}-17.184 * * * \\
\quad(0.000)\end{array}$ & $\begin{array}{l}-22.897 * * * \\
(0.000)\end{array}$ & $\begin{array}{l}-17.226 * * * \\
(0.000)\end{array}$ \\
\hline $\begin{array}{l}\text { Interactions between control variables from } \\
\text { Table } 5 \text { and future abnormal return }\end{array}$ & Yes & Yes & Yes & Yes & Yes & Yes \\
\hline Year-fixed effects & Yes & Yes & Yes & Yes & Yes & Yes \\
\hline Firm-fixed effects & Yes & Yes & Yes & Yes & Yes & Yes \\
\hline Pseudo $R^{2}$ & 0.1284 & 0.1280 & 0.1287 & 0.0411 & 0.0410 & 0.0411 \\
\hline N Obs & 11,178 & 11,178 & 11,178 & 11,178 & 11,178 & 11,178 \\
\hline
\end{tabular}

Notes:

1. This table reports the results of estimating logit (Panel A) and Tobit (Panel B) regressions from our matched-pair sample of an equal number of 5,589 days with and without insider selling to examine how cash-strapped and non-cash-strapped insiders with different levels of wealth and income time their insider selling. In Panel A, the dependent variable is a dummy variable equal to one if insider $i$ sells her insider stocks of firm $j$ on day $t$, and zero otherwise $\left(T R A D E_{i j t}\right)$. In Panel B, the dependent variable is the natural logarithm of the market value of the shares sold if insider $i$ sells her insider stocks of firm $j$ on day $t$, and zero otherwise $\left(S I Z E_{i j t}\right)$. Columns 1 and 4 (Columns 2 and 5) repeat the multivariate analysis presented in Table 5 (Columns 1 and 5 of Table 11) for insider selling, including a dummy variable for cash-strapped insiders ( $\left.C A S H \_S T R A P P E D_{i t}\right)$. Columns 3 and 6 repeat the analysis presented in Table 5 for insider selling, using six new dummy variables instead of the three wealth and income groups to identify cash-strapped and non-cash-strapped insiders with different levels of wealth and income (the dummy variables $L O W \_C A S H \_S T R A P P E D_{i t}, L O W \_N O N_{-} C A S H \_S T R A P P E D_{i t}, M E D \_C A S H \_S T R A P P E D_{i t}$, 
$M E D \_N O N \_C A S H \_S T R A P P E D_{i t}, H I G H \_C A S H \_S T R A P P E D_{i t}$, and $\left.H I G H \_N O N \_C A S H \_S T R A P P E D_{i t}\right)$. We form these six dummy variables by dividing insiders in each of the three wealth and income categories into cash-strapped and non-cash-strapped insiders. In these regressions, non-cash-strapped insiders in the high wealth/income category $\left(H I G H \_N O N_{-} C A S H \_S T R A P P E D_{i t}\right)$ are the control group. The dummy variables $L O W_{i t}$ and $M E D_{i t}$ equal one for insiders in the low and medium wealth/income categories, respectively, the high wealth and income category $\left(H I G H_{i t}\right)$ being the control group. The variable $\log \left(W I_{-} R A N K_{i t}\right)$ is the (base 10) logarithm of the continuous wealth and income ranking of insiders, where larger values correspond to a higher wealth and income level of the insider. The variable $B H A R_{j t}$ is the buy-and-hold abnormal (market-adjusted) return over a one-month period following day $t$ for firm $j$. The dummy variable $R I S K_{-} T A K E R_{i}$ measures an insider's lower risk aversion and equals one for insiders who have been convicted or suspected of crimes, and zero otherwise. Insider- and firm-level control variables from Table 5 and their interactions with the future one-month abnormal return as well as year- and firm-fixed effects are included in all regressions, but are not tabulated for the sake of brevity.

2. Refer to Table 12 for the procedure to identify cash-strapped and non-cash-strapped insiders. Refer to Section 3.3.2 and Appendix B for the construction of the three wealth and income categories and variable definitions. Refer to Section 4.4.2 for the construction of the variable WI_RANKit. All continuous variables are winsorized to the $1^{\text {st }}$ and $99^{\text {th }}$ percentiles of their distributions, with the exception of the variable WI_RANK $K_{i t}$. The sample includes all 3,388 insiders in all 393 listed firms in Sweden with at least one insider trade over the period from January 2000 to December 2008. $p$-values from robust standard errors are presented in parentheses. Significance at the $1 \%, 5 \%$, and $10 \%$ (two-tailed) levels is indicated by $* * *, * *$, and *. 
Table 14

Abnormal return following insider trades by the 20 least and most wealthy insiders.

\begin{tabular}{lccc}
\hline & Insider sales & & Insider purchases \\
\cline { 2 - 3 } 20 Least wealthy insiders & $-3.86 \% *$ & $3.28 \% *$ \\
& $\left(-2.97 \%^{* *}\right)$ & $\mathrm{N}=60$ & \\
& $0.63 \%$ & $\mathrm{~N}=96$ \\
20 Most wealthy insiders & $(0.15 \%)$ & $0.15 \%$ \\
& $\mathrm{~N}=158$ & & $(0.01 \%)$ \\
Difference: 20 Least wealthy insiders -20 Most wealthy insiders & $\mathrm{N}=342$ \\
Mean & $-4.49 \%^{*}$ & \\
(Median) & $-3.12 \%^{* *}$ & $3.13 \%^{*}$ \\
\hline
\end{tabular}

Notes:

1. This table reports the mean (median) one-month buy-and-hold abnormal (market-adjusted) returns following the insider trades made by the 20 least and the 20 most wealthy insiders in the wealth and income categories 'Low' and 'High,' respectively. We test for difference in the mean (median) future one-month abnormal returns between the 20 least wealthy and the 20 most wealthy insiders by using a two-tailed $t$-test (Wilcoxon rank-sum test).

2. Refer to Section 3.3.2.1 and Appendix B for the construction of the wealth and income categories 'Low' and 'High.' The sample includes all 3,388 insiders in all 393 listed firms in Sweden with at least one insider trade over the period from January 2000 to December 2008. Significance at the 5\% and 10\% (twotailed) levels is indicated by $* *$ and *. 